\title{
The combination of transcatheter arterial chemoembolisation (TACE) and thermal ablation versus TACE alone for hepatocellular carcinoma (Review)
}

Liu B, Zhang Y, Chen H, Li W, Tsochatzis E

Liu B, Zhang Y, Chen H, Li W, Tsochatzis E.

The combination of transcatheter arterial chemoembolisation (TACE) and thermal ablation versus TACE alone for hepatocellular carcinoma.

Cochrane Database of Systematic Reviews 2022, Issue 1. Art. No.: CD013345.

DOI: 10.1002/14651858.CD013345.pub2. 
TABLE OF CONTENTS

ABSTRACT 1

PLAIN LANGUAGE SUMMARY

BACKGROUND

OBJECTIVES

METHODS

RESULTS

Figure 1.

DISCUSSION

AUTHORS' CONCLUSIONS

ACKNOWLEDGEMENTS

REFERENCES

CHARACTERISTICS OF STUDIES

HISTORY

CONTRIBUTIONS OF AUTHORS

DECLARATIONS OF INTEREST

SOURCES OF SUPPORT

DIFFERENCES BETWEEN PROTOCOL AND REVIEW 
[Intervention Review]

\section{The combination of transcatheter arterial chemoembolisation (TACE) and thermal ablation versus TACE alone for hepatocellular carcinoma}

BoZhi Liu' ${ }^{1}$, YongChao Zhang ${ }^{1}$, Hui Chen ${ }^{2}$, Wei Li ${ }^{1}$, Emmanuel Tsochatzis ${ }^{3}$

1Cancer Center, Beijing Ditan Hospital, Capital Medical University, Beijing, China. 2School of Biomedical Engineering, Capital Medical University, Bejing, China. ${ }^{3}$ Sheila Sherlock Liver Centre, Royal Free Hospital and the UCL Institute of Liver and Digestive Health, London, UK

Contact: Wei Li, vision988@126.com.

Editorial group: Cochrane Hepato-Biliary Group.

Publication status and date: New, published in Issue 1, 2022.

Citation: Liu B, Zhang Y, Chen H, Li W, Tsochatzis E. The combination of transcatheter arterial chemoembolisation (TACE) and thermal ablation versus TACE alone for hepatocellular carcinoma. Cochrane Database of Systematic Reviews 2022, Issue 1. Art. No.: CD013345. DOI: 10.1002/14651858.CD013345.pub2.

Copyright $\odot 2021$ The Cochrane Collaboration. Published by John Wiley \& Sons, Ltd.

\section{A B S T R A C T}

\section{Background}

Hepatocellular carcinoma is the sixth most common cancer worldwide. Hepatic resection is regarded as the curative therapy for hepatocellular carcinoma. However, only about $20 \%$ of people with hepatocellular carcinoma are candidates for resection, which highlights the importance of effective nonsurgical therapies. Until now, transcatheter arterial chemoembolisation (TACE) is the most common palliative therapy for hepatocellular carcinoma, but its clinical benefits remain unsatisfactory. During recent years, some studies have reported that the combination of TACE plus thermal ablation can confer a more favourable prognosis than TACE alone. However, clear and compelling evidence to prove the beneficial or harmful effects of the combination of TACE and thermal ablation therapy is lacking.

\section{Objectives}

To assess the beneficial and harmful effects of the combination of thermal ablation with TACE versus TACE alone in people with hepatocellular carcinoma.

\section{Search methods}

We performed searches in the Cochrane Hepato-Biliary Group Controlled Trials Register, the Cochrane Central Register of Controlled Trials in the Cochrane Library, MEDLINE, Embase, LILACS, Science Citation Index Expanded, and Conference Proceedings Citation Index-Science. We endeavoured to identify relevant randomised clinical trials also in the China National Knowledge Infrastructure (CNKI) and Wanfang databases. We searched trial registration websites for ongoing studies. We also handsearched grey literature sources. The date of last search was 22 December 2020.

\section{Selection criteria}

We planned to include all randomised clinical trials comparing the combination of TACE plus thermal ablation versus TACE alone for hepatocellular carcinoma, no matter the language, year of publication, publication status, and reported outcomes.

\section{Data collection and analysis}

We planned to use standard methodological procedures expected by Cochrane. We planned to calculate risk ratios (RRs) with the corresponding 95\% confidence intervals (Cls). For time-to-event variables, we planned to use the methods of survival analysis and express the intervention effect as a hazard ratio (HR) with $95 \% \mathrm{Cl}$. If the log $\mathrm{HR}$ and the variance were not directly reported in reports, we planned to calculate them indirectly, following methods for incorporating summary time-to-event data into meta-analysis. We planned to assess 
the risk of bias of the included studies using the RoB 2 tool. We planned to assess the certainty of evidence with GRADE and present the evidence in a summary of findings table.

\section{Main results}

Out of 2224 records retrieved with the searches, we considered 135 records eligible for full-text screening. We excluded 21 of these records because the interventions used were outside the scope of our review or the studies were not randomised clinical trials. We listed the remaining 114 records, reporting on 114 studies, under studies awaiting classification because we could not be sure that these were randomised clinical trials from the information in the study paper. We could not obtain information on the registration of the study protocol for any of the 114 studies. We could not obtain information on study approval by regional research ethics committees, either from the study authors or through our own searches of trial registries. Corresponding authors did not respond to our enquiries about the design and conduct of the studies, except for one from whom we did not receive a satisfactory response. We also raised awareness of our concerns to editors of the journals that published the 114 studies, and we did not hear back with useful information. Moreover, there seemed to be inappropriate inclusion of trial participants, based on cancer stage and severity of liver disease, who should have obtained other interventions according to guidelines from learned societies.

Accordingly, we found no confirmed randomised clinical trials evaluating the combination of TACE plus thermal ablation versus TACE alone for people with hepatocellular carcinoma for inclusion in our review.

We identified five ongoing trials, by handsearching in clinical trial websites.

\section{Authors' conclusions}

We could not find for inclusion any confirmed randomised clinical trials assessing the beneficial or harmful effects of the combination of TACE plus thermal ablation versus TACE alone in people with hepatocellular carcinoma. Therefore, our results did not show or reject the efficiency of the combination of TACE plus thermal ablation versus TACE alone for people with hepatocellular carcinoma.

We need trials that compare the beneficial and harmful effects of the combination of TACE plus thermal ablation versus TACE alone in people with hepatocellular carcinoma, not eligible for treatments with curative intent (liver transplantation, ablation surgical resection) and who have sufficient liver reserve, as assessed by the Child Pugh score, and who do not have extrahepatic metastases. Therefore, future trial participants must be classified at Barcelona Clinic Liver Cancer Stage B (intermediate stage) (BCLC-B) or an equivalent, with other staging systems.

\section{PLAIN LANGUAGE SUMMARY}

\section{The combination of transcatheter arterial chemoembolisation and thermal ablation versus TACE alone for hepatocellular} carcinoma

\section{Background}

Hepatocellular carcinoma (a common kind of liver cancer) is the sixth most common cancer in the world. Transcatheter arterial chemoembolisation (TACE) (injecting agents into the feeding vessels of the tumour to reduce the blood supply to the tumour and kill the tumour) is the most common therapy for hepatocellular carcinoma, but the clinical outcome is poor. In recent years, the combination of TACE plus thermal ablation (killing the tumour cell by producing heat or cold) has shown better efficacy than TACE alone. However, evidence to prove the beneficial or harmful effect of the combination of TACE with ablation for people with hepatocellular carcinoma is still lacking.

\section{Aim}

We aimed to assess the beneficial and harmful effects of the combination of TACE with thermal ablation versus TACE alone for hepatocellular carcinoma.

\section{Key results}

We considered 135 records eligible for full-text screening. We excluded 21 of these records because the interventions used were outside the scope of our review or the studies were not randomised clinical trials. We listed the remaining 114 records, reporting on 114 studies, under studies awaiting classification because we could not be sure that these were randomised clinical trials from the information in the study paper. We could not obtain information on the registration of the study protocol for any of the 114 studies. We could not obtain information on study approval by regional research ethics committees, either from the study authors or through our own searches of trial registries. Corresponding authors did not respond to our enquiries about the design and conduct of the studies, except for one from whom we did not receive a satisfactory response. We also raised awareness of our concerns to editors of the journals that published the 114 studies, and we did not hear back with useful information. Moreover, there seemed to be inappropriate inclusion of trial participants, based on cancer stage and severity of liver disease, who should have obtained other interventions according to guidelines from learned societies.

We identified five ongoing trials, by handsearching in clinical trial websites. 


\section{Conclusions}

We found no confirmed randomised clinical trials evaluating the combination of TACE plus thermal ablation versus TACE alone for people with hepatocellular carcinoma for inclusion in our review. Therefore, we cannot conclude anything on the treatment of hepatocellular carcinoma using TACE plus thermal ablation versus TACE alone.

We need trials that compare the beneficial and harmful effects of the combination of TACE plus thermal ablation versus TACE alone in people with hepatocellular carcinoma, not eligible for treatments with curative intent (liver transplantation, ablation surgical resection) and who have sufficient liver reserve, as assessed by the Child Pugh score, and who do not have extrahepatic metastases. Therefore, future trial participants must be classified at Barcelona Clinic Liver Cancer Stage B (intermediate stage) (BCLC-B) or an equivalent, with other staging systems. 


\section{B A C K G R O U N D}

\section{Description of the condition}

Hepatocellular carcinoma is the most predominant form of primary liver cancer, accounting for approximately $90 \%$ of occurrences, and it represents an increasing serious health problem worldwide (Mohd 2013; Laursen 2014; National Center for Health Statistics (US) 2015). The pathogenesis of hepatocellular carcinoma is a highly complex process which usually occurs in the context of liver cirrhosis, mainly involving chronic inflammation injury and the accumulation of genetic alterations (Schulze 2016). Hepatocellular carcinoma is the sixth most common cancer and the second most common cancer-related cause of death worldwide. Around 782,000 people are diagnosed and 746,000 die from hepatocellular carcinoma every year worldwide, with China accounting for about $50 \%$ of the total number of cancers and deaths (Torre 2015; Forner 2018). The incidence of hepatocellular carcinoma varies among different global regions. Approximately $80 \%$ of hepatocellular carcinomas occur in sub-Saharan Africa and eastern Asia, due to the high prevalence of hepatitis $B$ virus infection and the intake of aflatoxin B1, with an incidence of over 20 per 100,000 individuals (El-Serag 2012). An intermediate hepatocellular carcinoma burden occurs in Mediterranean countries, with an incidence of 10 to 20 per 100,000 individuals. In America, the incidence is lower than 5 per 100,000 individuals (Mittal 2013). The main causes of hepatocellular carcinoma in Europe and America is hepatitis C virus infection and alcohol abuse (Trad 2017). Hepatocellular carcinoma incidence among men is four to eight times higher than among women (Yang 2014). Most hepatocellular carcinoma patients are older than 45 years (Llovet 2016).

The most prevalent staging system for hepatocellular carcinoma is the Barcelona Clinic Liver Cancer (BCLC) system which divides hepatocellular carcinoma into five stages based on the size and number of tumours, vascular invasion, and liver function (EASLEORTC 2012). The main risk factors are liver cirrhosis, infection with hepatitis $B$ virus and $C$ virus, intake of toxic substance (alcohol and aflatoxin B1), and metabolic syndromes (diabetes, obesity, nonalcoholic fatty liver disease, and hereditary haemochromatosis). Approximately $80 \%$ of hepatocellular carcinoma develops in people with liver cirrhosis (Kew 2014). The hepatocellular carcinoma mortality among men with a high baseline body mass index is five times higher than among men with a normal body mass index (Forner 2018). Other risk factors include age, tobacco use, and coinfection of human immunodeficiency virus (HIV). Diagnosis of hepatocellular carcinoma is confirmed by either histopathological biopsy or imaging techniques (ultrasound, contrast-enhanced computed tomography, or contrast-enhanced magnetic resonance imaging (MRI)) according to the current practice guideline of the American Association for the Study of Liver Diseases (AASLD) (Bruix 2011).

The treatment for hepatocellular carcinoma can be divided into curative therapies and palliative therapies. Resection, liver transplantation, and locoregional ablation are radical therapies with the curative intention of prolonging survival. However, only $20 \%$ of hepatocellular carcinoma patients, mostly diagnosed by regular screening, may gain survival benefit from resection and liver transplantation (Abdel-Rahman 2013). Curative ablation is recommended for patients with only two or three nodules which are less than $3 \mathrm{~cm}$ or a single nodule. The palliative therapies mainly involve transcatheter arterial chemoembolisation (TACE), sorafenib, and systemic treatment, with no, or moderate survival benefits (Oliveri 2011; Chacko 2016).

\section{Description of the intervention}

In this review, we planned to focus on the combination of TACE with sequential thermal ablation therapy. During this combined therapy, TACE is performed firstly for all baseline tumours, followed by thermal ablation on all baseline tumours or only tumours that remain active after TACE. Baseline tumours refer to all active tumours before TACE. Active tumours are defined as 'living' tumours, which show characteristic vascular features of hepatocellular carcinoma - arterial hyper-vascularisation with washout in the portal venous system or the late phase at contrastenhanced computed tomography, or contrast-enhanced MRI.

TACE is the most common treatment for hepatocellular carcinoma, which is recommended as the first-line treatment for intermediate stage hepatocellular carcinoma, according to the BCLC staging system (EASL-EORTC 2012). The mechanism of TACE consists of the injection of chemotherapeutic drugs, lipiodol and vascular occlusive agents into the hepatic artery; these can inhibit tumour growth, promote cell death, and maybe prolong survival (Oliveri 2011). The rationale for TACE is based on the concept that most of the blood supply of intra-hepatic tumours is provided by the hepatic artery, while $75 \%$ of the blood flow of the normal liver parenchyma is supplied by the portal vein (Vogl 2003). Therefore, TACE can lead to selective necrosis of the liver tumour while it hardly affects normal liver parenchyma (Jaeger 1996). Alternatively, TACE can also be used to downsize a tumour or as a bridge to liver transplantation (Martin 2015).

Thermal ablation refers to the ablation therapies that induce irreversible cellular injury of tumour cells through heat mechanisms or cold mechanisms. Most kinds of ablation therapies are performed using a percutaneous approach, under realtime contrast-enhanced computed tomography, dynamic MRI, or ultrasound guidance. A puncture needle is used to lead the electrode into the target. After setting appropriate output power and duration, the electrode begins to produce heat or cold to surrounding tissue to induce complete necrosis (Ahmed 2011).

There are five main thermal ablation techniques (Goldberg 2003): radiofrequency ablation (Ahmed 2011), microwave ablation (Brace 2007; Lubner 2013; Poggi 2015), laser ablation (Ahmed 2011), ultrasound ablation (Wijlemans 2012), and cryoablation (Rubinsky 1990; Ahmed 2011)

Radiofrequency ablation is the most widely used and the most wellstudied thermal ablation, and it is regarded as the standard therapy for BCLC-A tumours which are not suitable for surgery (EASL-EORTC 2012). It has been proved to have a therapeutic efficacy similar to that of surgical resection or liver transplantation for hepatocellular carcinoma with a diameter within $3 \mathrm{~cm}$ (Zhu 2016). Radiofrequency ablation can induce complete necrosis of surrounding tissue by generating heat. The radiofrequency ablation technique also serves as a model for exploring the use of thermal ablation in clinical practice.

Microwave ablation can induce tumour cell death by microwave heating, which is generated by dielectric hysteresis (Ahmed 2011). Microwave ablation can reduce tumour tissue in a more efficient way by producing faster heating and higher temperatures

The combination of transcatheter arterial chemoembolisation (TACE) and thermal ablation versus TACE alone for hepatocellular 
compared to radiofrequency ablation (Brace 2007; Yang 2007). Furthermore, microwave ablation, compared to radiofrequency ablation, has better performance on overcoming heat sink effect (Ahmed 2011). However, microwave ablation is still a novel ablation technique; more details should be explored in further clinical practice.

Laser ablation is an ablative therapy that can induce electromagnetic heating to increase tissue temperatures to lethal levels by laser beam and results in complete necrosis of surrounding tissue (Ahmed 2011).

Ultrasound ablation therapy can concentrate intersecting beams of ultrasound on a target tumour through an acoustic lens and thus induce irreversible damage (Zhu 2013a).

Cryoablation destroys cells by the application of alternating freezing and thawing to induce irreversible cellular injury (Awad 2009; Song 2016a).

\section{How the intervention might work}

TACE is a palliative therapy, with a tumour response rate of $24 \%$ to 53\% (Yang 2009). Generally, several sessions of TACE are needed to achieve a high necrosis rate and local tumour control (Satake 2008). Due to high toxicity and adverse effects of chemotherapeutic agents, repeated TACE may result in liver failure (Li 2010). Besides, the incomplete necrosis of the tumour after TACE may cause intra hepatic recurrence of malignancy (Wu 2005).

Thermal ablation is a minimally invasive and curative therapy, with a complete necrosis rate of $76 \%$ to $100 \%$ for small hepatocellular carcinoma (Morimoto 2010); and 30\% to 70\% for larger hepatocellular carcinoma (Livraghi 2000). In patients with early-stage hepatocellular carcinoma (BCLC 0 or A) who are not suitable for resection, ablation therapy achieved five-year survival rates of $50 \%$ to $70 \%$ (EASL-EORTC 2012). The main advantages of thermal ablation include effective tumour ablation, preservation of maximal normal liver parenchyma, and low rates of complications (Yang 2009). The introduction of the mechanism of five types of thermal ablation therapies is shown below.

During radiofrequency ablation, an electrical circuit is created between a radiofrequency probe, the patient, and the grounding pads (Ahmed 2011). The alternating current leads to frictional agitation at the ionic level and heat generation around the probe (Corwin 2001). Dehydration and subsequent carbonisation of surrounding tissues would occur when the temperature is above $100^{\circ} \mathrm{C}$ (Poggi 2015).

Microwave ablation generates heat through a process known as dielectric hysteresis, in which polar molecules in tissue (primarily water) are forced to continuously realign with the oscillating electric field (Lubner 2013). Thus, the kinetic energy of reformed molecules and the temperature of tissue increase. Microwave power can produce extremely high temperatures $\left(>150^{\circ} \mathrm{C}\right)$ and induce necrosis of tissue (Brace 2007).

Laser ablation treats the tumour by irradiating it with a laser beam, which is an efficient and precise energy source for tissue heating (Ahmed 2011).

Ultrasound ablation is a non-invasive therapy. The main mechanism of ultrasound ablation is the thermal energy deposition by a focussed ultrasound beam. The targeted tissue absorbs a significant amount of energy from a highly directional ultrasound beam, resulting in elevation of temperature (Wijlemans 2012).

Cryoablation is an ablative technique which can induce protein denaturation, cellular dehydration and subsequent tissue necrosis by the application of extreme low temperatures to tumour tissue (Rubinsky 1990; Wu 2015).

The rationale of the combination of TACE and sequential ablation is that sequential ablation therapy can remedy the limitation of TACE alone. Firstly, ablation therapy can directly destroy tumour tissue, increase complete necrosis rate and produce a favourable prognosis (Li 2010); secondly, sequential ablation therapy reduces the time needed for interventional treatment, which reduces liver damage and improves quality of life (Li 2016). In addition, the combination of TACE and sequential ablation has synergistic effects on treating liver tumours. The occlusion of hepatic arteries achieved by TACE can reduce blood flow and decrease the heat sink effect, which is helpful for enlarging the ablation zone and achieving complete necrosis (Peng 2013).

\section{Why it is important to do this review}

Hepatic surgical resection is regarded as a curative therapy for hepatocellular carcinoma. However, only about $20 \%$ of hepatocellular carcinoma patients are candidates for surgical resection, which highlights the importance of effective non-surgical therapies (Yin 2014). Until now, TACE is the most commonly used palliative therapy for hepatocellular carcinoma, but the effect remains unsatisfactory (Oliveri 2011). In recent years, the combination of TACE plus thermal ablation has shown better survival than TACE alone for people with hepatocellular carcinoma. Some studies have reported that the combination modality can confer a more favourable prognosis than TACE alone for different stages of hepatocellular carcinoma (Yang 2009; Azuma 2016; Hyun 2016; Song 2016a). However, there is still a lack of clear and compelling evidence on the beneficial or harmful effect of the combination of TACE and thermal ablation therapy. Therefore, we embarked on this Cochrane Review hoping to provide the best available level of evidence of the role of the combination of TACE plus thermal ablation versus TACE alone for hepatocellular carcinoma.

\section{O B JECTIVES}

To assess the beneficial and harmful effects of the combination of TACE plus thermal ablation compared with TACE alone in people with hepatocellular carcinoma.

\section{METHODS}

\section{Criteria for considering studies for this review}

\section{Types of studies}

We planned to include all randomised clinical trials comparing the combination of TACE and thermal ablation with TACE alone for hepatocellular carcinoma, irrespective of publication status or blinding.

The combination of transcatheter arterial chemoembolisation (TACE) and thermal ablation versus TACE alone for hepatocellular 


\section{Types of participants}

All trial participants older than 18 years, with hepatocellular carcinoma, diagnosed by either histopathological biopsy or the radiological criteria in clinical practice guidelines.

\section{Types of interventions}

\section{Experimental intervention}

- A combination of TACE plus thermal ablation. Thermal ablation can be performed with any of the following techniques: radiofrequency ablation, microwave ablation, laser ablation, ultrasound ablation, and cryoablation.

\section{Control intervention}

- TACE alone

For both experimental group and control groups, we planned to include all TACE treatments irrespective of dosage and types of chemotherapeutic drugs, and vascular occlusive agents (Imai 2014).

\section{Types of outcome measures}

We planned to measure the outcomes listed below. We planned to base our primary conclusions on the outcome results at the longest follow-up. We planned to include trials regardless of whether they reported on our outcomes of interest.

\section{Primary outcomes}

- All-cause mortality.

- Progression-free survival. This is defined as the period from the date of first treatment to the date of the first documented disease progression by either radiological assessment or liver biopsy or death caused by any reason, whichever happened first.

- Proportion of participants with serious adverse events. We planned to use the definition of serious adverse events in the International Conference on Harmonisation (ICH) Guidelines for Good Clinical Practice (ICH-GCP 1997): that is, any untoward medical occurrence that results in death, is lifethreatening, requires hospitalisation or prolongation of existing hospitalisation, results in persistent or significant disability or incapacity, or any medical event that might have jeopardised the patient, or required intervention to prevent it. All other adverse events were considered as non-serious adverse events. We planned to accept all reported serious adverse events assessed at variable time points throughout the conduct of the review. If possible, we noted the period of reported serious adverse events and classified them as short-term (primary observed period) and long-term serious adverse events.

\section{Secondary outcomes}

- Tumour response. We planned to evaluate the tumour response according to the Modified Response Evaluation Criteria in Solid Tumours (mRECIST) guideline (Lencioni 2010), as follows.

- Complete response (CR): disappearance of any intratumoural arterial enhancement in all target lesions.

- Partial response (PR): at least a 30\% decrease in the sum of diameters of viable (enhancement in the arterial phase) target lesions, taking as reference the baseline sum of the diameters of target lesions.

- Progressive disease (PD): an increase of at least $20 \%$ in the sum of the diameters of viable (enhancing) target lesions, taking as reference the smallest sum of the diameters of viable (enhancing) target lesions recorded since treatment started.

- Stable disease (SD): any cases that do not qualify for either partial response or progressive disease.

Whenever appropriate, we also planned to consider other criteria, such as World Health Organization (WHO) criteria (Kim 2015) and the Response Evaluation Criteria in Solid Tumours (RECIST) guideline (Therasse 2000). However, the mRECIST guideline was considered as the main tool.

- Proportion of participants with adverse events not considered serious. We planned to accept all reported non-serious adverse events assessed at variable time points throughout the conduct of the review. If possible, we planned to note the period of reported non-serious adverse events and classify them as shortterm (primary observed period) and long-term adverse events.

- Health-related quality of life as defined by the trial authors (short term: up to one year; medium term: one to five years; long term (primary time point): beyond five years).

- Duration of hospital stay.

\section{Search methods for identification of studies}

\section{Electronic searches}

We performed electronic searches in the Cochrane Hepato-Biliary Group Controlled Trials Register (searched through the Cochrane Library; December 2020), The Cochrane Central Register of Controlled Trials (CENTRAL; 2020, issue 12) in the Cochrane Library, MEDLINE (PubMed; December 2020), Embase (www.embase.com; December 2020), LILACS (Bireme; 1982 to December 2020), Science Citation Index Expanded (Web of Science; 1900 to December 20209), and Conference Proceedings Citation Index-Science (Web of Science; 1990 to December 2020). We also endeavoured to identify relevant RCTs in the China National Knowledge Infrastructure (CNKI) and Wanfang databases. Appendix 1 shows the search strategies with the time spans of the searches.

\section{Searching other resources}

We checked the reference lists of potentially relevant articles identified in the electronic searches. We also searched trial registration resources such as ClinicalTrials.gov, Chinese Clinical Trial Register (ChiCTR), and the World Health Organisation (WHO) International Clinical Trial Registry Platform (www.who.int/ictrp) to identify study protocols of the identified studies from the electronic searches and also to identify ongoing studies. We also handsearched grey literature sources, such as meeting abstracts and internal reports. We adapted the same or similar search terms to those used in the searching of English electronic databases.

During the selection of trials, whenever we identified observational studies of interest to the topic of this review (i.e. quasi-randomised studies, cohort studies, case-control studies, case reports, and case series) and also reporting on harms, we planned to discuss the data on harm in the review discussion part. We also planned to create a table with the extracted data on harm. In this way, we pay attention 
to late-occurring or rare events which are often underreported or overlooked by trialists (Storebø 2018).

\section{Data collection and analysis}

\section{Selection of studies}

We merged all search results and removed duplicates by using reference management software. Two review authors (BZL and $\mathrm{WL}$ ) independently examined titles and abstracts of the electronic search output to remove obviously irrelevant publications. After the initial assessment, we retrieved the full text of all potentially eligible articles, and we linked together multiple reports of the same trial.

Two review authors (BZL and WL) independently screened the full text to evaluate whether these trials met the inclusion criteria. We resolved disagreements on the eligibility of a trial by discussion. We consulted HC (the last author) or we wrote to the original trial investigators when necessary, to clarify trial eligibility. Then, we made a final decision on which trials fulfilled the inclusion criteria of our review. We did not blind our selection process regarding article information. We recorded the details of the whole screening process in a PRISMA flow chart. We also added information on the excluded studies in the 'Characteristics of excluded studies' table.

\section{Data extraction and management}

Two authors (BZL and YCZ) planned to independently extract the data from all included publications on the trials and complete the 'Characteristics of included studies' table. We planned to contact the authors of original trials whenever needed. We planned to resolve disagreement by discussion. We planned to consult HC (another review author), or we planned to write to the original trial investigators whenever needed. Two authors ( $\mathrm{HC}$ and $\mathrm{WL}$ ) planned to enter data into Review Manager 5. We planned to double-check that the data had been entered correctly by comparing the data presented in the systematic review with those in the data extraction form, which we had pre-piloted for the purpose of the review.

We planned to extract the following trial characteristics.

- Source (e.g. author, year of publication, contact details, journal citation, trial registration, ethics committee approval)

- Methods (e.g. trial design, total trial duration, sequence generation, allocation sequence concealment, blinding and other concerns about bias)

- Participants (e.g. age, sex, country, number randomised, number lost to follow-up/withdrawn, number analysed, inclusion criteria, exclusion criteria, diagnostic criteria)

- Interventions (e.g. intervention, comparison)

- Outcomes (for each outcome listed in the protocol, e.g. outcome definition and unit of measurement (if relevant), time points reported, scales, intensity)

- Miscellaneous (e.g. funding for trial, a notable conflict of interests of trial authors).

\section{Assessment of risk of bias in included studies}

Two review authors (BZL and WL) planned to independently assess the risk of bias in the included studies. We planned to assess risk of bias by using the RoB 2 tool, according to Chapter 8 in the Cochrane Handbook for Systematic Reviews of Interventions (Higgins 2019a). We planned to use the following domains.
Domain 1: bias arising from the randomisation process;

Domain 2: bias due to deviations from intended interventions;

Domain 3: bias due to missing outcome data;

Domain 4: bias in measurement of the outcome;

Domain 5: bias in selection of the reported report.

For each domain, there are a series of signalling questions: 'Yes', 'Probably yes', 'Probably no', 'No', and 'No information'.

Based on the replies, we planned to reach a risk-of-bias judgement, and we assigned one of three levels to each domain: 'low risk of bias', 'some concerns', or 'high risk of bias', following the RoB 2 tool (Sterne 2019).

\section{Overall risk of bias}

The following definitions of risk of bias were considered.

Low risk of bias: the trial is judged to be at low risk of bias for all domains for this result.

Some concerns: the trial is judged to raise some concerns in at least one domain for this result, but not to be at high risk of bias for any domain.

High risk of bias: the trial is judged to be at high risk of bias in at least one domain for this result; or the trial is judged to have some concerns for multiple domains in a way that substantially lowers confidence in the result.

We planned to present information in support of each response in the free-text box alongside the signalling questions and judgements. Additionally, for domain 2, we planned to assess the effect of the assignment to the intervention.

In this review, we planned to assess the risk of bias in the following outcome results: all-cause mortality; time to progression; serious adverse events; tumour response rate; and health-related quality of life, all at the longest follow-up.

\section{Measures of treatment effect}

For dichotomous variables, we planned to calculate the risk ratio (RR) and 95\% confidence interval ( $\mathrm{Cl}$ ) and Trial Sequential Analysis adjusted-Cl.

For continuous variables, we planned to use the mean difference (MD) (if all studies were made on the same scale) or the standardised mean difference (SMD) (if different scales were used) with $95 \% \mathrm{Cl}$ and Trial Sequential Analysis adjusted-Cl.

For time-to-event variables, we planned to use the methods of survival analysis and express the intervention effect as a hazard ratio (HR) with $95 \% \mathrm{Cl}$. If the logHR and their variance were not directly reported in reports, we planned to calculate them indirectly, following the methods introduced by Tierney 2007.

\section{Unit of analysis issues}

We planned to set the unit of analysis according to the methods mentioned in Chapter 6 and Chapter 23 in the Cochrane Handbook for Systematic Reviews of Interventions (Higgins 2019b; Higgins 2019c).

The combination of transcatheter arterial chemoembolisation (TACE) and thermal ablation versus TACE alone for hepatocellular 
We planned to analyse data at the single randomised individual level (Higgins 2019b). In trials with a two-parallel-group design, we planned to compare the experimental intervention group versus the control group. In the trials with a parallel-group design with more than two intervention groups, if relevant, we planned to compare separately each of the experimental groups with half of the control group if used within the same comparison (Higgins 2019c).

When only a subset of relevant participants was included in a trial, we planned to consider the trial only when the results were presented separately for the subgroup of interest for this review.

For cluster-randomised trials, we planned to analyse data by using the average cluster size and an estimate of the intraclass correlation coefficient (ICC) and the design effect to calculate effective sample size (Higgins 2019b; Higgins 2019c).

For crossover trials, we planned to only include data from the first intervention period to avoid carry-over effects (Higgins 2019a).

\section{Dealing with missing data}

We planned to contact the original investigators to request missing data; and we planned to extract all data for an intention-totreat (ITT) analysis if data were available. Otherwise, we planned to perform available case analyses, which assume that data are missing at random. We planned to assess if this assumption was reasonable by collecting data on the number of participants excluded or lost to follow-up, and the reasons for loss to followup by treatment group, from each included study (as reported). We planned to address the potential impact of missing data on the findings of the review in the Discussion section.

\section{Assessment of heterogeneity}

We planned to assess clinical and methodological heterogeneity by carefully examining the characteristics and design of the included trials. We planned to assess the presence of clinical heterogeneity by comparing effect estimates in people with different BCLC stage of hepatocellular carcinoma, different Child-Pugh Class of liver function, different criteria on assessment of tumour response and different follow-up time. Different study designs and risk of bias may contribute to methodological heterogeneity.

We planned to explore statistical heterogeneity by the $\mathrm{Chi}^{2}$ test with significance set at a $P$ value of less than 0.10 . In addition, we planned to access the degree of heterogeneity by using the $I^{2}$ statistic, which describes the percentage of the variability in effect estimates that is due to heterogeneity rather than sampling error.

Interpretation of $\mathrm{I}^{2}$ is listed as follows.

- $0 \%$ to $40 \%$ : might not be important

- $30 \%$ to $60 \%$ : may represent moderate heterogeneity ${ }^{\star}$

- $50 \%$ to $90 \%$ : may represent substantial heterogeneity *

- $75 \%$ to $100 \%$ : considerable heterogeneity*

*The importance of the observed value of $\mathrm{I}^{2}$ depends on (i) magnitude and direction of effects and (ii) strength of evidence for heterogeneity, e.g. $\mathrm{P}$ value from the $\mathrm{Chi}^{2}$ test, or a confidence interval for $I^{2}$.

\section{Assessment of reporting biases}

We planned to assess reporting bias by drawing funnel plots if ten or more trials were included.

\section{Data synthesis}

\section{Meta-analysis}

We aimed to conduct this review following the instructions stated in Chapter 10 in Cochrane Handbook for Systematic Reviews of Interventions (Deeks 2019). We planned to meta-analyse data whenever possible. Otherwise, we planned to provide a summary of the trial results in a narrative way. We planned to perform the primary analyses by pooling the results of all eligible trials, regardless of their risk of bias. We planned to analyse data using the Review Manager 5 software (Review Manager 2014) and RevMan Web provided by Cochrane (RevMan Web 2019). We aimed to perform all meta-analyses using the random-effect model because we expected that the included trials would be heterogeneous. We planned to present dichotomous outcomes as RR with $95 \% \mathrm{Cl}$. We planned to present continuous outcomes as MD or SMD, with $95 \%$ $\mathrm{Cl}$.

\section{Subgroup analysis and investigation of heterogeneity}

We aimed to assess differences between subgroups using the formal test for subgroup differences in Review Manager Web (RevMan Web 2019). We aimed to conduct the following subgroup analyses.

- Trials at low risk of bias, at some concern, and at high risk of bias

- Different ablation methods

\section{Sensitivity analysis}

We planned to perform sensitivity analyses by excluding studies at high risk of bias. Additionally, if cluster-randomised studies were found, we planned to perform sensitivity analysis to investigate possible effects of the randomisation unit. We planned to assess the intervention effect on mortality at one, three, and five years. We planned to repeat our analyses with the fixed-effect model.

We also planned to use Trial Sequential Analysis to assess imprecision for the following outcomes: all-cause mortality; time to progression; serious adverse events; tumour response; and quality of life (Thorlund 2011; Castellini 2018; Gartlehner 2019).

\section{Trial Sequential Analysis}

To control random errors from sparse data and repeated significance testing, we planned to apply Trial Sequential Analysis in our meta-analysis (Thorlund 2011; TSA 2011; Wetterslev 2017). Trial Sequential Analysis is a methodology that includes a combination of techniques, providing the threshold for a statistically significant treatment effect and the threshold for futility. Conclusions conducted by Trial Sequential Analysis indicate the potential to be more reliable than those using traditional metaanalysis techniques (Thorlund 2011; Wetterslev 2017).

For dichotomous outcomes, we aimed to calculate the required meta-analysis information size based on the event proportion in the control group; assumption of a plausible RR reduction of $20 \%$ or the RR reduction observed in the included trials at low risk of bias; a risk of type I error of $2.5 \%$ because of our three primary outcomes and $2.0 \%$ because of four secondary outcomes (Jakobsen 2014); a

The combination of transcatheter arterial chemoembolisation (TACE) and thermal ablation versus TACE alone for hepatocellular 
risk of type II error of 10\%; and the assumed diversity of the metaanalysis (Wetterslev 2009). For continuous outcomes, we aimed to calculate the required information size based on the SD observed in the control group of trials with low risk of bias and a minimal relevant difference of $50 \%$ of this SD, an alpha of $2.5 \%$, a beta of $10 \%$, and the diversity suggested by the trials in the meta-analysis.

The underlying assumption of Trial Sequential Analysis is that testing for significance may be performed each time a new trial is added to the meta-analysis. We aimed to add the trials according to the year of publication. If more than one trial was published during the same year, we planned to add trials alphabetically according to the last name of the first author. We aimed to construct trial sequential monitoring boundaries on the basis of the required information size (Wetterslev 2008; Thorlund 2011; Wetterslev 2017). These boundaries determine the statistical inference one may draw regarding the cumulative meta-analysis that does not reach the required information size; if the trial sequential monitoring boundary is crossed before the required information size is reached, firm evidence may, perhaps, have been established and further trials may be superfluous. On the other hand, if the boundaries are not surpassed, it probably is necessary to continue conducting trials in order to detect or reject a certain intervention effect. That is determined by assessing if the cumulative Z-curve crosses the trial sequential boundaries for futility.

\section{Summary of findings and assessment of the certainty of the evidence}

We aimed to create the Summary of findings tables using GRADEpro GDT software (GRADEpro GDT). We aimed to assess allcause mortality, progression-free survival, serious adverse events, tumour response rate, and health-related quality of life. We planned to provide a range of follow-up, and median follow-up, for all outcomes.

We aimed to use the GRADE approach to assess the certainty of evidence based on risk of bias, indirectness of evidence (population, intervention, control, outcomes), unexplained heterogeneity, inconsistency of results (including problems with subgroup analyses), imprecision of results, and a high probability of publication bias (Atkins 2004). The details are shown as follows:

(1) Risk of bias or limitations in the detailed design and implementation: the results of assessment of risk of bias by using RoB 2 tool in included RCTs were to be fed directly into the domain of 'Risk of bias' in GRADE. In particular, 'low' risk of bias would indicate 'no limitation'; 'some concerns' would indicate either 'no limitation' or 'serious limitation'; and 'high' risk of bias would indicate either 'serious limitation' or 'very serious limitation'. We also planned to use our judgements to decide between alternative categories, depending on the likely magnitude of the potential biases.

(2) Unexplained heterogeneity or inconsistency of results: when studies yield widely differing estimates of effect (heterogeneity or variability in results), investigators should look for robust explanations for that heterogeneity.

(3) Indirectness of evidence: two types of indirectness are relevant. First, a review comparing the effectiveness of alternative interventions (say $A$ and $B$ ) may find that randomised trials are available, but they have compared $A$ with placebo and $B$ with placebo. Second, a review may find randomised trials that meet eligibility criteria but address a restricted version of the main review question in terms of population, intervention, comparator or outcomes.

(4) Imprecision of results: when studies include few participants or few events, and thus have wide confidence intervals, review authors can lower their rating of the certainty of the evidence.

(5) High probability of publication bias: the certainty of evidence level may be downgraded if investigators fail to report studies on the basis of results (typically those that show no effect: publication bias) or outcomes (typically those that may be harmful or for which no effect was observed: selective outcome non-reporting bias).

We planned to define the levels of evidence as 'high', 'moderate', 'low', or 'very low' certainty. These grades are defined as follows.

- High certainty: we are very confident that the true effect lies close to that of the estimate of the effect.

- Moderate certainty: we are moderately confident in the effect estimate: the true effect is likely to be close to the estimate of the effect, but there is a possibility that it is substantially different.

- Low certainty: our confidence in the effect estimate is limited: the true effect may be substantially different from the estimate of the effect.

- Very low certainty: we have very little confidence in the effect estimate: the true effect is likely to be substantially different from the estimate of effect.

\section{RES U L T S}

\section{Description of studies}

\section{Results of the search}

Appendix 1 shows the search strategies. We identified 2803 records through the electronic database search of the Cochrane HepatoBiliary Group Controlled Trials Register $(n=8)$, CENTRAL $(n=224)$, PubMed $(n=173)$, Embase $(n=825)$, LILACS $(n=2)$, Web of Science $(n=735)$, CNKI $(n=457)$, and Wanfang databases $(n=379)$.

After removing duplicates, we screened the titles and abstracts of 2224 records. In total, we considered 135 records eligible for fulltext screening. We excluded 21 of these records (see below). We listed the remaining 114 records, reporting on 114 studies, under studies awaiting classification because we could not be sure that these were randomised clinical trials from the information in the study paper. We could not obtain information on the registration of the study protocol for any of the 114 studies. We could not obtain information on study approval by regional research ethics committees, neither from the study authors nor through our own searches of trial registries. Corresponding authors did not respond to our enquiries about the design and conduct of the studies, except for one from whom we did not receive a satisfactory response. We also raised awareness of our concerns to editors of the journals that published the 114 studies, and we did not hear back with useful information. Moreover, there seemed to be inappropriate inclusion of trial participants based on cancer stage and severity of liver disease, who should have obtained other interventions according to guidelines from learned societies (Omata 2010; EASLEORTC 2012; Heimbach 2018).

We identified five ongoing trials, by hand-searching in clinical trial websites (see Characteristics of ongoing studies).

The details of our selection are shown in the flow diagram (Figure 1). 
Figure 1. Study flow diagram

Date of last search 22 December 2020

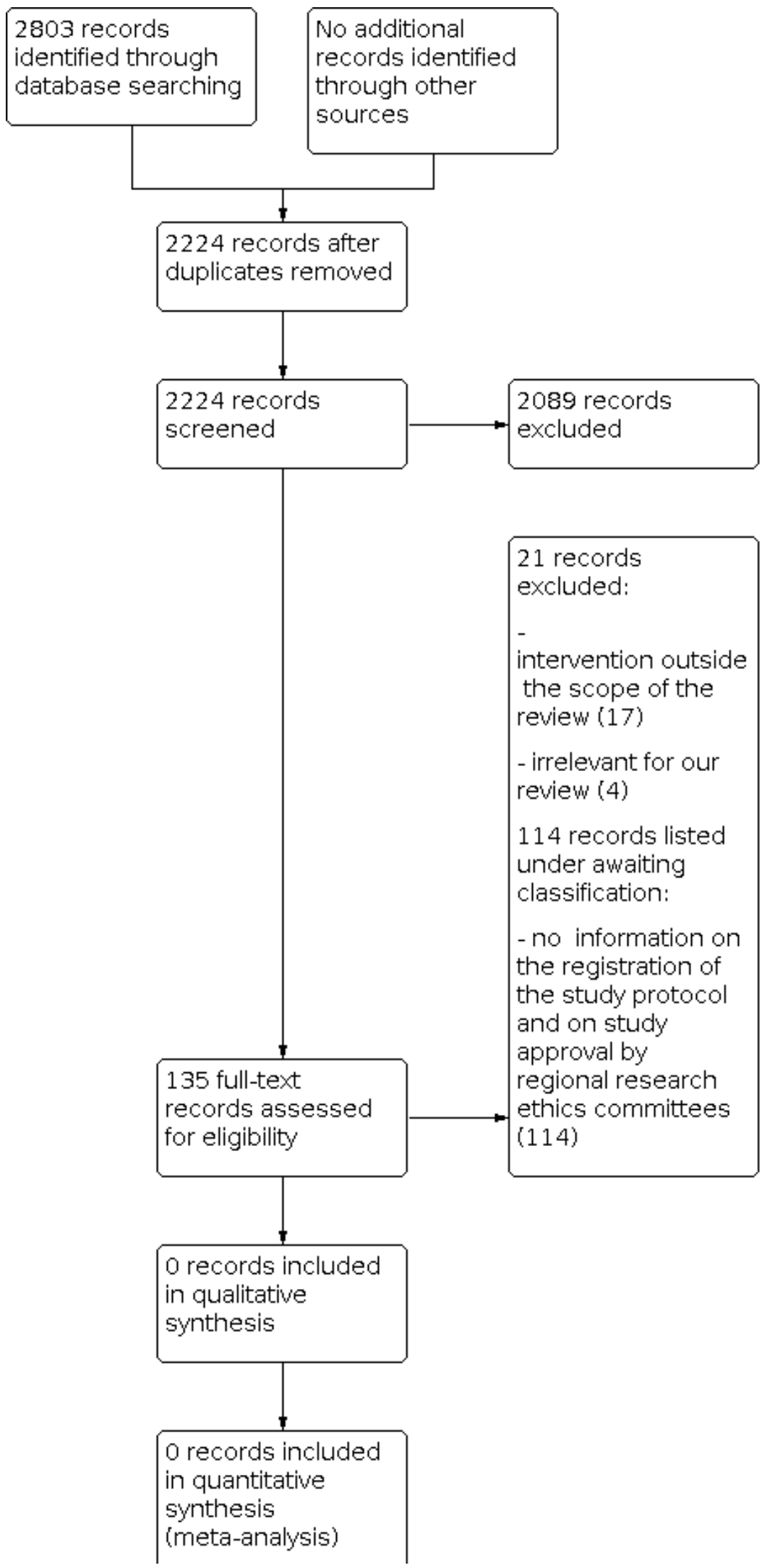

The combination of transcatheter arterial chemoembolisation (TACE) and thermal ablation versus TACE alone for hepatocellular 
Figure 1. (Continued)

$$
\text { (meta-analysis) }
$$

\section{Included studies}

We were unable to identify any randomised clinical trials evaluating the combination of TACE plus thermal ablation versus TACE alone for people with hepatocellular carcinoma. Please see above.

\section{Excluded studies}

The reasons for exclusion of the 21 studies are shown in Characteristics of excluded studies. The main reasons for exclusion of the studies were that studies used interventions outside the scope of our review, or studies were not randomised clinical trials.

\section{Risk of bias in included studies}

There were no trials to assess.

\section{Effects of interventions}

We could not assess the beneficial or harmful effects of the combination of TACE with ablation versus TACE alone for people with hepatocellular carcinoma, as we could find no trials for inclusion.

\section{DISCUSSION}

\section{Summary of main results}

Although we identified 114 potentially eligible studies, claiming to assess the beneficial or harmful effects or both combination of TACE plus thermal ablation versus TACE alone for hepatocellular carcinoma, these are all listed as awaiting classification and were not analysed.

There are a number of points that deserve attention and discussion.Firstly, there was absence of evidence of randomisation in the published reports, i.e. that the participants were indeed randomised. This means that the randomisation process was not described, or that the study authors did not provide details on the randomised trial design; there was no description of the methods used for generation of the allocation sequence and allocation concealment. Secondly, study authors, except for one, did not reply to our requests for missing information. We identified no multiple publications of the studies in order to check for required information. Furthermore, we could not obtain information from the study authors on the registration of the study protocol and on study approval by regional research ethics committees. We also raised awareness of our concerns to editors of the journals that published the 114 studies, and we did not hear back with useful information. Thirdly, there was no mention of ethical approval of the studies with appropriate approval number and documentation of the ethical review board. Fourthly, none of the 113 studies conducted after 2005 or the one study from 2003 (Jin 2003) were registered at the protocol stage as per current requirement for randomised clinical trials. There was no study registration number or similar identification and no published protocol, and we were not able to find these studies in any trial registry. Fifthly, there seemed to be inappropriate inclusion of participants based on cancer stage and severity of liver disease, that contravenes guidelines from learned societies (Omata 2010; EASL-EORTC 2012; Heimbach 2018). This could have resulted in significant harm for participants and raised important ethical issues. TACE should not be offered in patients with Child Pugh B8/B9 or Child Pugh C due to significant risk of deterioration of liver function and death (EASL-EORTC 2012;Granito 2017). TACE should also not be first-line treatment in patients with tumours greater than $3 \mathrm{~cm}$, where therapies with curative intent such as resection, ablation, or liver transplantation are recommended. All these recommendations are clearly stated in the Asian Pacific Association for the Study of the Liver (APASL), European Association for the Study of the Liver (EASL), and AASLD guidelines (Omata 2010; EASL-EORTC 2012; Heimbach 2018). In the studies awaiting classification, $6 \%$ to $23 \%$ of included patients had Child Pugh C cirrhosis, and there was no information on Child Pugh B8/B9 (apart from the fact that up to 50\% of patients had Child Pugh B). Moreover, $25 \%$ of patients had TNM stage I (and should, therefore, have received a curative treatment, not TACE which is a palliative treatment (Sirivatanauksorn 2011)). Therefore, there are significant concerns on the selection of patients.

If our decision to list all 114 studies in studies awaiting classification is not considered appropriate in any way, we hereby invite trialists or journal editors to send us information that can prove or disprove that these studies were indeed randomised clinical trials. We wrote to the journals that published the 114 studies, and we did not hear back with useful information.

\section{Overall completeness and applicability of evidence}

We designed comprehensive and scientific search strategies. We searched in English, Spanish, and Chinese databases.

\section{Quality of the evidence}

We found no eligible randomised clinical trials evaluating the beneficial or harmful effects, or both, of the combination of TACE plus thermal ablation versus TACE alone, thus we cannot analyse the certainty (quality) of evidence.

\section{Potential biases in the review process}

The systematic review has been conducted following the corresponding protocol (Liu 2019a). The process of preparing this review was rigorous. We did a comprehensive search for eligible trials.

\section{Agreements and disagreements with other studies or reviews}

We found 15 meta-analyses (Fan 2009; Fan 2011; Sun 2011; Lei 2013; Zhao 2013; Cao 2014; Gu 2014; Hu 2015; Wang 2016b; Katsanos 2017; Yang 2017; Zhao 2017; Liu 2018a; Xiong 2018a; Xiong 2018b) comparing the efficacy and safety of TACE plus radiofrequency ablation versus TACE alone. These 15 meta-analyses were based on the same studies that we have identified during our trial selection.

The combination of transcatheter arterial chemoembolisation (TACE) and thermal ablation versus TACE alone for hepatocellular 
We have not included these studies in our review for the reasons listed above.

\section{AUTHORS' CONCLUSIONS}

\section{Implications for practice}

No eligible randomised clinical trials assessing the beneficial and harmful effects of the combination of TACE plus thermal ablation versus TACE alone were included into this review. Therefore, our results did not show or reject the efficiency of any treatment strategy for hepatocellular carcinoma.

\section{Implications for research}

Large prospectively registered trials with rigorous methods comparing the beneficial and harmful effects of the combination of TACE plus thermal ablation versus TACE alone in hepatocellular carcinoma are needed. Such randomised clinical trials should be designed according to the SPIRIT statement (Chan 2013); registered in a WHO data register; with obtained full ethical approval; and reported according to the CONSORT statement (Schulz 2010). Such trials should be conducted in people who are not eligible for treatments with curative intent (liver transplantation, ablation surgical resection), who have sufficient liver reserve as assessed by the Child Pugh score, and do not have extrahepatic metastases. Therefore, future trial participants must be classified at Barcelona Clinic Liver Cancer Stage B (intermediate stage) (BCLC-B) or an equivalent, with other staging systems.

In view of the large number of studies we have identified as potentially problematic, there is an urgent need for validated tools to assist systematic review teams in identifying problematic studies. Our approach to assessing the 114 studies identified through electronic searching reinforces the importance of systematic review teams carefully appraising the studies they identify in order to reduce the impact of potentially problematic studies on evidence used to inform healthcare decision-making.

\section{ACK N O WLEDGEMENTS}

Cochrane Review Group funding acknowledgement: the Danish State is the largest single funder of the Cochrane Hepato-Biliary Group through its investment in the Copenhagen Trial Unit, Centre for Clinical Intervention Research, the Capital Region, Rigshospitalet, Copenhagen, Denmark. Disclaimer: the views and opinions expressed in this review are those of the authors and do not necessarily reflect those of the Danish State or the Copenhagen Trial Unit.

Authors' Disclaimer: The presented information within this review covers the current status of published studies on the topic, as assessed by our review team. We welcome journals or authors of the studies to help us in further classification of the studies, and on basis of this to decide whether to retract the studies or not.

Peer reviewers: Karl Heinz Weiss, Germany; Vanja Giljaca, UK Contact editors: Stefano Trastulli, Italy; Luit Penninga, Denmark Sign-off editor: Christian Gluud, Denmark Methodological Editor: Theresa Moore, UK Methods Support Unit Lead and Statistical Editor: Kerry Dwan, UK Cochrane Abdomen and Endocrine Network Editor: Rachel Richardson, UK 


\section{R E F E R E N C E S}

\section{References to studies excluded from this review}

Chen 2014 \{published data only\}

Chen L, Li D, Huang J, Li W, Gao Z. Comparative study of radiofrequency ablation and transcatheter arterial chemoembolization in hepatocellular carcinoma [超声引导单 极冷循环射频消融联合TACE治疗肝癌的对比研究]. Zhong Guo Chao Sheng Yi Xue Za Zhi [Chinese Journal of Ultrasound in Medicine] 2014;30(3):238-42.

\section{Chen 2015 \{published data only\}}

Chen W. The combination of transcatheter arterial chemoembolisation and ultrasound ablation for primary liver cancer [高强度聚焦超声联合动脉栓塞化疗治疗中晚期原发性 肝癌]. In: Di Si Jie Quan Guo Xiao Hua Dao E Xing Bing Bian Yan Tao Hui Lun Wen Ji [Biomedical Engineering Meeting in China]. Vol. 735. 2015:91-2.

\section{Hou 2017 \{published data only\}}

Hou P, Chen Y, Liu W, Jiao L, Yang J. Clinical effects of ultrasound-guided percutaneous microwave ablation and transcatheter arterial chemoembolization for primary liver cancer [超声引导下经皮微波消融与肝动脉化疗栓塞治疗原 发性肝癌的临床效果. ]. Shi Yong Ai Zheng Za Zhi [Practical Journal of Cancer] 2017;32(10):1667-70.

\section{Hu 2010 \{published data only\}}

Hu Z, Peng Y, Li Y, Chen S, Zeng X, Huang Q, et al. Therapeutic effect of radio-frequency ablation and transcatheter arterial chemoembolization for the treatment of liver cancer [ 射频消 融与肝动脉栓塞化疗对肝癌疗效的临床分析]. Zhong Hua Lin Chuang Xin Yi Xue [Chinese Journal of New Clinical Medicine] 2010;3(9):823-6.

\section{Huang 2015b \{published data only\}}

Huang S, Chen S, Zhang T, Li J. The huge liver cancer treated by the combination of TACE and microwave ablation [巨大肝癌肝 动脉栓塞化疗联合微波消融的临床分析]. Chong Qing Yi Xue [Chongqing Medicine] 2015;44(36):5149-52.

\section{Kong 2015 \{published data only\}}

Kong Y. The short-term efficacy of the combination of transcatheter arterial chemoembolisation with radiofrequency ablation [肝癌患者行TACE联合RFA治疗的近期疗效及其对 肿瘤局部复发的影响. ]. Zhong Guo Shi Yong Yi Yao [China Practical Medical] 2015;19:170-1.

\section{Li 2013a \{published data only\}}

Li P. Clinical study of TACE combined with high-intensity focused ultrasound in the treatment of stage $\mathbb{I I}$ and $\mathrm{N}$ liver cancer [TACE联合高强度聚焦超声治疗III、IV期肝癌的临床研 究] . cdmd.cnki.com.cn/Article/CDMD-10114-1013223852.htm (date accessed prior to 2 Dec 2021).

Li 2013b \{published data only\}

Li P, Zhou D, Lv W, Zhao Q, Li C. Clinical study of TACE in combination with high intensity focused ultrasound therapy for advanced stage hepatocellular carcinoma [TACE联合高强度聚 焦超声治疗中晚期肝癌的临床研究]. Zhong Guo Xian Dai Pu
Tong Wai Ke Jin Zhan [Chinese Journal of Current Advances in General Surgery] 2013;16(11):870-4.

\section{Li 2015b \{published data only\}}

Li Y, Ao G, Ma W, Wang H, An W. Transarterial chemoembolization plus radiofrequency ablation for middleand advanced-stage hepatocellular carcinoma [肝动脉栓 塞联合射频消融治疗中晚期肝癌效果观察]. Ren Min Jun Yi [People's Military Surgeon] 2015;58(1):60-2.

\section{Liu 2007 \{published data only\}}

Liu Y, Zheng X, Wei Y, Lin S. Transarterial chemoembolization plus cryoablation for liver cancer [TACE联合氩氦刀冷冻治疗 HCC疗效分析] . Shan Dong Yi Yao [Shandong Medical Journal] 2007;47(20):36-7.

\section{Liu 2015 \{published data only\}}

Liu J, Pan W, Chen C. The efficacy of the radiofrequency ablation plus TACE for primary liver cancer [射频消融联合经导管肝 动脉栓塞化疗治疗原发性肝癌的疗效]. Chinese Journal of Modern Drug Application 2015;9:62-3.

\section{Liu 2016b \{published data only\}}

Liu S. Analysis of the artery embolism chemotherapy with radiofrequency ablation treatment of primary liver cancer [动 脉栓塞化疗联合射频消融治疗原发性肝癌临床疗效分析]. He Bei Yi Xue [Hebei Medicine] 2016;22(7):1109-11.

Lu 2015 \{published data only\}

Lu A. Radio-interventional treatment for the improvement of qulaity of life in patients with hepatocellular carcinoma [放射 介入治疗对中晚期肝癌患者生活质量的改善作用研究]. Yi Yao Qian Yan [Yiayao Qianyan] 2015;5(21):156-8.

\section{Sha 2012 \{published data only\}}

Sha Q. The clinical efficacy of transcatheter arterial chemoembolisation plus radiofrequency ablation for liver cancer [肝动脉化疗栓塞联合射频消融治疗中晚期肝癌的临 床疗效]. Zhong Liu Ji Chu Yu Lic Chuang [Journal of Basic and Clinical Oncology] 2012;6:498-500.

\section{Wang 2011 \{published data only\}}

Wang X, Fu S. The combination of radiofrequency ablation with transarterial chemoembolization for liver cancer [射频 消融联合肝动脉栓塞术治疗中晚期肝癌的疗效观察]. Qi Qi Ha Er Yi Xue Bao [Journal of Qiqihar University of Medicine] 2011;32(18):2957-8.

\section{Wang 2016a \{published data only\}}

Wang $\mathrm{H}$. The combination of transarterial chemoembolization with cryoablation in 33 patients with liver cancer [TACE 联 合氩氦刀冷冻消融治疗中晚期原发性肝癌 33 例临床效果 评价]. She Qu Yi Xue Za Zhi [Journal of Community Medicine] 2016;14(22):68-9.

\section{Wu 2006 \{published data only\}}

Wu P. The efficacy of the combination of CT-guided ablation with transcatheter arterial chemoembolization, presented at the 1st Chinese Symposium on Minimally linvasive Cancer

The combination of transcatheter arterial chemoembolisation (TACE) and thermal ablation versus TACE alone for hepatocellular 
Therapy and the Founding Meeting of Minimally Invasive Therapy Committee of Chinese Anti-Cancer Association. April 2005. In: The 1st Interventional Treatment Meeting in Henan. Guangzhou, 2006.

\section{Wu 2011a \{published data only\}}

Wu L, Li Z. TACE combined with the argon-helium cryoablation treatment of liver cancer [磁共振手术系统氩氦刀消融与 TACE协同治疗无手术指证原发性肝癌的临床分析]. In: China (Seventh) Academic Conference on Minimally Invasive Tumor Therapy; 2011 Sep 23; Guangzhou, Guangdong, China. 2011:343-6.

\section{Wu 2017a \{published data only\}}

Wu L, Shen F. Clinical effects of combination of microwave ablation and chemoembolization in treating hepatocellular carcinoma with portal vein tumor thrombosis [微波消融联合 化疗栓塞治疗肝细胞肝癌伴门脉癌栓的临床疗效]. Zhong Guo Lin Chuang Yi Xue [Chinese Journal of Clinical Medicine] 2017;24(2):272-6.

\section{Xiang 2007 \{published data only\}}

Xiang H, Long L, Zhang Z, Liu J, Fang Z, Sun L, et al. The combined interventional treatments for huge hepatocellular carcinoma [联合介入治疗大肝癌的临床疗效分析]. Nan Hua Da Xue Xue Bao [Journal Of Nanhua University] 2007;35(5):761-3.

\section{Yang 2016 \{published data only\}}

Yang X, Zhang X, Liu H, Song W, Gao H. The curative effect and prognostic analysis of transcatheter arterial chemoembolization combined with radiofrequency ablation in treatment of liver cancer [肝动脉化疗栓塞联合射频消融治疗 肝癌疗效及预后分析]. Zhong Guo Ji Ceng Yi Yao [China Basic Medicine] 2016;23(17):2609-12.

\section{References to studies awaiting assessment}

\section{Ai 2019 \{published data only\}}

Ai Z, Cheng Y, Zhang X. A clinical study on transcatheter arterial chemoembolization combined with radiofrequency ablation in treatment of Barcelona Clinic liver cancer stage B hepatocellular carcinoma [肝动脉化疗栓塞联合射频消融术治疗巴塞罗那B 期肝癌的临床研究]. Academic Journal of Guangzhou Medical College 2019;47(4):17-9, 26.

\section{An 2017 \{published data only\}}

An XY. The efficacy of the combination of TACE with microwave ablation for huge hepatocellular carcinoma [TACE联合微 波消融治疗对巨大肝癌患者的疗效探究]. Lin Chuang Yi Yao Wen Xian Za Zhi [Journal of Clinical Medical Literature] 2017;4(3):420-1.

\section{Bao 2020 \{published data only\}}

Bao X. The effect of transhepatic artery chemoembolization combined with radiofrequency ablation in the treatment of advanced primary liver cancer [经肝动脉化疗栓塞联合射频 消融术治疗中晚期原发性肝癌的效果]. Medical Information 2020;33(19):110-2.
Bian 2020 \{published data only\}

Bian J, Da T, Luo J, Zhou Q, Jiang Y, Wu T. Ultrasound-guided percutaneous microwave ablation combined with transarterial arterial chemoembolization for primary hepatocellular carcinoma [超声引导下经皮微波消融联合肝动脉化疗栓 塞治疗原发性肝癌的疗效观] . Journal of Chinese Practical Diagnosis and Therapy 2020;34(5):509-12.

\section{Chen 2020 \{published data only\}}

Chen J, Liang Y, Lin J, Yang J. The combination of TACE with CTguided radiofrequency for small liver cancer [肝动脉化疗栓 塞术联合CT引导下经皮射频消融治疗小肝癌的临床观察] . Modern Medical Imageology 2020;29(3):567-9.

\section{Cui 2015 \{published data only\}}

Cui H, Zhao H, Wu Y, Dong Q, Zhang X. Observation of the efficacy of the combination of TACE with radiofrequency for hepatocellular carcinoma [TACE 联合 R FA 治疗原发性肝癌的 临床效果观察] . Lin Chuang He Li Yong Yao [Chinese Journal of Clinical Rational Drug Use] 2015;19:130-1.

\section{Cui 2017 \{published data only\}}

Cui M. Results observation of primary liver cancer treatment by transcatheter arterial chemoembolization combined radio frequency ablation [肝动脉化疗栓塞联合射频消融治疗原发 性肝癌效果观察]. She Qu Yi Xue Za Zhi [Journal of Community Medicine] 2017;4:3-5.

\section{Dan 2014 \{published data only\}}

Dan XG. The efficacy of intervential treatments for hepatocellular carcinoma [介入治疗原发性肝癌临床分析] . Zhong Guo Xian Dai Yao Wu Ying Yong [Chinese Journal of Modern Drug Application] 2014;8(14):27-8.

\section{Ding 2017 \{published data only\}}

Ding M, Tan Y, He G, Han D, Wen W, Qiu J, et al. The efficacy of radiofrequency ablation for hepatocellular carcinoma [射频消 融术在中晚期肝癌中的应用效果]. Lin Chuang He Li Yong Yao [Chinese Journal of Clinical Rational Drug Use] 2018;11(9):123-4.

\section{Dong 2013 \{published data only\}}

Dong YS, Zhang Z, Yang X. The clinical efficacy of the combination of TACE with RFA for HCC [肝动脉化疗栓塞联 合射频消融治疗大肝癌的临床疗效].Pu Tong Wai Ke Jin Zhan [Chinese Journal of Current Advances in General Surgery] 2013;16(6):486-8.

\section{Dong 2018 \{published data only\}}

Dong H. Clinical efficacy of transcatheter arterial chemoembolization combined with radiofrequency ablation in the treatment of hepatocellular carcinoma [肝动脉化疗栓塞术 联合射频消融术治疗肝细胞癌患者的临床疗效观察]. Zhong Guo Shi Yong Yi Yao [China Practical Medical] 2018;13(6):25-7.

\section{Du 2017 \{published data only\}}

Du X. Effect analysis of transcatheter arterial chemoembolization combined with radiofrequency catheter ablation on primary hepatocellular carcinoma [肝动脉化疗栓 塞联合射频消融术治疗原发大肝癌的疗效分析]. Lin Chuang Yi Xue [Clinical Research and Practice] 2017;2(25):15-6. 


\section{Fan 2016 \{published data only\}}

Fan L. The combination of transcatheter arterial chemoembolisation with radiofrequency ablation for hepatocellular carcinoma [经肝动脉化疗栓塞术联合射频消 融术治疗原发性肝癌的临床疗效]. Lin Chuang He Li Yong Yao [Chinese Journal of Clinical Rational Drug Use] 2017;9(36):113-4.

\section{Fang 2016 \{published data only\}}

Fang A. The clinical efficacy of the combnation of transcatheter arterial chemoembolisation with radiofrequency ablation for hepatocellular carcinoma [肝动脉化疗栓塞联合射频消融治疗 肝癌疗效的观察]. Yi Xue Li Lun Yu Shi Jian [Journal of Medical Theory and Practice] 2016;2:197-8.

\section{Fang 2020 \{published data only\}}

Fang L, Ding J, Luo G, Cheng S, Zheng Y, Wang C. TACE plus microwave ablation for large and huge hepatocellular carcinoma [TACE联合微波消融同步治疗大肝癌和巨块型肝癌 的临床疗效及预后分析]. World Latest Medicine Information 2020;20(19):156, 158.

\section{Geng 2020 \{published data only\}}

Geng X, Li C, Xu H. Effect of TACE combined with MWA on liver cancer and its influence on serum tumour markers [TACE联合 MWA治疗肝癌的效果及对血清肿瘤标志物的影响]. Clinical Research and Practice 2020;5(33):76-7.

\section{Gong 2019 \{published data only\}}

Gong A, Tan Y, Luo X. The clinical efficacy of microwave ablation plus TACE on hepatocellular carcinoma [微波消融术联合肝动 脉化疗栓塞术对中晚期肝癌的疗效及对免疫功能的影响]. Zhejiang Practical Medicine 2019;24(6):405-7, 430.

\section{Guo 2015c \{published data only\}}

Guo J, Cao M. The assessment of efficacy and safety of the combination of transcatheter arterial chemoembolisation with high intensity focused ultrasound ablation [高强度聚焦超声 在经肝动脉化疗栓塞治疗中的效果及安全性分析]. Zhong Guo Xian Dai Pu Tong Wai Ke Jin Zhan [Chinese Journal of Current Advances in General Surgery] 2015;1:76-9.

\section{He 2016 \{published data only\}}

He Z, Liu Y, Wen J, Zhang Z, He W, Chen H. Clinical application of hepatic arterial chemoembolization combined with percutaneous microwave coagulation therapy for primary massive liver cancer [肝动脉化疗栓塞联合微波消融治疗原发 性巨块型肝癌的疗效] .Yi Xue Lin Chuang Yan Jiu [Journal of Clinical Research] 2016;33(7):1348-50.

\section{He 2020 \{published data only\}}

HeX. The clincal effect of the combination of TACE with RFA for hepatocellular carcinoma [肝动脉化疗栓塞联合射频消融治疗 原发性肝癌患者的效果]. Medical Journal of Chinese People's Health 2020;32(9):16-8.

\section{Hou 2013 \{published data only\}}

Hou X, Song Q, Li L, Zhuang X. The efficacy of primary hepatic carcinoma treated by transcatheter arterial chemoembolisation combined with argon-helium cryoablation [TACE 联合氩氦 冷冻消融治疗原发性肝癌效果观察]. Shi Yong Yi Yao Za Zhi [Practical Journal of Medicine \& Pharmacy] 2013;30(4):293-5.

\section{Hua 2020 \{published data only\}}

Hua L, Zhang T, Hua L. The observation on the clinical efficacy of the combination of TACE with radiofrequency ablation [肝动 脉化疗栓塞联合射频消融术治疗原发性大肝癌的效果观察与 护理]. Journal of Clinic Nursing's Practicality 2020;5(29):26, 41.

Huang 2013 \{published data only\}

Huang Y, Xu Q, Shen T, Shi H. Clinical efficacy and safety of transcatheter arterial chemoembolization combined with radiofrequency ablation in the treatment of advanced hepatocellular carcinoma [肝动脉化疗栓塞联合射频消融治 疗中晚期肝癌的疗效评价]. Hai Nan Yi Xue [Hainan Medical Journal] 2013;24(24):3630-2.

\section{Huang 2015a \{published data only\}}

Huang Q. The application value of hepatic artery interventional embolization combined with radiofrequency ablation for the recurrence of small liver cancer after surgery [动脉介入栓塞联 合射频消融术在小肝癌术后复发中的应用价值]. Lin Chuang Yi Yao Shi Jian [Proceeding of Clinical Medicine] 2015;6:408-11.

Huang 2016 \{published data only\}

Huang L, Shang H, Xu G. The assessment of clinical efficacy on the combination of transcatheter arterial chemoembolisation with radiofrequency ablation [肝动脉化疗栓塞和射频消 融联合治疗中晚期肝癌的可行性研究]. Dang Dai Yi Xue [Contemporary Medicine] 2016;22(13):63-4.

\section{Huang 2017a \{published data only\}}

Huang Q, Liu H, Xu J, Ni Y, Yang Z. The combination of high intensity focused ultrasound ablation and transcatheter arterial chemoembolisation for hepatocellular carcinoma [TACE, 热学 疗法联合治疗肝癌的临床疗效分析]. Da Jia Jian Kang [For All Health] 2017;11(8):119-20.

\section{Huang 2017b \{published data only\}}

Huang Y. The clinical efficacy of transcatheter arterial chemoembolisation plus radiofrequency ablation for hepatocellular carcinoma [经肝动脉化疗栓塞术与经皮穿刺 射频消融治疗原发性肝癌的临床效果]. Zhong Guo Shi Yong Yi Kan [Chinese Journal of Practical Medicine] 2017;44(13):92-4.

Huang 2019 \{published data only\}

Huang Y, Xu F, Zhong L. Effects of transcatheter arterial chemoembolization combined with radiofrequency ablation on cellular immune function in patients with hepatocellular carcinoma [肝动脉化疗栓塞联合射频消融对肝癌患者细 胞免疫功能的影响]. Chinese Journal of General Practice 2019;17(9):1521-3, 1614.

\section{Jiang 2015a \{published data only\}}

Jiang X. The combination of transcatheter arterial chemoembolisation with radiofrequency ablation for hepatocellular carcinoma [射频消融和肝动脉栓塞化疗治 疗原发性肝癌的效果比较]. Dang Dai Yi Xue [Contemporary Medicine] 2015;12:71-2.

\section{Jiang 2015b \{published data only\}}

Jiang X, Cui H, Zhang J, Yang H, Zhang C. Effects of transcatheter arterial chemoembolisation combined with radiofrequency ablation for hepatocellular carcinoma and prognostic factors

The combination of transcatheter arterial chemoembolisation (TACE) and thermal ablation versus TACE alone for hepatocellular 
analysis [TACE联合RFA治疗无法手术的肝细胞癌疗效及预后分 析] . Zhong Liu Yao Xue [Anti-Tumor Pharmacy] 2015;5:379-83.

Jiang 2017 \{published data only\}

Jiang FQ, Lu W, Yang C, Du P, Ma JP, Yang J, et al. Curative effect of transcatheter arterial chemoembolization combined with radiofrequency ablation in treating hepatic cell carcinoma and its effect on serum markers. Cancer Biomarkers 2017;20(1):17-22.

\section{Jiang 2018 \{published data only\}}

Jiang B, Li H. Effects of transcatheter arterial chemoembolisation combined with MCT on vascular endothelial growth factor and T cell subsets in patients with primary liver cancer [TACE 联合 MCT 治疗对原发性肝癌患者血 管内皮生长因子和T 细胞亚群的影响] . Liao Ning Yi Xue Za Zhi [Medical Journal of Liaoning] 2018;32(1):31-4.

\section{Jin 2003 \{published data only\}}

Jin CB, Wu F, Wang ZB, Chen WZ, Zhu H. [High intensity focused ultrasound therapy combined with transcatheter arterial chemoembolization for advanced hepatocellular carcinoma] [高强度聚焦超声联合动脉栓塞化疗治疗晚期肝癌的初步临床 研究]. Zhonghua Zhong Liu Za Zhi [Chinese Journal of Oncology] 2003;25(4):401-3. [PMID: 12921577]

\section{Lai 2019 \{published data only\}}

Lai X, Ye J, Zeng J, Huang C, Wang S. The effect of the combination of TACE with MWA on the immunological function in patients with primary liver cancer [联合肝动脉栓塞化疗与 微波消融对原发性肝癌患者免疫功能的影响]. Contemporary Medicine 2019;25(34):134-6.

\section{Li 2012 \{published data only\}}

Li Y, Ma C, Ma W, Long J. Therapeutic efficacy of high-intensity focused ultrasound plus hepatic artery chemoembolization in patients with hepatocellular carcinoma [肝癌患者高强度聚焦 超声联合肝动脉栓塞化疗的临床疗效观察]. Zhong Guo Yi Xue Zhuang Bei [China Medical Equipment] 2012;9(12):94-6.

\section{Li 2015 \{published data only\}}

Li D, Xiang H, Zhang Z, Liu J, Fang Z, Long L, et al. The changes of VEGF level in patients with hepatocellular carcinoma after argon-helium cryoablation combined with transcatheter arterial chemoembolization treatment [肝细胞肝癌氞氦 刀联合肝动脉介入治疗前后血清 VEGF 的变化]. Jie Ru Fang She Xue Za Zhi [Journal of Interventional Radiology] 2015;24(5):400-3.

\section{Li 2016a \{published data only\}}

$\mathrm{Li}$ B. The clinical effect of the combination of transcatheter arterial chemoembolisation with radiofrequency ablation for hepetocellular carcinoma [肝动脉化疗栓塞术联合射频消融治 疗肝癌的临床观察]. Zhong Guo Shi Yong Yi Yao [China Practical Medical] 2016;31:88-9.

\section{Li 2016b \{published data only\}}

Li X, Lv H. The efficacy observation of transcatheter arterial chemoembolization combined with radiofrequency ablation for primary liver cancer [肝动脉化疗栓塞联合射频消融治疗原发
性肝癌的疗效观察] . Ji Ceng Yi Xue Lun Tan [Medical Forums in Basic] 2016;20(10):1322-3.

Li 2017a \{published data only\}

$\mathrm{Li}$ J. The clinical effect of the combination of transcatheter arterial chemoembolisation with cryoablation for hepetocellular carcinoma [肝动脉栓塞化疗结合氩氦刀治 疗中晚期肝癌的临床疗效]. Dang Dai Yi Xue [Contemporary Medicine] 2017;23:104-6.

\section{Li 2017b \{published data only\}}

Li S. The effect of the combination of transcatheter arterial chemoembolisation with microwave ablation for hepatocellular carcinoma [肝动脉导管化疗栓塞联合CT引导精准微波消融治 疗原发性肝癌的效果观察]. Bai Qiu En Yi Xue Za Zhi [Journal of Bethune Military Medical College] 2017;16(6):753-5.

\section{Li 2017c \{published data only\}}

Li X, Zhang $\mathrm{H}$. The quality of patients with hepatocellular carcinoma treated with intervention treatments [放射介入治疗 对中晚期肝癌患者生活质量的改善效果]. Shan Xi Yi Xue Za Zhi [Shanxi Medical Journal] 2017;46(9):1237-8.

\section{Li 2018 \{published data only\}}

Li W, Chen J, Zhao S. Improvement of the efficacy of patients with primary hepatic carcinoma by TACE combined with RFA [TACE联合RFA疗法可有效提高原发性肝癌患者的疗效] . Ji Yin Zu Xue Yu Ying Yong Sheng Wu Xue [Genomics and Applied Biology] 2018;37(1):109-14.

\section{Li 2019a \{published data only\}}

Li H. Clinical study of transcatheter arterial chemoembolization combined with radiofrequency ablation in the treatment of hepatocellular carcinoma [肝动脉介入栓塞化疗联合射频消 融治疗肝癌的临床效果]. He Ze Yi Xue [Journal of Heze Medical College] 2019;31(1):45-7, 57.

\section{Li 2020 \{published data only\}}

Li X. TACE plus MWA for hepatic cancer and the level of AFP [动] 脉栓塞化疗联合微波消融治疗肝癌的临床疗效及对血清AFP水 平的影响]. Clinical Research 2020;28(10):80-1.

\section{Lin 2017 \{published data only\}}

Lin H. The efficacy of the combination of TACE with radiofrequency ablation for advanced liver cancer [肝动脉栓 塞配合射频消融对中晚期肝癌的治疗作用评价]. Te Bie Jian Kang [Special Health] 2017;17:63.

\section{Liu 2016a \{published data only\}}

Liu J. The efficacy and safety of the combinaiton of transcatheter arterial chemoembolisation with microwave ablation for hepatocellular carcinoma [肝动脉化疗栓塞联 合微波消融治疗原发性肝癌的临床疗效观察]. Zhong Guo Gao Deng Yi Xue Jiao Yu [China Higher Medical Education] 2016;10:135-6.

\section{Liu 2017 \{published data only\}}

Liu Q, Yu G, Yang G, Zhang Q, Qiu F, Li C, et al. Clinical efficacy and safety of cool-tip microwave ablation combining transcatheter arterial chemoembolization in treatment of patients with primary liver cancer [冷循环微波消融联合肝动

The combination of transcatheter arterial chemoembolisation (TACE) and thermal ablation versus TACE alone for hepatocellular 
脉灌注化疗栓塞治疗原发性肝癌患者疗效及安全性研究]. Shi Yong Gan Zang Bing Za Zhi [Journal of Practical Hepatology] 2017;20(3):316-9.

\section{Liu 2018b \{published data only\}}

Liu D. The effect of the combination of transcatheter arterial chemoembolisation and microwave ablation on serum biomarkers of hepatocellular carcinoma [经动脉导管灌注化疗 栓塞术联合微波消融术治疗对肝癌血清标志物的影响].Gui Zhou Yi Yao [Guizhou Medical Journal] 2018;42(5):567-8.

\section{Liu 2019b \{published data only\}}

Liu L. The analysis on the efficacy of the combination of TACE with CT-guided RFA in patients with primary liver cacner [ 肝 动脉化疗栓塞术联合CT引导下射频消融术对原发性肝癌患 者治疗效果分析]. Journal of Imaging Research and Medical Applications 2019;3(14):211-2.

\section{Liu 2019c \{published data only\}}

Liu L. The analysis on the efficacy of TACE plus CT-guided ablation on primary cancer [肝动脉化疗栓塞术联合CT引导 下射频消融术对原发性肝癌患者治疗效果分析]. Journal of Imaging Research and Medical Applications 2019;3(14):211-2.

\section{Liu 2019d \{published data only\}}

Liu Q. The comparison on the clinical efficacy between TACE plus MWA and TACE [Tace联合微波消融与单纯tace治疗晚期肝 癌的临床疗效对比]. Yiyao Qianyan 2019;9(31):82-3.

\section{Liu 2020 \{published data only\}}

Liu S, Zhong Y, Peng H. The clinical efficacy of the combination of TACE with ultrasound-guided microwave ablation [肝动脉化 疗栓塞TACE联合超声引导下微波消融治疗特殊部位肝癌疗效 观察]. Guizhou Medical Journal 2020;44(2):212-4.

\section{Lu 2018 \{published data only\}}

Lu C. The clinical effect of the combination of transcatheter arterial chemoembolisation with radiofrequency ablation in hepatocellular carcinoma [经肝动脉化疗栓塞术与经皮穿刺射 频消融治疗原发性肝癌的临床效果]. Ji Lin Yi Xue [Jilin Medical Journal] 2018;39(8):1553-4.

\section{Luo 2019 \{published data only\}}

Luo Y, Jiang Y. Comparison of efficiency of TACE plus HIFU and TACE alone on patients with primary liver cancer. Journal of the College of Physicians and Surgeons - Pakistan 2019;29(5):414-7. [PMID: 31036108]

\section{Lv 2016 \{published data only\}}

Lv S. The efficacy and safety or transcatheter arterial chemoembolisation plus radiofrequency in hepatocellular carcinma [TACE联合射频消融术治疗原发性肝癌的临床分析]. Lin Chuang Yi Yao Dian Zi Wen Xian Za Zhi [Journal of Clinical Medical Literature] 2016;3(52):10366-7.

\section{Ma 2017 \{published data only\}}

Ma N. Efficacy observation of chemoembolization combined with radio-frequency ablation in the treatment of hepatocellular carcinoma [化疗栓塞术联合射频消融治疗肝 癌的疗效观察] . Lin Chuang Yi Xue Yan Jiu Yu Shi Jian [Clinical Research and Practice] 2017;2(34):30-2.
Ma 2019a \{published data only\}

$\mathrm{Ma} \mathrm{H}$. The clinical observation of transcatheter arterial chemoembolisation plus radiofrequency ablation [肝动脉栓塞 化疗联合射频消融在原发性肝癌患者中的疗效观察]. Zhong Guo She Qu Yi Shi [Chinese Community Doctors] 2019;35(9):47, 51.

\section{Ma 2019b \{published data only\}}

Ma W. Clinical effect of CT guided precise microwave ablation combined with TACE in the treatment of patients with primary liver cancer [CT引导精准微波消融术联合TACE术治疗原发性 肝癌患者的临床效果]. Xian Dai Yi Yong Ying Xiang Xue [Modern Medical Imagelogy] 2019;28(2):272-3.

\section{Ma 2020 \{published data only\}}

Ma Z, Yang L, Wei Q. The effect of ultrasound-guided microwave ablation on the level of TBIL, DBIL, and ALT in patients with intermediate- and advanced-liver cancer [超声引导下微波消 融术对中晚期原发性肝癌患者血清TBIL、DBIL、ALT水平的 影响及安全性分析]. Modern Medicine and Health Research 2020;4(18):16-8.

\section{Mo 2017 \{published data only\}}

Mo Q, Liu L, Yang X, Duo Y, Yang T. Effect of TACE combined with RFA on serum tumor markers and postoperative survival in patients with primary liver cancer [肝动脉栓塞联合射频 消融术治疗对原发性肝癌患者血清肿瘤标志物及术后生存 的影响]. Zhong Liu Xue Za Zhi [Journal of Chinese Oncology] 2017;23(12):1142-5.

\section{Pan 2016 \{published data only\}}

Pan W, Huang T, Xie W. The combination of transcatheter arterial chemoembolisation with CT-guided radiofrequency ablation for hepat cellular carcinoma [肝动脉栓塞化疗术联 合 CT引导下射频消融治疗肝癌的疗效观察]. Lin Chuang He Li Yong Yao Za Zhi [Chinese Journal of Clinical Rational Drug Use] 2016;9(23):86-7.

\section{Peng 2017 \{published data only\}}

Peng S, Zhu Z, Huang Q. Clinical application of transcatheter arterial chemoembolization combined with microwave ablation in the treatment of primary liver cancer [肝动脉栓塞化疗联合 微波消融术治疗原发性肝癌的临床应用]. Lin Chuang Yi Xue Gong Cheng [Clinical Medical and Engineering] 2017;24(7):923-4.

\section{Qu 2014 \{published data only\}}

Qu Z, Wang W, Wan L, Cai Z. The combination of transcatheter arterial chemoembolisation with radiofrequency ablation for 40 patients with hepatocellular carcinoma [肝动脉化疗栓塞 联合射频消融治疗原发性肝癌40例分析]. Chong Qing Yi Xue [Chongqing Medicine] 2014;28:3779-81.

\section{Qu 2015 \{published data only\}}

Qu XY, Qin CH, Wu J, Chen ZL, Yang WJ. Transcatheter hepatic arterial chemoembolization in combination with radiofrequency ablation for treatment of patients with hepatocellular carcinoma: curative efficacy and effect on serum BDNF level [化疗栓塞联合射频消融治疗肝癌的疗效及对患 者BDNF水平的影响]. Shi Jie Hua Ren Xiao Hua Za Zhi [World Chinese Journal of Digestology] 2015;23(9):1473-8. 


\section{Shen 2015 \{published data only\}}

Shen J, Fu S. The efficacy of the combination of transcatheter arterial chemoembolisation with radiofrequency ablation for primary liver cancer [经导管动脉灌注栓塞化疗联合射频消融 治疗原发性肝癌疗效评价] . Yi Xue Li Lun Yu Shi Jian [Journal of Medical Theory and Practice] 2015;20:2781-2.

\section{Shen 2020 \{published data only\}}

Shen Q. Effect of transcatheter arterial chemoembolization combined with percutaneous radiofrequency ablation on postoperative sleep quality in patients with advanced hepatocellular carcinoma [经导管肝动脉化疗栓塞联合经皮射 频消融术治疗中晚期肝癌患者术后睡眠质量的影响]. World Journal of Sleep Medicine 2020;7(2):220-1.

\section{Song 2016b \{published data only\}}

Song Z, Li H, Qiang Y. To observe the therapeutic effect of transcatheter arterial chemoembolization combined with microwave ablation in the treatment of primary hepatic carcinoma [观察肝动脉化疗栓塞术联合微波消融治疗原 发性大肝癌的疗效]. Zhong Guo Ji Xu Yi Xue Jiao Yu [China Continuing Medical Education] 2016;8(23):100-2.

\section{Song 2018 \{published data only\}}

Song X, Qin P, Teng X, Song R, Dong Z. The clinical efficacy of the combination of transcatheter arterial chemoembolisation with microwave ablation for middle and advanced liver cancer [肝动] 脉化疗栓塞联合微波消融治疗中晚期肝癌的疗效观察]. Dong Fang Shi Liao Yu Bao Jiang [Oriental Diet Therapy and Health Care] 2018;1:76.

\section{Song 2019 \{published data only\}}

Song $\mathrm{B}$, Jiang $\mathrm{H}$. The feasibility or the combination of transcatheter arterial chemoembolisation with radiofrequency ablation for large hepatocellular carcinoma [肝动脉灌注化疗 栓塞术联合射频消融对原发性大肝癌的疗效及可行性研究]. Zhong Guo Xian Dai Yao Wu Ying Yong [Chinese Journal of Modern Drug Application] 2019;13(1):43-4.

\section{Tong 2018 \{published data only\}}

Tong D, Wang H, Jia J, Zhang G, Qiu H, Zhang H. Effect of transcatheter arterial chemoembolization combined with radiofrequency ablation in the treatment of liver cancer [肝动 脉化疗栓塞术联合射频消融治疗肝癌疗效观察]. Zhong Guo Ji Ceng Yi Yao [Chinese Journal of Primary Medicine and Pharmacy] 2018;25(1):1-5.

\section{Wang 2013 \{published data only\}}

Wang H, Wang Y, Hou R, Zhang M, Liu C, Xu C. The combination of TACE plus RFA for primary liver cancer [TACE 联合 R FA 治疗 原发性肝癌的临床疗效]. Shan Dong Yi Yao [Shandong Medical Journal] 2013;53(29):52-4.

\section{Wang 2015a \{published data only\}}

Wang W, Liu W, Duan T, Peng Z. Observation the efficacy of TACE combined with RFA for patients with primary liver cancer [TACE 联合RFA治疗原发性肝癌的疗效观察]. Zhong Guo Yi Yao Zhi Nan [Guide of China Medicine] 2015;12:13-5.
Wang 2015b \{published data only\}

Wang X, Sun J, Xiao B. Efficacy and safety of transcatheter arterial chemoembolization combined with radiofrequency ablation in the treatment of primary liver cancer [肝动脉化疗 栓塞联合射频消融治疗原发性肝癌的疗效及安全性]. Zhong Guo Zhong Liu Lin Chuang Yu Kang Fu [Chinese Journal of Clinical Oncology and Rehabilitation] 2015;22(9):1068-70.

\section{Wang 2017a \{published data only\}}

Wang E, Xu J. Effects of transcatheter arterial chemoembolization combined with radio frequency ablation on primary liver cancer [化疗栓塞术结合射频消融术治疗原发性 肝癌的效果观察]. Zhong Guo Shi Yong Qi Kan [Chinese Journal of Practical Medicine] 2017;44(3):53-5.

Wang 2017b \{published data only\}

Wang M, Yin D, Zhu X. The combination of transcatheter arterial chemoembolisation with ultrasound-guided radiofrequency ablation for liver cancer [超声引导下单极冷循环射频消融联合 TACE治疗肝癌的效果观察]. Ji Ceng Yi Xue Lun Tan [The Medical Forum] 2017;21(10):1268-9.

\section{Wang 2017c \{published data only\}}

Wang Y, Wang H, You L, Luo D. Clinical observation of transcatheter arterial chemoembolization combined with radio frequency ablation in the treatment of primary liver cancer [ 肝 动脉化疗栓塞联合射频消融治疗原发性肝癌的临床观察]. Shi Yong Yi Yuan Lin Chuang Za Zhi [Practical Journal of Clinical Medicine] 2017;14(4):192-4.

\section{Wang 2017d \{published data only\}}

Wang Z. The combination of transcatheter arterial chemoembolisation with radiofrequency ablation for huge liver cancer [多极射频消融联合 TACE 治疗巨块型肝癌的效 果观察] . Lin Chuang He Li Yong Yao Za Zhi [Clinical Research] 2017;10(1):125-6

\section{Wang 2018a \{published data only\}}

Wang $\mathrm{H}$, Chen $\mathrm{H}$, Song T. Effect of radiofrequency ablation combined with transcatheter arterial chemoembolization on gene expression and survival of primary hepatocellular carcinoma [射频消融联合肝动脉化疗栓塞对原发性肝癌基 因表达及生存期的影响]. Xian Dai Zhong Liu Yi Xue [Journal of Modern Oncology] 2018;26(22):3597-601.

\section{Wang 2018b \{published data only\}}

Wang $\mathrm{H}$, Chen $\mathrm{H}$, Song T. The clinical efficacy of the combination of transcatheter arterial chemoembolisation with radiofrequency ablation for liver cancer [TACE联合射频消融 术治疗巨块型肝癌临床疗效分析]. Hu Bei Ke Ji Xue Yuan Xue Bao [Journal of Hubei University of Science and Technology] 2018;32(5):390-3.

\section{Wang 2018c \{published data only\}}

Wang J, Liu T, Li X. Efficacy of transcatheter arterial chemoembolization combined with ultrasound-guided radiofrequency ablation for primary carcinoma of liver [经 肝动脉栓塞化疗联合超声引导下射频消融治疗原发性肝癌 的效果]. Zhong Guo Shi Yong Yi Yao [China Practical Medical] 2018;13(30):22-3. 
Wen 2018 \{published data only\}

Wen P, Lin Z. Efficacy and safety of transcatheter arterial chemoembolization combined with cryoablation in the treatment of unresectable large hepatocellular carcinoma [经 导管动脉化疗栓塞术联合冷冻消融治疗不可切除性大肝癌 效果与安全性分析]. Zhong Guo Zong He Lin Chuang [Clinical Medicine of China] 2018;34(4):339-43.

\section{Wu 2011b \{published data only\}}

Wu L, Li Z. The combination of cryoablation with transcatheter arterial chemoembolisation for unresectable liver cancer [氩氦 刀冷冻与TACE协同治疗无手术指证肝癌的临床分析] . Zhong Wai Jian Kang Wen Zhai [World Health Digest] 2011;8(40):128-9.

\section{Wu 2017b \{published data only\}}

Wu X, Cai B, Wang D. Observation on curative effect of TACE combined with cool-tip microwave ablation in treatment of primary liver cancer [TACE联合冷循环微波消融治疗原发性肝 癌的疗效观察]. Zhong Guo Yi Yao Ke Xue [China Medicine and Pharmacy] 2017;7(9):214-6.

\section{Wu 2020 \{published data only\}}

Wu J, Dong G, Liu T. Microwave ablation plus TACE for treating primary liver cancer [冷循环微波消融联合TACE术治疗原发性 肝癌的临床研究] . Chinese Hepatology 2020;25(10):1058-61.

\section{Xie 2017 \{published data only\}}

Xie $\mathrm{H}$, Zhong W. Effect of TACE combined with HIFU on elderly patients with primary liver cancer and its effect on immune function [TACE联合HIFU治疗老年原发性肝癌疗效 及对患者免疫功能的影响]. He Bei Yi Xue [Hebei Medicine] 2017;23(11):1761-4.

\section{Xiong 2013 \{published data only\}}

Xiong J, Fan G, Chen L. Therapeutic effect of transarterial chemo-embolization combined with radio frequency ablation for treatment of middle or advanced stage hepatocellular carcinoma in elderly [肝动脉化疗栓塞联合经皮射频治疗中 晚期老年肝癌的临床观察. ]. Zhong Guo Xian Dai Pu Tong Wai Ke Jin Zhan [Chinese Journal of Current Advances in General Surgery] 2013;16(5):355-8.

\section{Xiong 2017 \{published data only\}}

Xiong L, Zhang L, Ma J, Li J. Efficacy of radiofrequency ablation plus hepatic arterial chemoembolization in primary hepatic carcinoma and its effect on serum markers. International Journal Of Clinical And Experimental Medicine 2017;10(9):14076-82.

\section{Xu 2016 \{published data only\}}

Xu L, Li C, Zhang B. The combination of transcatheter arterial chemoembolisation with radiofrequency ablation for progressive liver cancer [超声引导下射频消融联合TACE治 疗进展期原发性肝癌疗效及并发症分析].Gui Zhou Yi Yao [Guizhou Medical Journal] 2016;40(3):265-7.

\section{Xue 2019 \{published data only\}}

Xue J, Chen L, Liao L. The observation on the efficacy of the combination of TACE with MWA [肝动脉栓塞化疗联合冷循 环微波消融治疗肝癌的临床疗效观察]. Chinese Journal of Physical Medicine and Rehabilitation 2019;41(6):458-60.

\section{Yao 2018 \{published data only\}}

Yao Y. The efficacy of transcatheter arterial chemoembolisation plus radiofrequency ablation for liver cancer [肝动脉化疗栓 塞术联合CT引导下射频消融术对原发性肝癌患者治疗效 果]. Man Xing Bing Xue Za Zhi [Chronic Pathematology Journal] 2018;19(4):503-5.

\section{Yi 2015 \{published data only\}}

Yi Y, Lv J, Wang B. The short and long term clinical effect of TACE combined with RFA for patients with primary liver cancer [TACE 与RFA联合治疗原发性肝癌患者近远期疗效观察]. Zhong Guo Xian Dai Yi Sheng [China Modern Doctor] 2015;53(24):76-9.

\section{Yu 2019 \{published data only\}}

$\mathrm{Yu} \mathrm{H}$. Clinical effect of trans-catheter arterial chemoembolization combined With ultrasound-guided radiofrequency ablation in the treatment of large hepatocellular carcinoma with lack of blood supply [肝动脉化疗栓塞联合超 声引导下射频消融治疗乏血供大肝癌的临床效果]. Zhong Guo Dang Dai Yi Yao [China Modern Medicine] 2019;26(5):92-4.

\section{Yuan 2015 \{published data only\}}

Yuan X. The combination or microwave ablation with transcatheter arterial chemoembolisation for hepatocellular carcinoma [微波消融联合血管介入治疗原发性肝癌临床研 究]. Zhong Guo Yi Xue Gong Cheng [China Medical Engineering] 2015;23(12):63.

\section{Zhang 2013 \{published data only\}}

Zhang SJ, Ma YL. TACE combined with percutaneous microwave ablation in treatment of large primary hepatocellular carcinoma [经导管动脉化疗栓塞术联合经皮微波消融治疗大肝癌]. Zhong Guo Jie Ru Ying Xiang Yu Zhi Liao Xue [Chinese Journal of Interventional Imaging and Therapy] 2013;10(7):397-400.

\section{Zhang 2014 \{published data only\}}

Zhang S. Clinical effect of primary liver cancer treatment by transcatheter arterial chemoembolization combined radio frequency ablation [肝动脉栓塞化疗联合射频消融治疗原发 性肝癌的临床观察]. Zhong Guo Zhong Liu Lin Chuang Yu Jian Kang [Chinese Journal of Clinical Oncology and Rehabilitation] 2014;21(5):576-8.

\section{Zhang 2016 \{published data only\}}

Zhang Z. The combination of cryoablation with transcatheter arterial chemoembolisation for unresectable liver cancer [肝 动脉化疗栓塞联合氩氦刀冷冻消融治疗对不能手术的中晚 期肝癌疗效的临床分析]. Zhong Guo Xian Dai Yao Wu Fan Ying [Chinese Journal of Modern Drug Application] 2016;10(10):41-2.

Zhang 2017a \{published data only\}

Zhang H, Ma X, Fu Q, Cao C, Cao L. The efficacy and safety of the combination of microwave ablation with transcatheter arterial chemoembolisation for middle and advanced hepatocellular carcinoma [经肝动脉化疗栓塞联合经皮微波消融序贯治疗中 晚期肝癌的疗效及预后分析] . Gan Zang [Chinese Hepatology] 2017;22(5):431-4.

\section{Zhang 2017b \{published data only\}}

Zhang W, Chen G, Sun M, An Y, Wang Y, Shang Q. Clinical efficacy of TACE and radiofrequency ablation in treatment of patients

The combination of transcatheter arterial chemoembolisation (TACE) and thermal ablation versus TACE alone for hepatocellular 
with primary liver cancer [经导管肝动脉化疗栓塞联合射频 消融治疗原发性肝癌患者临床疗效评价]. Shi Yong Gan Zang Bing Za Zhi [Journal of Practical Hepatology] 2017;20(4):472-6.

Zhang 2017c \{published data only\}

Zhang Y. Observation of the efficacy of the combination of microwave ablation and transcatheter arterial chemoembolisation for liver cancer [肝动脉化疗栓塞联合微波 消融治疗肝癌的临床疗效探讨]. Xin Li Yi Sheng [Psychological Doctor] 2017;23(19):191-2.

\section{Zhang 2018a \{published data only\}}

Zhang $\mathrm{H}$, Zheng W, Ren N. Observation and nursing of effect of hepatic arterial chemoembolization combined with radiofrequency ablation in treatment of large primary hepatic carcinoma [肝动脉化疗栓塞联合射频消融术治疗原发性大 肝癌的效果观察与护理]. Hu Li Shi Jian Yu Yan Jiu [Nursing Practice and Research] 2017;14(16):81-3.

\section{Zhang 2018b \{published data only\}}

Zhang J. The efficacy and safety of the combination of the transcatheter arterial chemoembolisation with radiofrequency ablation for liver cancer [肝动脉化疗栓塞联合射频消融治疗原 发性肝癌的疗效及安全性评价]. Lin Chuang Yi Yao Dian Zi Wen Xian Za Zhi [Journal of Clinical Medical Literature] 2018;5(3):54-5.

\section{Zhang 2018c \{published data only\}}

Zhang Q, Zhang Z, Zhang W, Du X. Effect of radiofrequency ablation combined with transcatheter arterial chemoembolization on primary hepatocellular carcinoma and serum cytokines [射频消融联合肝动脉化疗栓塞对原发性肝 癌的疗效及对细胞因子的影响]. Shan Xi Yi Yao Za Zhi [Shanxi Medical Journal] 2018;47(11):1244-7.

\section{Zhang 2018d \{published data only\}}

Zhang J, Gao Z, Qian Y, Zhang M, Tan G, Liu Z. Ultrasoundguided microwave ablation plus transcatheter arterial chemoembolisation for primary liver cancer [超声引导下微 波消融联合TACE治疗进展期原发性肝癌的疗效分析]. Zhong Guo Yi Yao Zhi Nan [Guide of China Medicine] 2018;16(4):119-20.

\section{Zhang 2019 \{published data only\}}

Zhang $\mathrm{G}$. The transcatheter arterial chemoembolisation plus radiofrequent ablation for hepatocellular carcinoma [肝动] 脉化疗栓塞术联合射频消融术治疗原发性肝癌].Zhong Guo Lao Nian Xue Za Zhi [Chinese Journal of Gerontology] 2019;39(8):1855-7.

\section{Zhang 2020 \{published data only\}}

Zhang F, Zhou $\mathrm{H}$. The efficacy of the combination of TACE with MWA for primary liver cancer [肝动脉化疗栓塞联合微波消 融治疗原发性肝癌的临床效果]. Henan Medical Research 2020;29(19):3524-5.

\section{Zhao 2014b \{published data only\}}

Zhao Z, Wang R, Zhao F, Li J, Guo S. The transcatheter arterial chemoembolisation plus radiofrequency ablation for 40 patients with hepatocellular carcinoma [肝动脉栓塞联合射频 消融治疗肝癌40例疗效评价]. Shan Xi Yi Xue Za Zhi [Shaanxi Medical Journal] 2015;4:587-8.
Zhao 2015a \{published data only\}

Zhao H, Cui H. The efficacy of the combination of TACE with RFA for primary liver cancer [ 原发性肝癌 TACE与 RFA 联合治疗临 床效果评价] . Da Jia Jian Kang [For All Health] 2015;24:119.

Zhao 2016 \{published data only\}

Zhao Y, Jia B. Clinical application of hepatic arterial chemoembolization combined with CT guided radiofrequency ablation in the treatment of primary hepatic carcinoma [肝动 脉栓塞化疗联合CT引导射频消融治疗原发性肝癌的临床应 用]. Yi Xue Ying Xiang Xue Za Zhi [Journal of Medical Imaging] 2016;26(2):364-7.

Zhao 2018 \{published data only\}

Zhao X. The efficacy of the combination of transcatheter arterial chemoembolisation with microwave ablation for large primary liver cancer [肝动脉化疗栓塞术联合微波消融治疗原发性 大肝癌的临床疗效探究]. Te Bie Jian Kang [Special Health] 2018;19:64

Zhao 2020 \{published data only\}

Zhao C, Ji L. The effect of the combination of TACE and microwave ablation on the level of AFP and tumour progression [微波消融联合经肝动脉化疗栓塞术治疗肝癌的效果及对血 清AFP水平的影响]. Journal of Medical Theory and Practice 2020;33(9):1454-5

\section{Zheng 2015 \{published data only\}}

Zheng Z. The transcatheter arterial chemoembolisation plus cryoablation for middle and advanced liver cancer [肝动脉 化疗栓塞联合氩氦刀冷冻消融治疗中晚期肝癌患者的疗效 观察] . Xian Dai Zhen Duan Yu Zhi Liao [Modern Diagnosis and Treatment] 2015;20:4728-9.

\section{Zhu 2013b \{published data only\}}

Zhu L. The transcatheter arterial chemoembolisation plus microwave ablation for 36 patients with hepatocellular carcinoma [肝动脉栓塞化疗联合微波消融治疗中晚期肝癌 36 例] . Lin Chuang Yi Xue [Clinical Medicine] 2013;33(8):50-1.

\section{Zhu 2015 \{published data only\}}

Zhu H, Chen P. Therapeutic effect of transcatheter arterial chemoembolization combined with radiofrequency ablation for primary liver cancer [经肝动脉化疗栓塞术联合射频消融对原 发性肝癌的治疗效果]. Zhong Guo Ji Xu Yi Xue Jiao Yu [China Continuing Medical Education] 2015;7(33):124-6.

\section{Zhuang 2016 \{published data only\}}

Zhuang W, Huang C, Ji Z, Lin S, Huang Y, Tang Y, et al. Analysis of therapeutic effectiveness of argon-helium cryoablation combined with transcatheter arterial chemoembolization for the treatment of advanced hepatocellular carcinoma [TACE 联 合氩氦刀冷冻消融治疗中晚期肝癌的疗效分析].Yi Xue Ying Xiang Za Zhi [Journal of Medical Imaging] 2016;26(12):2247-50.

\section{References to ongoing studies}

ChicTR-IOR-16007915 \{unpublished data only\}

ChiCTR-IOR-16007915. Transarterial chemoembolization (TACE) with or without sequential cryoablation in hepatocellular 
carcinoma of BCLC B: a multicentral randomized controlled trial [Transarterial chemoembolization (TACE) with or without sequential cryoablation in hepatocellular carcinoma of BCLC B: a multicentral randomized controlled trial]. chictr.org.cn/ showproj.aspx?proj=13377 (first received 13 February 2016).

\section{ChicTR-IOR-17013743 \{unpublished data only\}}

ChiCTR-IOR-17013743. Treatment of BCLC medium-term hepatocellular carcinoma $(\mathrm{HCC})$ of randomized controlled study of conventional TACE sequential microwave ablation (MWA) and conventional TACE alone [Treatment of BCLC medium-term hepatocellular carcinoma (HCC) of randomized controlled study of conventional TACE sequential microwave ablation (MWA) and conventional TACE alone]. chictr.org.cn/showproj.aspx? proj=23656 (first received 6 December 2017).

\section{NCT02301091 \{unpublished data only\}}

NCT02301091. Combine TACE and RFA versus TACE alone for HCC with PVTT (CORTT) [Combine transcatheter arterial embolization and radiofrequency ablation versus transcatheter arterial embolization alone for hepatocellular carcinoma with portal vein tumor thrombus]. clinicaltrials.gov/ct2/show/ NCT02301091 (first received 25 November 2014).

\section{NCT02435953 \{unpublished data only\}}

NCT02435953. TACE + RFA versus TACE alone for intermediate-stage hepatocellular carcinoma [Transarterial chemoembolization plus radiofrequency ablation versus transarterial chemoembolization alone for intermediatestage hepatocellular carcinoma]. clinicaltrials.gov/ct2/show/ NCT02435953 (first received 6 May 2015).

\section{NCT02646137 \{unpublished data only\}}

NCT02646137. Single session combined locoregional therapies for hepatocellular carcinoma [Comparison of single session transarterial chemoembolization combined with microwave ablation or radiofrequency ablation in treatment of hepatocellular carcinoma: a randomized controlled study]. clinicaltrials.gov/ct2/show/NCT02646137 (first received 5 January 2016)

\section{Additional references}

\section{Abdel-Rahman 2013}

Abdel-Rahman O, Elsayed ZA. Combination trans arterial chemoembolization (TACE) plus sorafenib for the management of unresectable hepatocellular carcinoma: a systematic review of the literature. Digestive Diseases and Sciences 2013;58(12):3389-96. [PMID: 24046163]

\section{Ahmed 2011}

Ahmed M, Brace CL, Lee FT Jr, Goldberg SN. Principles of and advances in percutaneous ablation. Radiology 2011;258(2):351-69. [PMID: 21273519]

\section{Atkins 2004}

Atkins D, Best D, Briss PA, Eccles M, Falck-Ytter Y, Flottorp S, et al, GRADE Working Group. Grading quality of evidence and strength of recommendations. BMJ (Clinical Research Ed.) 2004;328(7454):1490.

\section{Awad 2009}

Awad T, Thorlund K, Gluud C. Cryotherapy for hepatocellular carcinoma. Cochrane Database of Systematic Reviews 2009, Issue 4. Art. No: CD007611. [DOI: 10.1002/14651858.CD007611.pub2] [PMID: 19821432]

\section{Azuma 2016}

Azuma S, Asahina Y, Nishimura-Sakurai Y, Kakinuma S, Kaneko S, Nagata $\mathrm{H}$, et al. Efficacy of additional radiofrequency ablation after transcatheter arterial chemoembolization for intermediate hepatocellular carcinoma. Hepatology Research 2016;46(4):312-9. [PMID: 26224167]

\section{Brace 2007}

Brace CL, Laeseke PF, Sampson LA, Frey TM, Van der Weide DW, Lee FT Jr. Microwave ablation with a single small-gauge triaxial antenna: in vivo porcine liver model. Radiology 2007;242(2):435-40. [PMID: 17255414]

\section{Bruix 2011}

Bruix J, Sherman M, American Association for the study of liver diseases. Management of hepatocellular carcinoma: an update. Hepatology (Baltimore, Md.) 2011;53(3):1020-2.

\section{Cao 2014}

Cao X. Meta-analysis on radiofrequency ablation in combination with transarterial chemoembolization for the treatment of hepatocellular carcinoma. Journal of Huazhong University of Science and Technology 2014;35(4):692-700.

\section{Castellini 2018}

Castellini G, Bruschettini M, Gianola S, Gluud C, Moja L. Assessing imprecision in Cochrane systematic reviews: a comparison of GRADE and Trial Sequential Analysis. Systematic Reviews 2018;7(110):1-10.

\section{Chacko 2016}

Chacko S, Samanta S. Hepatocellular carcinoma: a lifethreatening disease. Biomedicine \& Pharmacotherapy 2016;84:1679-88. [PMID: 27823920]

\section{Chan 2013}

Chan A-W, Tetzlaff JM, Altman DG, Laupacis A, Gøtzsche PC, Krleža-Jerić K, et al. SPIRIT 2013 statement: defining standard protocol items for clinical trials. Annals of Internal Medicine 2013;158:200-7.

\section{Corwin 2001}

Corwin TS, Lindberg G, Traxer O, Gettman MT, Smith TG, Pearle MS, et al. Laparoscopic radiofrequency thermal ablation of renal tissue with and without hilar occlusion. Journal of Urology 2001;166(1):281-4. [PMID: 11435886]

\section{Deeks 2019}

Deeks JJ, Higgins JP, Altman DG (editors). Chapter 10: Analysing data and undertaking meta-analyses. In: Higgins JPT, Thomas J, Chandler J, Cumpston M, Li T, Page MJ, Welch VA (editors). Cochrane Handbook for Systematic Reviews of Interventions version 6.0 (updated July 2019). Cochrane, 2019. Available from www.training.cochrane.org/handbook. 


\section{EASL-EORTC 2012}

European Association For The Study Of The Liver, European Organisation For Research And Treatment Of Cancer. EASL-EORTC clinical practice guidelines: management of hepatocellular carcinoma. Journal of Hepatology 2012;56(4):908-43. [PMID: 22424438]

\section{El-Serag 2012}

El-Serag HB. Epidemiology of viral hepatitis and hepatocellular carcinoma. Gastroenterology 2012;142(6):1264-73.e1. [PMID: 22537432]

\section{Fan 2009}

Fan W, Li J, Li H, Wang Y, Tan G, Chen Z, et al. Interventional treameant for unresectable hepatocellular carcinoma: a systematic review and meta-analysis. Contemporary Medicine 2009;15(35):677-80.

\section{Fan 2011}

Fan W, Li J, Yang J, Wang Y, Xiang X, Li H. Interventional treatment for unresectable hepatocellular carcinoma: a systematic review and meta-analysis. Chinese Archives of General Surgery (electronic version) 2011;5(1):62-7.

\section{Forner 2018}

Forner A, Reig M, Bruix J. Hepatocellular carcinoma. Lancet (London, England) 2018;391(10127):1301-14. [PMID: 29307467]

\section{Gartlehner 2019}

Gartlehner G, Nussbaumer-Streit B, Wagner G, Patel S, SwinsonEvans T, Dobrescu A, et al. Increased risks for random errors are common in outcomes graded as high certainty of evidence. Journal of Clinical Epidemiology 2019;106:50-9. [DOI: 10.1016/ j.jclinepi.2018.10.009]

\section{Goldberg 2003}

Goldberg SN, Charboneau JW, Dodd GD 3rd, Dupuy DE, Gervais DA, Gillams AR, et al. Image-guided tumor ablation: proposal for standardization of terms and reporting criteria. Radiology 2003;228(2):335-45. [PMID: 12893895]

\section{GRADEpro GDT [Computer program]}

McMaster University (developed by Evidence Prime) GRADEpro GDT. Version accessed 13 May 2020. Hamilton (ON): McMaster University (developed by Evidence Prime), 2015. Available at gradepro.org.

\section{Granito 2017}

Granito A, Bolondi L. Non-transplant therapies for patients with hepatocellular carcinoma and Child-Pugh-Turcotte class B cirrhosis. Lancet Oncology 2017;18:e101-e112. [DOI: 10.1016/ S1470-2045(16)30569-1]

\section{Gu 2014}

Gu L, Liu H, Fan L, Lv Y, Cui Z, Luo Y, et al. Treatment outcomes of transcatheter arterial chemoembolization combined with local ablative therapy versus monotherapy in hepatocellular carcinoma: a meta-analysis. Journal of Cancer Research and Clinical Oncology 2014;140(2):199-210.

\section{Heimbach 2018}

Heimbach JK, Kulik LM, Finn RS, Sirlin CB, Abecassis MM, Roberts LR, et al. AASLD guidelines for the treatment of hepatocellular carcinoma. Hepatology 2018;67(1):358-80.

\section{Higgins 2019a}

Higgins JP, Savović J, Page MJ, Elbers RG, Sterne JA. Chapter 8: Assessing risk of bias in a randomized trial. In: Higgins JPT, Thomas J, Chandler J, Cumpston M, Li T, Page MJ, Welch VA (editors). Cochrane Handbook for Systematic Reviews of Interventions version 6.0 (updated July 2019). Cochrane, 2019. Available from www.training.cochrane.org/handbook.

\section{Higgins 2019b}

Higgins JP, Li T, Deeks JJ (editors). Chapter 6: Choosing effect measures and computing estimates of effect. In: Higgins JPT, Thomas J, Chandler J, Cumpston M, Li T, Page MJ, Welch VA (editors). Cochrane Handbook for Systematic Reviews of Interventions version 6.0 (updated July 2019). Cochrane, 2019. Available from www.training.cochrane.org/handbook.

\section{Higgins 2019c}

Higgins JP, Eldridge S, Li T (editors). Chapter 23: Including variants on randomized trials. In: Higgins JPT, Thomas J, Chandler J, Cumpston M, Li T, Page MJ, Welch VA (editors). Cochrane Handbook for Systematic Reviews of Interventions version 6.0 (updated July 2019). Cochrane, 2019. Available from www.training.cochrane.org/handbook.

\section{Higgins 2021}

Higgins JP, Thomas J, Chandler J, Cumpston M, Li T, Page MJ, Welch VA, editor(s). Cochrane Handbook for Systematic Reviews of Interventions Version 6.2 (updated February 2021). Cochrane, 2021. Available from www.training.cochrane.org/handbook.

\section{Hu 2015}

$\mathrm{Hu}$ Yi, Xu Mingxi. A meta-analysis of the combination of transarterial chemoembolization and percutaneous radiofrequency ablation for treatment of primary liver cancer. Clinical Misdiagnosis \& Mistherapy 2015;1:101-5.

\section{Hyun 2016}

Hyun D, Cho SK, Shin SW, Park KB, Park HS, Choo SW, et al. Early stage hepatocellular carcinomas not feasible for ultrasoundguided radiofrequency ablation: comparison of transarterial chemoembolization alone and combined therapy with transarterial chemoembolization and radiofrequency ablation. Cardiovascular and Interventional Radiology 2016;39(3):417-25. [PMID: 26246215]

\section{ICH-GCP 1997}

International Conference on Harmonisation Expert Working Group. ICH Harmonised Tripartite Guideline: Guideline for Good Clinical Practice. Vol. 1. Philadelphia (PA): Barnett International/ PAREXEL, 1997.

\section{Imai 2014}

Imai N, Ishigami M, Ishizu Y, Kuzuya T, Honda T, Hayashi K, et al. Transarterial chemoembolization for hepatocellular carcinoma: a review of techniques. World Journal of Hepatology 2014;6(12):844-50. [PMID: 25544871] 


\section{Jaeger 1996}

Jaeger HJ, Mehring UM, Castaneda F, Hasse F, Blumhardt G, Loehlein $D$, et al. Sequential transarterial chemoembolization for unresectable advanced hepatocellular carcinoma. Cardiovascular and Interventional Radiology 1996;19(6):388-96. [PMID: 8994703]

\section{Jakobsen 2014}

Jakobsen JC, Wetterslev J, Winkel P, Lange T, Gluud C. Thresholds for statistical and clinical significance in systematic reviews with meta-analytic methods. BMC Medical Research Methodology 2014;14:120. [PMID: 25416419]

\section{Katsanos 2017}

Katsanos K, Kitrou P, Spiliopoulos S, Maroulis I, Petsas T, Karnabatidis D. Comparative effectiveness of different transarterial embolization therapies alone or in combination with local ablative or adjuvant systemic treatments for unresectable hepatocellular carcinoma: a network meta-analysis of randomized controlled trials. PLOS One 2017;12(9):e0184597.

\section{Kew 2014}

Kew MC. Hepatocellular carcinoma: epidemiology and risk factors. Journal of Hepatocellular Carcinoma 2014;1:115-25. [PMID: 27508181]

\section{Kim 2015}

Kim MN, Kim BK, Han KH, Kim SU. Evolution from WHO to EASL and $\mathrm{mRECIST}$ for hepatocellular carcinoma: considerations for tumor response assessment. Expert Review of Gastroenterology \& Hepatology 2015;9(3):335-48. [PMID: 25370168]

\section{Laursen 2014}

Laursen L. A preventable cancer. Nature 2014;516(7529):S2-3. [PMID: 25470197]

\section{Lei 2013}

Lei Y, Guo X, Wang L, Wang Y, Zhu L, Liu L. A system evaluation of radiofrequency ablation plus transcatheter hepatic arterial chemoembolization for primary hepatocellular carcinoma. Journal of Modern Oncology 2013;21(6):1285-8.

\section{Lencioni 2010}

Lencioni R, Llovet JM. Modified RECIST (mRECIST) assessment for hepatocellular carcinoma. Seminars in Liver Disease 2010;30(1):52-60. [PMID: 20175033]

\section{Li 2010}

Li C, Zhang W, Zhang R, Zhang L, Wu P, Zhang F. Therapeutic effects and prognostic factors in high-intensity focused ultrasound combined with chemoembolisation for larger hepatocellular carcinoma. European Journal of Cancer 2010;46(13):2513-21. [PMID: 20663659]

\section{Li 2016}

Li W, Man W, Guo H, Yang P. Clinical study of transcatheter arterial chemoembolization combined with microwave ablation in the treatment of advanced hepatocellular carcinoma. Journal of Cancer Research and Therapeutics 2016;12(Suppl):C217-20. [PMID: 28230020]

\section{Liu 2018a}

Liu Y, Zhuo L, Zhu P, He M, Xu Y, Wang T, et al. Transcatheter arterial chemoembolization combination therapy vs transcatheter arterial chemoembolization for the treatment of unresectable hepatocellular carcinoma:a meta-analysis of survival rate. Journal of Clinical Radiology 2018;37(2):314-8.

\section{Livraghi 2000}

Livraghi T, Goldberg SN, Lazzaroni S, Meloni F, lerace T, Solbiati L, et al. Hepatocellular carcinoma: radiofrequency ablation of medium and large lesions. Radiology 2000;214(3):761-8. [PMID: 10715043]

\section{Llovet 2016}

Llovet JM, Zucman-Rossi J, Pikarsky E, Sangro B, Schwartz M, Sherman M, et al. Hepatocellular carcinoma. Nature Reviews. Disease Primers 2016;2:16018. [PMID: 27158749]

\section{Lubner 2013}

Lubner MG, Brace CL, Ziemlewicz TJ, Hinshaw JL, Lee FT Jr. Microwave ablation of hepatic malignancy. Seminars in Interventional Radiology 2013;30(1):56-66. [PMID: 24436518]

\section{Martin 2015}

Martin RC 2nd, Scoggins CR, Schreeder M, Rilling WS, Laing CJ, Tatum CM, et al. Randomized controlled trial of irinotecan drugeluting beads with simultaneous FOLFOX and bevacizumab for patients with unresectable colorectal liver-limited metastasis. Cancer 2015;121(20):3649-58. [PMID: 26149602]

\section{Mittal 2013}

Mittal S, El-Serag HB. Epidemiology of hepatocellular carcinoma: consider the population. Journal of Clinical Gastroenterology 2013;47(Suppl):S2-6. [PMID: 23632345]

\section{Mohd 2013}

Mohd Hanafiah K, Groeger J, Flaxman AD, Wiersma ST. Global epidemiology of hepatitis $C$ virus infection: new estimates of age-specific antibody to HCV seroprevalence. Hepatology 2013;57(4):1333-42. [PMID: 23172780]

\section{Morimoto 2010}

Morimoto M, Numata K, Kondou M, Nozaki A, Morita S, Tanaka K. Midterm outcomes in patients with intermediatesized hepatocellular carcinoma: a randomized controlled trial for determining the efficacy of radiofrequency ablation combined with transcatheter arterial chemoembolization. Cancer 2010;116(23):5452-60. [PMID: 20672352]

\section{National Center for Health Statistics (US) 2015}

National Center for Health Statistics (US). Health, United States, 2014: With Special Feature on Adults Aged 55-64. Hyattsville (MD): National Center for Health Statistics (US); 2015 May. Available from: https://www.ncbi.nlm.nih.gov/books/ NBK299348/. [PMID: 26086064]

\section{Oliveri 2011}

Oliveri RS, Wetterslev J, Gluud C. Transarterial (chemo)embolisation for unresectable hepatocellular carcinoma. Cochrane Database of Systematic

The combination of transcatheter arterial chemoembolisation (TACE) and thermal ablation versus TACE alone for hepatocellular carcinoma (Review)

Copyright (c) 2021 The Cochrane Collaboration. Published by John Wiley \& Sons, Ltd. 
Reviews 2011, Issue 3. Art. No: CD004787. [DOI:

10.1002/14651858.CD004787.pub2]

\section{Omata 2010}

Omata M, Lesmana LA, Tateishi R, Chen PJ, Lin SM, Yoshida H, et al. Asian Pacific Association for the Study of the Liver consensus recommendations on hepatocellular carcinoma. Hepatology International 2010;4(2):439-74.

\section{Peng 2013}

Peng ZW, Zhang YJ, Chen MS, Xu L, Liang HH, Lin XJ, et al. Radiofrequency ablation with or without transcatheter arterial chemoembolization in the treatment of hepatocellular carcinoma: a prospective randomized trial. Journal of Clinical Oncology 2013;31(4):426-32. [PMID: 23269991]

\section{Poggi 2015}

Poggi G, Tosoratti N, Montagna B, Picchi C. Microwave ablation of hepatocellular carcinoma. World Journal of Hepatology 2015;7(25):2578-89. [PMID: 26557950]

\section{Review Manager 2014 [Computer program]}

Nordic Cochrane Centre, The Cochrane Collaboration Review Manager 5 (RevMan 5). Version 5.3. Copenhagen: Nordic Cochrane Centre, The Cochrane Collaboration, 2014.

\section{RevMan Web 2019 [Computer program]}

The Cochrane Collaboration Review Manager Web (RevMan Web). The Cochrane Collaboration, 2019. Available at revman.cochrane.org.

\section{Rubinsky 1990}

Rubinsky B, Lee CY, Bastacky J, Onik G. The process of freezing and the mechanism of damage during hepatic cryosurgery. Cryobiology 1990;27(1):85-97. [PMID: 2311412]

\section{Satake 2008}

Satake M, Uchida H, Arai Y, Anai H, Sakaguchi H, Nagata T, et al. Transcatheter arterial chemoembolization (TACE) with lipiodol to treat hepatocellular carcinoma: survey results from the TACE study group of Japan. Cardiovascular and Interventional Radiology 2008;31(4):756-61. [PMID: 18389187]

\section{Schulz 2010}

Schulz KF, Altman DG, Moher D. CONSORT 2010 Statement: updated guidelines for reporting parallel group randomised trials. BMJ 2010;340:c332.

\section{Schulze 2016}

Schulze K, Nault JC, Villanueva A. Genetic profiling of hepatocellular carcinoma using next-generation sequencing. Journal of Hepatology 2016;65(5):1031-42. [PMID: 27262756]

\section{Sirivatanauksorn 2011}

Sirivatanauksorn Y, Tovikkai C. Comparison of staging systems of hepatocellular carcinoma. A World Journal of Hepatic, Pancreatic \& Biliary Surgery 2011;2011:818217. [DOI: $10.1155 / 2011 / 818217]$

\section{Song 2016a}

Song KD. Percutaneous cryoablation for hepatocellular carcinoma. Clinical and Molecular Hepatology 2016;22(4):509-15. [PMID: 28081593]

\section{Sterne 2019}

Sterne JA, Savović J, Page MJ, Elbers RG, Blencowe NS, Boutron I, et al. RoB 2: a revised tool for assessing risk of bias in randomised trials. BMJ (Clinical Research Ed.) 2019;366:14898.

\section{Storebø 2018}

Storebø OJ, Pedersen N, Ramstad E, Kielsholm ML, Nielsen SS, Krogh HB, et al. Methylphenidate for attention deficit hyperactivity disorder (ADHD) in children and adolescents - assessment of adverse events in non-randomised studies. Cochrane Database of Systematic Reviews 2018, Issue 5. Art. No: CD012069. [DOI: 10.1002/14651858.CD012069.pub2]

\section{Sun 2011}

Sun J, He S, Shen J, Chen H, Chen Y, Jiang T. Transarterial chemoembolization in combination with radiofrequency thermal ablation in hepatocellular carcinoma: a systematic review and meta-analysis. Chinese Journal of Clinical Medicine 2011;18(6):803-8.

\section{Therasse 2000}

Therasse P, Arbuck SG, Eisenhauer EA, Wanders J, Kaplan RS, Rubinstein L, et al, European Organization for Research and Treatment of Cancer, National Cancer Institute of the United States, National Cancer Institute of Canada. New guidelines to evaluate the response to treatment in solid tumors. Journal of the National Cancer Institute 2000;92(3):205-16. [PMID: 10655437]

\section{Thorlund 2011}

Thorlund K, Engstrøm J, Wetterslev J, Brok J, Imberger G, Gluud C. User manual for Trial Sequential Analysis (TSA). ctu.dk/ wp-content/uploads/2020/12/tsa_manual_ENG.pdf 2011 (accessed 13 May 2020).

\section{Tierney 2007}

Tierney JF, Stewart LA, Ghersi D, Burdett S, Sydes MR. Practical methods for incorporating summary time-to-event data into meta-analysis. Trials 2007;8:16. [PMID: 17555582]

\section{Torre 2015}

Torre LA, Bray F, Siegel RL, Ferlay J, Lortet-Tieulent J, Jemal A. Global cancer statistics, 2012. CA: a Cancer Journal for Clinicians 2015;65(2):87-108. [PMID: 25651787]

\section{Trad 2017}

Trad D, Bibani N, Sabbah M, Elloumi H, Gargouri D, Ouakaa A, et al. Known, new and emerging risk factors of hepatocellular carcinoma (review). Presse Medicale 2017;46(11):1000-7. [PMID: 29089219]

\section{TSA 2011 [Computer program]}

Copenhagen Trial Unit TSA - Trial Sequential Analysis. Version 0.9.5.10 Beta. Copenhagen: Copenhagen Trial Unit, 2011. www.ctu.dk/tsa/downloads.aspx. 


\section{Vogl 2003}

Vogl TJ, Mack MG, Balzer JO, Engelmann K, Straub R, Eichler K, et al. Liver metastases: neoadjuvant downsizing with transarterial chemoembolization before laser-induced thermotherapy. Radiology 2003;229(2):457-64. [PMID: 14500854]

\section{Wang 2016b}

Wang Y, Deng T, Zeng L, Chen W. Efficacy and safety of radiofrequency ablation and transcatheter arterial chemoembolization for treatment of hepatocellular carcinoma: a meta-analysis. Hepatology Research 2016;46(1):58-71.

\section{Wetterslev 2008}

Wetterslev J, Thorlund K, Brok J, Gluud C. Trial sequential analysis may establish when firm evidence is reached in cumulative meta-analysis. Journal of Clinical Epidemiology 2008;61(1):64-75. [PMID: 18083463]

\section{Wetterslev 2009}

Wetterslev J, Thorlund K, Brok J, Gluud C. Estimating required information size by quantifying diversity in random-effects model meta-analyses. BMC Medical Research Methodology 2009;9:86. [PMID: 20042080]

\section{Wetterslev 2017}

Wetterslev J, Jakobsen JC, Gluud C. Trial Sequential Analysis in systematic reviews with meta-analysis. BMC Medical Research Methodology 2017;17(1):39.

\section{Wijlemans 2012}

Wijlemans JW, Bartels LW, Deckers R, Ries M, Mali WP, Moonen CT, et al. Magnetic resonance-guided high-intensity focused ultrasound (MR-HIFU) ablation of liver tumours. Cancer Imaging 2012;12(2):387-94. [PMID: 23022541]

\section{Wu 2005}

Wu F, Wang ZB, Chen WZ, Zou JZ, Bai J, Zhu H, et al. Advanced hepatocellular carcinoma: treatment with high-intensity focused ultrasound ablation combined with transcatheter arterial embolization. Radiology 2005;235(2):659-67. [PMID: 15858105]

\section{Wu 2015}

Wu S, Hou J, Ding Y, Wu F, Hu Y, Jiang Q, et al. Cryoablation versus radiofrequency ablation for hepatic malignancies: a systematic review and literature-based analysis. Medicine 2015;94(49):e2252. [PMID: 26656371]

\section{Xiong 2018a}

Xiong K, Bai F, Chen D, Wei X, Xue D. Comparison of the efficacy and safety of the combined treatment of transcatheter arterial chemoembolization and radiofrequency ablation with transcatheter arterial chemoembolization or radiofrequency ablation treatment alone in patients with primary hepatic carcinoma in China. Chinese Health Resources 2018;21(3):271-4, 279 .

\section{Xiong 2018b}

Xiong K, Chen D, Bai F, Wei X, Xue D. Efficacy and safety of seven non-surgical therapies for primary hepatic carcinoma: a network meta-analysis. Chinese Health Resources 2018;21(4):307-11, 322.

\section{Yang 2007}

Yang D, Converse MC, Mahvi DM, Webster JG. Measurement and analysis of tissue temperature during microwave liver ablation. IEEE Transactions on Bio-Medical Engineering 2007;54(1):150-5. [PMID: 17260866]

\section{Yang 2009}

Yang W, Chen MH, Wang MQ, Cui M, Gao W, Wu W, et al. Combination therapy of radiofrequency ablation and transarterial chemoembolization in recurrent hepatocellular carcinoma after hepatectomy compared with single treatment. Hepatology Research 2009;39(3):231-40. [PMID: 19054154]

\section{Yang 2014}

Yang D, Hanna DL, Usher J, LoCoco J, Chaudhari P, Lenz HJ, et al. Impact of sex on the survival of patients with hepatocellular carcinoma: a surveillance, epidemiology, and end results analysis. Cancer 2014;120(23):3707-16. [PMID: 25081299]

\section{Yang 2017}

Yang DJ, Luo KL, Liu H, Cai B, Tao GQ, Su XF, et al. Metaanalysis of transcatheter arterial chemoembolization plus radiofrequency ablation versus transcatheter arterial chemoembolization alone for hepatocellular carcinoma. Oncotarget 2017;8(2):2960-70.

\section{Yin 2014}

Yin X, Zhang L, Wang YH, Zhang BH, Gan YH, Ge NL, et al. Transcatheter arterial chemoembolization combined with radiofrequency ablation delays tumor progression and prolongs overall survival in patients with intermediate (BCLC B) hepatocellular carcinoma. BMC Cancer 2014;14:849. [PMID: 25409554]

\section{Zhao 2013}

Zhao S, Chen X, Long Q, Zhang X. Transcatheter arterial chemoembolization combined with radiofrequency ablation for the treatment of hepatocellular carcinoma: a systematic review and meta analysis. Journal of Interventional Radiology 2013;22(11):908-13.

\section{Zhao 2017}

Zhao J, Zhang H, Wei L, Xie S, Suo Z. Comparing the longterm efficacy of standard and combined minimally invasive procedures for unresectable HCC: a mixed treatment comparison. Oncotarget 2017;8(9):15101-13.

\section{Zhu 2013a}

Zhu J, Zhu H, Mei Z, Jin C, Ran L, Zhou K, et al. High-intensity focused ultrasound ablation for treatment of hepatocellular carcinoma and hypersplenism: preliminary study. Journal of Ultrasound in Medicine 2013;32(10):1855-62. [PMID: 24065267]

\section{Zhu 2016}

Zhu ZX, Huang JW, Liao MH, Zeng Y. Treatment strategy for hepatocellular carcinoma in China: radiofrequency ablation versus liver resection. Japanese Journal of Clinical Oncology 2016;46(12):1075-80. [PMID: 27677661]

The combination of transcatheter arterial chemoembolisation (TACE) and thermal ablation versus TACE alone for hepatocellular 


\section{References to other published versions of this review}

Liu 2019a

Liu B, Chen H, Li W. The combination of transcatheter arterial chemoembolisation (TACE) and thermal ablation versus TACE

\section{CHARACTERISTICS OF STUDIES}

Characteristics of excluded studies [ordered by study ID] alone for hepatocellular carcinoma. Cochrane Database of Systematic Reviews 2019, Issue 5. Art. No: CD013345. [DOI: 10.1002/14651858.CD013345]

\begin{tabular}{|c|c|}
\hline Study & Reason for exclusion \\
\hline Chen 2014 & Intervention not of interest to our review \\
\hline Chen 2015 & Not an RCT \\
\hline Hou 2017 & Intervention not of interest to our review \\
\hline Hu 2010 & Intervention not of interest to our review \\
\hline Huang 2015b & Intervention not of interest to our review \\
\hline Kong 2015 & Intervention not of interest to our review \\
\hline Li 2013a & Not an RCT \\
\hline Li 2013b & Intervention not of interest to our review \\
\hline Li 2015b & Intervention not of interest to our review \\
\hline Liu 2007 & Intervention not of interest to our review \\
\hline Liu 2015 & Intervention not of interest to our review \\
\hline Liu 2016b & Intervention not of interest to our review \\
\hline Lu 2015 & Intervention not of interest to our review \\
\hline Sha 2012 & Intervention not of interest to our review \\
\hline Wang 2011 & Intervention not of interest to our review \\
\hline Wang 2016a & Intervention not of interest to our review \\
\hline Wu 2006 & Not a RCT \\
\hline Wu 2011a & Not an RCT \\
\hline Wu 2017a & Intervention not of interest to our review \\
\hline Xiang 2007 & Intervention not of interest to our review \\
\hline Yang 2016 & Intervention not of interest to our review \\
\hline
\end{tabular}

$\mathrm{RCT}$ : randomised clinical trial

The combination of transcatheter arterial chemoembolisation (TACE) and thermal ablation versus TACE alone for hepatocellular 
Characteristics of studies awaiting classification [ordered by study ID]

Ai 2019

Methods

Study design: randomised clinical trial

Study duration: July 2010 to June 2012

Setting: hospital

Participants

Number of participants: 70

Inclusion criteria: diagnosed as HCC; BCLC B stage

Age (mean \pm SD, range ): TACE + RFA: $56.97 \pm 7.41$ years, $21-73$ years; TACE alone: $56.58 \pm 8.66$ years, 21-74 years

Male (n/total): TACE + RFA: 30/35; TACE alone: 29/35

\section{Interventions}

TACE + RFA group $(n=35)$ :

TACE: TACE comprised of hepatic arterial infusion chemotherapy and hepatic artery embolisation Chemotherapeutic drugs: theprubicin and oxaliplatin

\section{RFA: CT-guided}

Control group $(n=35)$ :

TACE comprised of hepatic arterial infusion chemotherapy and hepatic artery embolisation Chemotherapeutic drugs: theprubicin and oxaliplatin

\begin{tabular}{ll}
\hline Outcomes & Tumour response: measured by contrast-enhanced CT at 1 month after treatment \\
Survival rates: measured at 1 year after treatment \\
Adverse events \\
Liver function: blood testing \\
\hline Country of study: China \\
Source of funding: none \\
There was insufficient information available to satisfactorily determine the method of randomisa- \\
tion and the study data could not be verified. We have attempted to contact the study authors for \\
more information, but so far, we have not been successful in doing this.
\end{tabular}

An 2017

Methods

Study design: randomised clinical trial

Study duration: January 2013 to January 2015

Duration of follow-up: 2 years

Setting: hospital

Participants

Number of participants: 98

Inclusion criteria: diagnosed as HCC; single or huge tumour; no PVTT; no history of other tumours

The combination of transcatheter arterial chemoembolisation (TACE) and thermal ablation versus TACE alone for hepatocellular 
An 2017 (Continued)

Age (mean \pm SD, range): TACE + MWA: $51.3 \pm 2.9$ years, $24-78$ years; TACE alone: $50.3 \pm 2.6$ years, 23-78 years

Male (n/total): TACE + MWA: 40/49; TACE alone: 39/49

Interventions

TACE + MWA group $(n=49)$ :

TACE: TACE comprised of hepatic arterial infusion chemotherapy and hepatic artery embolisation Chemotherapeutic drugs: adriamycin $40 \mathrm{mg}$ and fluorouracil $1 \mathrm{~g}$

MWA: the interval between TACE and MWA was 2 weeks. Output power of 50-60W. Time of 10-20 minutes per ablation application

Control group $(n=49)$ :

TACE comprised of hepatic arterial infusion chemotherapy and hepatic artery embolisation Chemotherapeutic drugs: adriamycin $40 \mathrm{mg}$ and fluorouracil $1 \mathrm{~g}$

\begin{tabular}{ll}
\hline Outcomes & Tumour response: measured by contrast-enhanced CT; at 4 months after treatment \\
& 1-year and 2-year survival rates: measured at 1 year and 2 years after treatment \\
Adverse events & Country of study: China \\
Sotes & Tource of funding: none \\
there was insufficient information available to satisfactorily determine the method of randomisa- \\
more information, but so far, we have not been successful in doing this.
\end{tabular}

\begin{tabular}{|c|c|}
\hline Methods & $\begin{array}{l}\text { Study design: randomised clinical trial } \\
\text { Study duration: February } 2018 \text { to February } 2020 \\
\text { Duration of follow-up: } 1 \text { month } \\
\text { Setting: hospital }\end{array}$ \\
\hline \multirow{3}{*}{ Participants } & Inclusion criteria: diagnosed as HCC; intermediate- or advanced-stage \\
\hline & $\begin{array}{l}\text { Age (mean } \pm \text { SD, range ): TACE + RFA: } 59.87 \pm 5.20 \text { years, } 21-73 \text { years; TACE alone: } 59.15 \pm 6.75 \text { years, } \\
40-73 \text { years }\end{array}$ \\
\hline & Male (n/total): TACE + RFA: 14/27; TACE alone: 15/27 \\
\hline \multirow[t]{4}{*}{ Interventions } & TACE + RFA group $(n=27)$ : \\
\hline & $\begin{array}{l}\text { TACE: TACE comprised of hepatic arterial infusion chemotherapy and hepatic artery embolisation } \\
\text { Chemotherapeutic drugs: theprubicin } 20-30 \mathrm{~g} \text {, cisplatin } 80 \mathrm{mg}\end{array}$ \\
\hline & RFA: the interval between TACE and RFA was 2 weeks. Output power of $150 \mathrm{~W}$ \\
\hline & Control group $(n=27)$ : \\
\hline
\end{tabular}


Bao 2020 (Continued)

TACE comprised of hepatic arterial infusion chemotherapy and hepatic artery embolisation

Chemotherapeutic drugs: theprubicin 20-30g, cisplatin $80 \mathrm{mg}$

\begin{tabular}{ll}
\hline Outcomes & Tumour response: measured by contrast-enhanced CT according to WHO criteria \\
Tumour diameter: measured by CT images \\
Adverse events \\
Liver function: measured by blood testing \\
\hline Country of study: China \\
Source of funding: none \\
There was insufficient information available to satisfactorily determine the method of randomisa- \\
tion and the study data could not be verified. We have attempted to contact the study authors for \\
more information, but so far, we have not been successful in doing this.
\end{tabular}

Bian 2020

Study design: randomised clinical trial
Study duration: June 2014 to June 2017
Duration of follow-up: 2 years
Setting: hospital

Purticipants
Inclusion criteria:diagnosed as HCC; age < 80; BCLC B or C stage; Child-Pugh Class A or B
Age (mean \pm SD, range ): TACE + MWA: $56.12 \pm 6.59$ years; TACE alone: $57.03 \pm 6.73$ years
Male (n/total): TACE + MWA: $38 / 52 ;$ TACE alone: $35 / 49$

Interventions $\quad$ TACE + MWA group $(\mathrm{n}=52)$

TACE: TACE comprised of hepatic arterial infusion chemotherapy and hepatic artery embolisation Chemotherapeutic drugs: 5-fluorouracil 30-40 mL, cisplatin 40-60 mg

MWA: The interval between TACE and MWA was 3-7 days.

Output power of $60 \mathrm{~W}$

Control group $(n=49)$ :

TACE comprised of hepatic arterial infusion chemotherapy and hepatic artery embolisation Chemotherapeutic drugs: 5-fluorouracil 30-40 mL, cisplatin 40-60 mg

\begin{tabular}{ll}
\hline Outcomes & Tumour response: measured by contrast-enhanced CT at 1 month after treatment \\
& Survival rates: measured at 2 years after treatment \\
& Adverse events \\
& SSC-Ag: blood testing \\
\hline Notes & Country of study: China \\
& Source of funding: China National Science Funding
\end{tabular}

The combination of transcatheter arterial chemoembolisation (TACE) and thermal ablation versus TACE alone for hepatocellular 
There was insufficient information available to satisfactorily determine the method of randomisation and the study data could not be verified. We have attempted to contact the study authors for more information, but so far, we have not been successful in doing this.

\section{Chen 2020}

Methods
Study design: randomised clinical trial
Suration of follow-up: 6 months
Setting: hospital

\section{Participants}

Number of participants: 80

Inclusion criteria: diagnosed as HCC; tumour diameter $\leq 3 \mathrm{~cm}$

Age (mean \pm SD, range ): TACE + RFA: $67.25 \pm 7.28$ years; TACE alone: $67.98 \pm 7.94$ years

Male (n/total): TACE + RFA: 22/40; TACE alone: $21 / 40$

Interventions

TACE + RFA group $(n=40)$ :

TACE: TACE comprised of hepatic arterial infusion chemotherapy and hepatic artery embolisation Chemotherapeutic drugs: theprubicin, mitomycin, and lobaplatin

\section{RFA: CT-guided}

Control group $(n=40)$ :

TACE comprised of hepatic arterial infusion chemotherapy and hepatic artery embolisation Chemotherapeutic drugs: theprubicin, mitomycin, and lobaplatin

\begin{tabular}{ll}
\hline Outcomes & Tumour response: measured by contrast-enhanced CT at 6 months after treatment \\
Adverse events & Liver function: measured by blood testing \\
\hline Notes & Country of study: China \\
Source of funding: none \\
There was insufficient information available to satisfactorily determine the method of randomisa- \\
tion and the study data could not be verified. We have attempted to contact the study authors for \\
more information, but so far, we have not been successful in doing this.
\end{tabular}


Cui 2015 (Continued)

Participants
Inclusion criteria: diagnosed as HCC; tumour diameter of 2-10 cm and tumour number $\leq 3$; liver function of Child-Pugh Class A or B; willing to sign a written informed consent document

Age (mean $\pm S D$, range): TACE + RFA: $45.38 \pm 4.72$ years, $21-70$ years; TACE alone: $45.96 \pm 5.12$ years, 22-70 years

Male (n/total): TACE + RFA: 65/110; TACE alone: 66/110

With single tumour/multiple tumours (patients): TACE + RFA: 79/31; TACE alone: 75/35

Child-Pugh Class (patients):

Class A: TACE + RFA: 77; TACE alone: 66

Class B: TACE + RFA: 33; TACE alone: 44
$\operatorname{TACE}+\operatorname{RFA}$ group $(n=110)$ :

TACE: Chemotherapeutic drugs: epirubicin $40 \mathrm{mg}$; oxaliplatin $100 \mathrm{mg}$. For patients with poor liver function, the dose of chemotherapeutic drugs was reduced.

RFA: The interval between TACE and RFA was 2 weeks. COSMAN MEDICAL, INC, RFG-4 system. Ablation margin of $1 \mathrm{~cm}$. Ultrasound-guided RFA

TACE group $(n=110)$ :

Chemotherapeutic drugs: epirubicin 40 mg; oxaliplatin 100 mg. For patients with poor liver function, the dose of chemotherapeutic drugs was reduced.

Outcomes Clinical efficacy: measured by contrast-enhanced CT

1-, 2-, and 3-year survival rates

Adverse events

Notes

Country of study: China

Source of funding: none

There was insufficient information available to satisfactorily determine the method of randomisation and the study data could not be verified. We have attempted to contact the study authors for more information, but so far, we have not been successful in doing this.

\begin{tabular}{l} 
Study design: randomised clinical trial \\
Study duration: November 2014 to November 2016 \\
Duration of follow-up: 2 months \\
Setting: hospital \\
\hline Inclusion criteria: diagnosed as HCC by pathology \\
Exclusion criteria: intrahepatic disseminated tumours; with electrolyte imbalance; with arrhyth- \\
mia; with contraindications for intervention therapy \\
Age (mean \pm SD, range): TACE + RFA: $63.1 \pm 6.9$ years, 51-76 years; TACE alone: $62.3 \pm 6.5$ years, $50-76$ \\
years
\end{tabular}


Cui 2017 (Continued)

Male (n/total): TACE + RFA: 27/43; TACE alone: 26/43

Interventions $\quad$ TACE + RFA group $(n=43)$ :

TACE: chemotherapeutic drugs: cisplatin $80 \mathrm{mg}$, epirubicin $30 \mathrm{mg}$, and theprubicin $30 \mathrm{mg}$

RFA: The interval between TACE and RFA was two weeks. RADIONICS system. Output power of 40 W. Fifteen minutes per RFA application

TACE group $(n=43)$ :

Chemotherapeutic drugs: cisplatin $80 \mathrm{mg}$, epirubicin $30 \mathrm{mg}$, and theprubicin $30 \mathrm{mg}$

\begin{tabular}{ll}
\hline Outcomes & Tumour response: measured by contrast-enhanced images at 2 months after treatment \\
& Serum level of CD3+ cell, CD4/CD8, NK cell, and TNF-a。 \\
& Serum level of AFP, CA199, and GGT \\
\hline Notes & Country of study: China \\
& Source of funding: none \\
& $\begin{array}{l}\text { There was insufficient information available to satisfactorily determine the method of randomisa- } \\
\text { tion and the study data could not be verified. We have attempted to contact the study authors for } \\
\text { more information, but so far, we have not been successful in doing this. }\end{array}$
\end{tabular}

\begin{tabular}{|c|c|}
\hline \multirow[t]{4}{*}{ Methods } & Study design: randomised clinical trial \\
\hline & Study duration: January 2010 to January 2012 \\
\hline & Duration of follow-up: 2 years \\
\hline & Setting: hospital \\
\hline \multirow{2}{*}{ Participants } & Age (mean $\pm S D$, range): $58.5 \pm 2.4$ years, $25-74$ years \\
\hline & Male (n/total): 85/120 \\
\hline \multirow[t]{4}{*}{ Interventions } & TACE + MWA group $(n=60):$ \\
\hline & MWA: the interval between TACE and MWA was 2 weeks. \\
\hline & TACE group $(n=60)$ : \\
\hline & Chemotherapeutic drugs: 5-fluorouracil 0.5-1 g, cisplatin 40-60 mg, and epirubicin 20-40 mg \\
\hline \multirow[t]{3}{*}{ Outcomes } & Tumour response: measured by image examinations \\
\hline & 2-year survival rate \\
\hline & Adverse events \\
\hline \multirow[t]{2}{*}{ Notes } & Country of study: China \\
\hline & Source of funding: none \\
\hline
\end{tabular}

The combination of transcatheter arterial chemoembolisation (TACE) and thermal ablation versus TACE alone for hepatocellular 
There was insufficient information available to satisfactorily determine the method of randomisation and the study data could not be verified. We have attempted to contact the study authors for more information, but so far, we have not been successful in doing this.

\section{Ding 2017}

Study design: randomised clinical trial
Study duration: January 2015 to April 2017
Duration of follow-up: not reported
Setting: hospital

Participants Inclusion criteria: diagnosed as middle or advanced HCC

Exclusion criteria: with intrahepatic disseminated tumours; liver function of Child-Pugh Class C; with tumour thrombus in portal vein trunk.

Age (mean \pm SD, range): TACE + RFA: $57.3 \pm 2.9$ years, $52-78$ years; TACE alone: $57.6 \pm 2.1$ years, 51-76 years

Male (n/total): TACE + RFA: 20/44; TACE alone: 21/44

Tumour diameter (mean \pm SD, range): TACE + RFA: $6.2 \pm 2.1 \mathrm{~cm}, 3-13 \mathrm{~cm}$; TACE alone: $6.2 \pm 2.2 \mathrm{~cm}$, $3-13 \mathrm{~cm}$

With single/multiple/giant tumours (patients): TACE + RFA: 22/11/11; TACE alone: 23/10/11

TACE: Chemotherapeutic drugs: hydroxy camptothecin $10 \mathrm{mg}$, cisplatin $30 \mathrm{mg}$, and 5-fluorouracil 1 g

RFA: Ablation of 1-2 cm. Twelve minutes per ablation session

TACE group $(n=44)$ :

Chemotherapeutic drugs: hydroxy camptothecin $10 \mathrm{mg}$, cisplatin $30 \mathrm{mg}$, and 5-fluorouracil $1 \mathrm{~g}$

\begin{tabular}{ll}
\hline Outcomes & Serum level of AFP \\
& Clinical response: measured by image examinations \\
& Adverse events \\
\hline Notes & Country of study: China \\
Source of funding: none & There was insufficient information available to satisfactorily determine the method of randomisa- \\
tion and the study data could not be verified. We have attempted to contact the study authors for \\
more information, but so far, we have not been successful in doing this.
\end{tabular}


Dong 2013 (Continued)

Duration of follow-up: 6 months

Setting: hospital

\section{Participants}

Inclusion criteria: diagnosed as large HCC (tumour maximal diameter $>5 \mathrm{~cm}$ ) by liver biopsy; single tumour

Age (mean \pm SD, range): TACE + RFA: $57.3 \pm 3.2$ years; TACE alone: $58.4 \pm 2.9$ years

Male (n/total): TACE + RFA: 14/22; TACE alone: 16/22

Tumour diameter (mean \pm SD): TACE + RFA: $8.7 \pm 2.1 \mathrm{~cm}$; TACE alone: $9.1 \pm 2.5 \mathrm{~cm}$

Serum level of AFP:

Abnormal: TACE + RFA: 21 patients; TACE alone: 19 patients

Normal: TACE + RFA: 1 patients; TACE alone: 3 patients

TACE + RFA group $(n=22)$ :

TACE: the combination of hepatic arterial infusion chemotherapy and hepatic artery embolisation

RFA: ultrasound-guided RFA

TACE group $(n=22)$ :

The combination of hepatic arterial infusion chemotherapy and hepatic artery embolisation

$\begin{array}{ll}\text { Outcomes } & \text { Serum level of AFP } \\ \text { Clinical efficacy: measured by image examinations at } 6 \text { months after treatment } \\ \text { Adverse events } \\ \text { Country of study: China } \\ \text { Source of funding: none } \\ \begin{array}{l}\text { There was insufficient information available to satisfactorily determine the method of randomisa- } \\ \text { tion and the study data could not be verified. We have attempted to contact the study authors for } \\ \text { more information, but so far, we have not been successful in doing this. }\end{array}\end{array}$

Dong 2018

Methods
Study design: Randomised clinical trial
Study duration: July 2014 to June 2015
Duration of follow-up: 2 years
Setting: Hospital
Inclusion criteria: Diagnosed as HCC by pathology; the total tumour volume $<70 \%$ of volume of
whole liver; without complete obstruction of portal vein; life expectancy $>3$ months
Exclusion criteria: With serious systematic disease; with obvious fistula
Age (mean \pm SD, range): TACE + RFA: $42.52 \pm 8.50$ years, $29-68$ years; TACE alone: $43.03 \pm 7.66$ years,
$27-66$ years


Dong 2018 (Continued)

Male (n/total): TACE + RFA: 22/31; TACE alone: 21/31

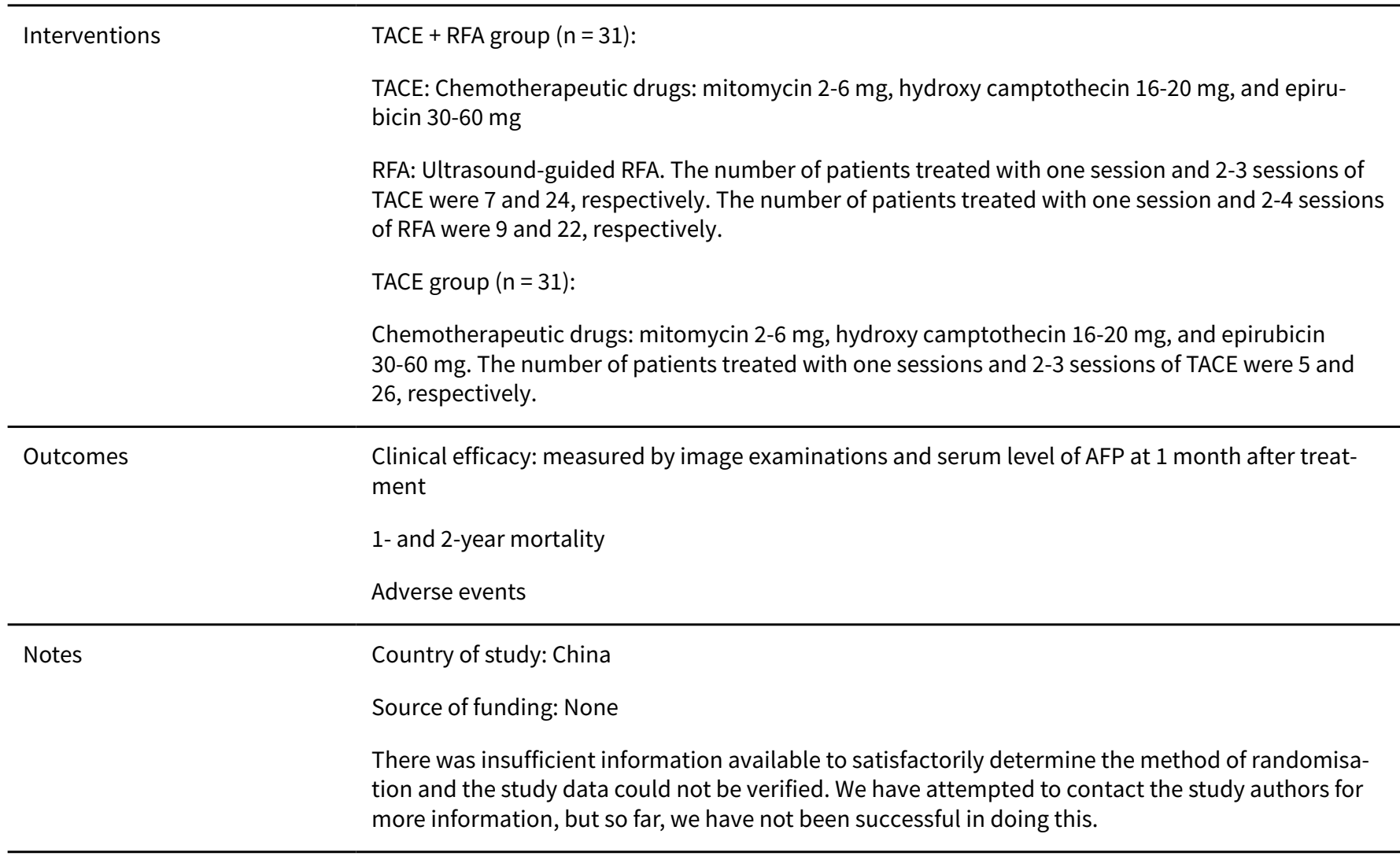

Du 2017

Methods
Study design: Randomised clinical trial
Study duration: December 2012 to December 2015
Setting: Hospital

Participants

Inclusion criteria: Diagnosed as HCC by liver biopsy; the maximal tumour diameter $\geq 5 \mathrm{~cm}$; single tumour

Exclusion criteria: Portal vein was completely obstructed; serious portal hypertension

Age (mean \pm SD, range): TACE + RFA: $57.14 \pm 5.27$ years, $28-73$ years; TACE alone: $57.48 \pm 3.71$ years, 26-71 years

Male (n/total): TACE + RFA: 28/40; TACE alone: 27/40

Tumour diameter (mean \pm SD): TACE + RFA: $8.27 \pm 2.35 \mathrm{~cm}$; TACE alone: $8.80 \pm 2.57 \mathrm{~cm}$

Serum level of AFP:

Abnormal: TACE + RFA: 38 patients; TACE alone: 36 patients

Normal: TACE + RFA: 2 patients; TACE alone: 4 patients 
Du 2017 (Continued)

TACE: Chemotherapeutic drugs: epirubicin 50-60 mg

RFA: Output power of 70-90 W. Multiple sessions of RFA were performed with an interval of 1-2 weeks. For patients with the tumour maximal diameter less than $10 \mathrm{~cm}$, the total time per RFA treatment was 30-60 minutes. For patients with the tumour maximal diameter $\geq 10 \mathrm{~cm}$, the total time per RFA treatment was 80-100 minutes.

TACE group $(n=40)$ :

Chemotherapeutic drugs: epirubicin 50-60 mg

\begin{tabular}{ll}
\hline Outcomes & $\begin{array}{l}\text { Tumour response: measured by image examinations at } 6 \text { months after treatment } \\
\text { Clinical efficacy (serum level of ALT, TBIL, AFP, and tumour diameter) } \\
\text { Adverse events }\end{array}$ \\
\hline Cotes & Sountry of study: China \\
& $\begin{array}{l}\text { There was insufficient information available to satisfactorily determine the method of randomisa- } \\
\text { tion and the study data could not be verified. We have attempted to contact the study authors for } \\
\text { more information, but so far, we have not been successful in doing this. }\end{array}$ \\
\hline
\end{tabular}

Methods Study design: Randomised clinical trial

Study duration: 2013

Duration of follow-up: 3 years

Setting: Hospital

Participants

Age (mean \pm SD, range ): TACE + RFA: 60. $4 \pm 11.2$ years, $46-72$ years; TACE alone: $60.4 \pm 11.2$ years, 45-73 years

Male (n/total): TACE + RFA: 20/33; TACE alone: 20/32

Child-Pugh Class (patients):

Class A: TACE + RFA: 22; TACE alone: 23

Class B: TACE + RFA: 10; TACE alone: 10

Interventions $\quad$ TACE + RFA group $(n=33)$ :

TACE: Chemotherapeutic drugs: oxaliplatin $200 \mathrm{mg}$ and fluorouracil $15 \mathrm{~g}$

RFA: The interval between TACE and RFA was 2 weeks. Output power of $60 \mathrm{~W}$.

TACE group $(n=32)$ :

Chemotherapeutic drugs: oxaliplatin $200 \mathrm{mg}$ and fluorouracil $15 \mathrm{~g}$

Outcomes

Tumour response: measured by image examinations

Serum level of AFP

Survival rates (free tumour)

The combination of transcatheter arterial chemoembolisation (TACE) and thermal ablation versus TACE alone for hepatocellular carcinoma (Review)

Copyright (C) 2021 The Cochrane Collaboration. Published by John Wiley \& Sons, Ltd. 
Fan 2016 (Continued)

Notes
Country of study: China

Source of funding: None

There was insufficient information available to satisfactorily determine the method of randomisation and the study data could not be verified. We have attempted to contact the study authors for more information, but so far, we have not been successful in doing this.

\section{Fang 2016}

\begin{tabular}{ll}
\hline Methods & Study design: Randomised clinical trial \\
Study duration: February 2014 to February 2015 \\
Duration of follow-up: 1 year \\
Setting: Hospital
\end{tabular}

\section{Participants}

Inclusion criteria: Diagnosed as HCC by liver biopsy; tumour maximal diameter $\geq 5 \mathrm{~cm}$

Age (mean \pm SD, range): TACE + RFA: $63.4 \pm 5.6$ years, $37-79$ years; TACE alone: $62.8 \pm 5.2$ years, $35-81$ years

Male (n/total): TACE + RFA: 16/25; TACE alone: 14/25

Child-Pugh Class (patients):

Class A: 44; Class B: 6

Interventions

TACE + RFA group $(n=25)$ :

TACE: Chemotherapeutic drugs: epirubicin, oxaliplatin, and hydroxy camptothecin

RFA: Ultrasound-guided RFA

TACE group $(n=25)$ :

Chemotherapeutic drugs: epirubicin, oxaliplatin, and hydroxy camptothecin

\begin{tabular}{ll}
\hline Outcomes & Tumour response: measured by contrast-enhanced CT or MRI at 3 days after treatment \\
\hline Notes & Country of study: China \\
& Source of funding: None \\
& There was insufficient information available to satisfactorily determine the method of randomisa- \\
tion and the study data could not be verified. We have attempted to contact the study authors for \\
more information, but so far, we have not been successful in doing this.
\end{tabular}


Fang 2020 (Continued)

Participants
Number of participants: 50

Inclusion criteria: Diagnosed as HCC; Child-Pugh Class A or B; large or huge tumour

Age (mean \pm SD, range ): TACE + MWA: $55.10 \pm 5.32$ years; TACE alone: $54.26 \pm 5.09$ years

Male (n/total): TACE + MWA: 15/25; TACE alone: 16/25
Interventions
TACE + MWA group $(n=25):$

TACE: TACE comprised of hepatic arterial infusion chemotherapy and hepatic artery embolisation Chemotherapeutic drugs: epirubicin 20-50 mg and oxaliplatin 50-150 mg

MWA: The interval between TACE and MWA was 14 days.

Control group $(n=25)$ :

TACE comprised of hepatic arterial infusion chemotherapy and hepatic artery embolisation Chemotherapeutic drugs: epirubicin 20-50 mg and oxaliplatin 50-150 mg

Outcomes
Sumour response: measured by contrast-enhanced CT at 6 months after treatment
Adverse events
Country of study: China
Source of funding: None
$\begin{aligned} & \text { There was insufficient information available to satisfactorily determine the method of randomisa- } \\ & \text { tion and the study data could not be verified. We have attempted to contact the study authors for } \\ & \text { more information, but so far, we have not been successful in doing this. }\end{aligned}$

Study design: Randomised clinical trial
Study duration: August 2016 to March 2020
Duration of follow-up: 1 month
Setting: Hospital

Participants Number of participants: 32

Inclusion criteria: Diagnosed as HCC; age $<75$; tumour number $\leq 3$; tumour diameter of 5-10 cm; TNM III-N

Age (mean \pm SD, range ): TACE + MWA: $57.51 \pm 4.66$ years; TACE alone: $59.51 \pm 4.83$ years

Male (n/total): TACE + MWA: 10/16; TACE alone: 11/16

TACE: TACE comprised of hepatic arterial infusion chemotherapy and hepatic artery embolisation Chemotherapeutic drugs: oxaliplatin 50-100 mg and theprubicin $20 \mathrm{mg}$

MWA: ultrasound-guided; MTI-5DT

Control group $(n=16)$ : 
TACE comprised of hepatic arterial infusion chemotherapy and hepatic artery embolisation Chemotherapeutic drugs: oxaliplatin 50-100 mg and theprubicin $20 \mathrm{mg}$

\section{Outcomes}

Tumour response: measured by contrast-enhanced CT at 1 month after treatment

The level of AFP and GGT: measured by blood testing

Notes

Country of study: China

Source of funding: None

There was insufficient information available to satisfactorily determine the method of randomisation and the study data could not be verified. We have attempted to contact the study authors for more information, but so far, we have not been successful in doing this.

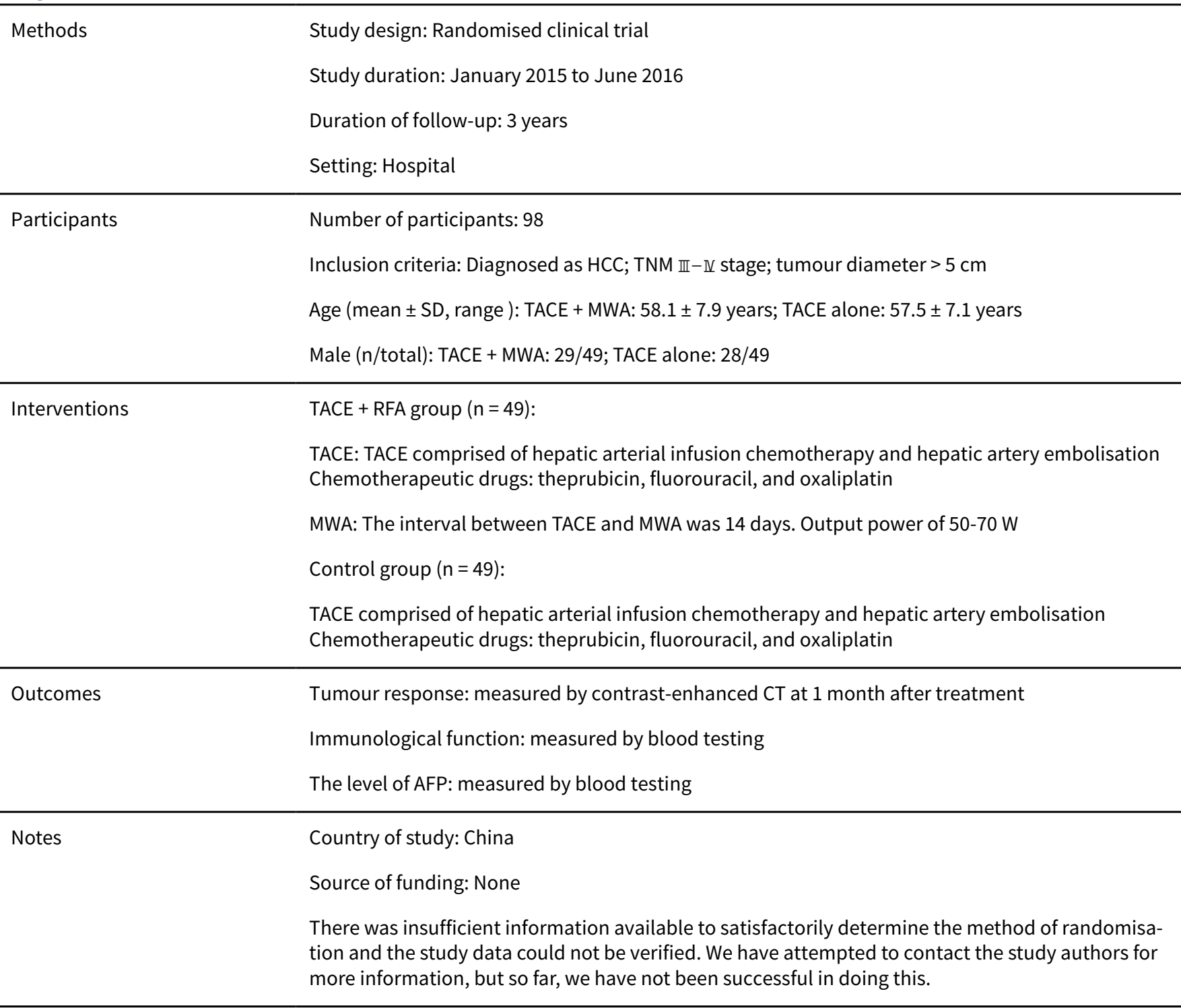


Guo 2015c

\begin{tabular}{|c|c|}
\hline \multirow[t]{4}{*}{ Methods } & Study design: Randomised clinical trial \\
\hline & Study duration: February 2011 to January 2013 \\
\hline & Duration of follow-up: 1 year \\
\hline & Setting: Hospital \\
\hline \multirow[t]{4}{*}{ Participants } & Age $($ mean $\pm S D): 51.8 \pm 9.6$ years \\
\hline & Male (n/total): $47 / 72$ \\
\hline & Tumour diameter: $6.3 \pm 2.5 \mathrm{~cm}$ \\
\hline & Child-Pugh Class: Class A: 9; Class B: 46; Class C: 17 \\
\hline \multirow[t]{5}{*}{ Interventions } & TACE + ultrasound ablation group $(n=36)$ : \\
\hline & TACE: Chemotherapeutic drugs: $10-40 \mathrm{mg}$ epirubicin \\
\hline & Ultrasound ablation frequency $0.96 \mathrm{MHz}$, focal length $134 \mathrm{~mm}$ \\
\hline & TACE group $(n=36)$ : \\
\hline & Chemotherapeutic drugs: $10-40$ mg epirubicin \\
\hline \multirow[t]{5}{*}{ Outcomes } & Tumour response: measured by image examinations at 1 month after treatment \\
\hline & Clinical efficacy \\
\hline & Serum level of AFP \\
\hline & 1-year survival rate \\
\hline & Adverse events \\
\hline \multirow[t]{3}{*}{ Notes } & Country of study: China \\
\hline & Source of funding: None \\
\hline & $\begin{array}{l}\text { There was insufficient information available to satisfactorily determine the method of randomisa- } \\
\text { tion and the study data could not be verified. We have attempted to contact the study authors for } \\
\text { more information, but so far, we have not been successful in doing this. }\end{array}$ \\
\hline
\end{tabular}

He 2016

\begin{tabular}{ll} 
Methods & Study design: Randomised clinical trial \\
& Study duration: March 2015 to December 2015 \\
& Duration of follow-up: 2 years \\
& Setting: Hospital \\
\hline Participants & Inclusion criteria: Diagnosed as HCC by pathology or imaging examination; AFP $>400 \mu \mathrm{g} / \mathrm{L} ;$ liver \\
& function of Child-Pugh Class A or B; the number of tumours $\leq 2$ \\
& Exclusion criteria: With portal vein tumour thrombus and extrahepatic metastasis \\
& Age (mean): TACE + MWA: 52.6 years; TACE alone: 52.9 years
\end{tabular}

The combination of transcatheter arterial chemoembolisation (TACE) and thermal ablation versus TACE alone for hepatocellular 
He 2016 (Continued)

Male (n/total): TACE + MWA: 25/32; TACE alone: 22/28

Tumour diameter (mean): .TACE + MWA: $8.2 \mathrm{~cm}$; TACE alone: $7.9 \mathrm{~cm}$

Child-Pugh Class (patients):

Class A: TACE + MWA: 13; TACE alone: 11

Class B: TACE + MWA: 19; TACE alone: 17

Interventions

TACE + MWA group $(n=32)$ :

TACE: Chemotherapeutic drugs: epirubicin 30-50 mg and oxaliplatin 200-150 mg

MWA: CT-guided MWA. Output power of 55-60 W. The ablation time of per application was 5-10 minutes.

TACE group $(n=28)$ :

Chemotherapeutic drugs: epirubicin 30-50 mg and oxaliplatin 200-150 mg

\begin{tabular}{ll}
\hline Outcomes & Serum level of AFP \\
& Tumour response: measured by contrast-enhanced CT or MRI at 1 month after treatment \\
& Adverse events \\
& 1- and 2-year survival rates \\
\hline Notes & $\begin{array}{l}\text { Country of study: China } \\
\text { Source of funding: None } \\
\text { There was insufficient information available to satisfactorily determine the method of randomisa- } \\
\text { tion and the study data could not be verified. We have attempted to contact the study authors for } \\
\text { more information, but so far, we have not been successful in doing this. }\end{array}$ \\
\hline
\end{tabular}

He 2020

\begin{tabular}{ll}
\hline Methods & Study design: Randomised clinical trial \\
Study duration: January 2017 to December 2018 \\
Duration of follow-up: 2 years \\
Setting: Hospital
\end{tabular}

Participants

Number of participants: 72

Inclusion criteria: Diagnosed as HCC; age $>30$

Age (mean \pm SD, range ): TACE + RFA: $52.41 \pm 5.85$ years; TACE alone: $52.39 \pm 5.97$ years

Male (n/total): TACE + RFA: 22/36; TACE alone: 20/36

Interventions

TACE + RFA group $(n=36)$ :

TACE: TACE comprised of hepatic arterial infusion chemotherapy and hepatic artery embolisation Chemotherapeutic drugs: 5-fluorouracil $500 \mathrm{mg}$ and oxaliplatin $50 \mathrm{mg}$

RFA: US-guided

Control group $(n=36)$ : 
He 2020 (Continued)

TACE comprised of hepatic arterial infusion chemotherapy and hepatic artery embolisation

Chemotherapeutic drugs: 5-fluorouracil $500 \mathrm{mg}$ and oxaliplatin $50 \mathrm{mg}$

\begin{tabular}{ll}
\hline Outcomes & Tumour response: measured by contrast-enhanced CT at 2 weeks after treatment \\
& Survival rates: measured at 2 years after treatment \\
& Adverse events \\
\hline Notes & Country of study: China \\
Source of funding: None \\
There was insufficient information available to satisfactorily determine the method of randomisa- \\
tion and the study data could not be verified. We have attempted to contact the study authors for \\
more information, but so far, we have not been successful in doing this.
\end{tabular}

Hou 2013

\begin{tabular}{ll}
\hline Methods & Study design: Randomised clinical trial \\
& Study duration: January 2008 to December 2012 \\
& Duration of follow-up: 1 month \\
& Setting: Hospital \\
\hline Participants & Inclusion criteria: Diagnosed as HCC by images or liver biopsy; with liver function of Child-Pugh \\
& Class A or B; adequate renal function; expected survival > 3 months \\
& Age (mean, range): 52.3 years, $32-72$ years \\
& Male (n/total): $34 / 42$ \\
Child-Pugh Class A-B: 42 patients
\end{tabular}

Interventions

TACE + cryoablation group $(n=22)$ :

TACE: Chemotherapeutic drugs: theprubicin 20-40 mg, 5-fluorouracil 1-1.5 g, and cisplatin 60-80 mg. TACE treatment was performed 2-4 times with an interval of 4 weeks.

Cryoablation: The temperature was $40^{\circ} \mathrm{C}$ or $-150^{\circ} \mathrm{C}$. Cryoablation was performed 1-2 times.

TACE group $(n=20)$ :

Chemotherapeutic drugs: theprubicin 20-40 mg, 5-fluorouracil 1-1.5 g, and cisplatin 60-80 mg TACE was performed at 2-4 weeks.

\begin{tabular}{ll}
\hline Outcomes & Tumour response: measured by image examinations at 4 weeks after treatment \\
& Serum level of AFP \\
Immune function & Country of study: China \\
Source of funding: None & $\begin{array}{l}\text { There was insufficient information available to satisfactorily determine the method of randomisa- } \\
\text { tion and the study data could not be verified. We have attempted to contact the study authors for } \\
\text { more information, but so far, we have not been successful in doing this. }\end{array}$
\end{tabular}


Setting: Hospital

Pumber of participants: 86
Age (mean \pm SD, range ): TACE + RFA: $55.4 \pm 4.57$ years; TACE alone: $55.45 \pm 4.25$ years
Male (n/total): TACE + RFA: $24 / 43 ;$ TACE alone: $26 / 43$

Interventions

$\operatorname{TACE}+\operatorname{RFA}$ group $(n=43)$ :

TACE: TACE comprised of hepatic arterial infusion chemotherapy and hepatic artery embolisation Chemotherapeutic drugs: cisplatin 40-80 mg and epirubicin 30-50 mg

RFA: The interval between TACE and RFA was 2-4 weeks.

Control group $(n=43)$ :

TACE comprised of hepatic arterial infusion chemotherapy and hepatic artery embolisation Chemotherapeutic drugs: cisplatin 40-80 mg and epirubicin 30-50 mg

\begin{tabular}{ll}
\hline Outcomes & Liver function, AFP: measured by blood testing \\
\hline Notes & Country of study: China \\
Source of funding: None & \\
& There was insufficient information available to satisfactorily determine the method of randomisa- \\
tion and the study data could not be verified. We have attempted to contact the study authors for \\
more information, but so far, we have not been successful in doing this.
\end{tabular}

Huang 2013

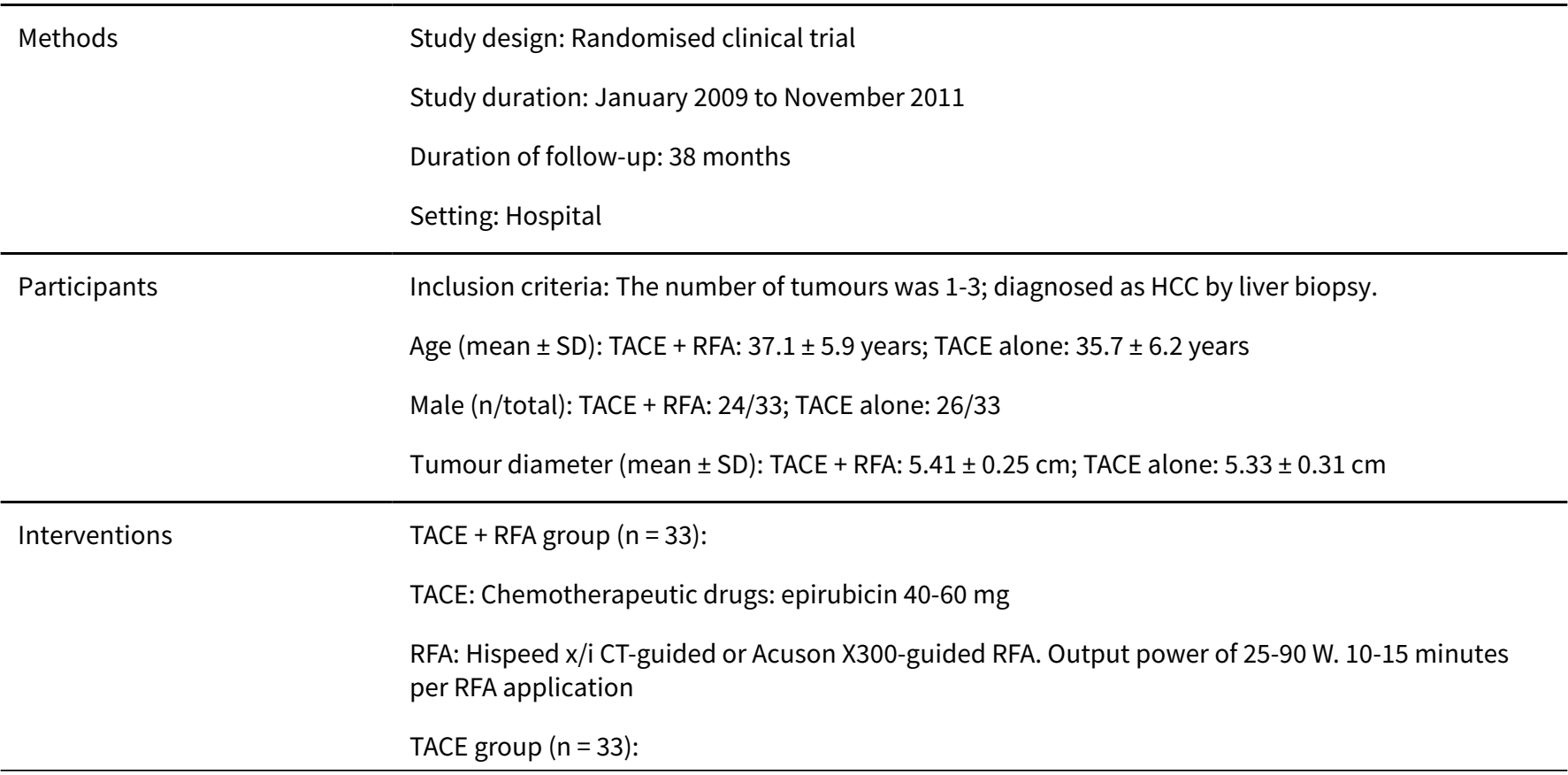

The combination of transcatheter arterial chemoembolisation (TACE) and thermal ablation versus TACE alone for hepatocellular 
Huang 2013 (Continued)

Chemotherapeutic drugs: epirubicin 40-60 mg

Outcomes Tumour response: measured by image examinations

1-, 2-, and 3-year survival rates

Notes

Country of study: China

Source of funding: None

There was insufficient information available to satisfactorily determine the method of randomisation and the study data could not be verified. We have attempted to contact the study authors for more information, but so far, we have not been successful in doing this.

Huang 2015a

Study design: Randomised clinical trial
Study duration: August 2008 to January 2011
Duration of follow-up: 3 years
Setting: Hospital

Participants Inclusion criteria: Diagnosed as HCC by pathology; with history of liver resection before tumour recurrence; rejection of the secondary liver resection

Age (range): TACE + RFA: 65-78 years; TACE alone: 66-77 years

Male (n/total): TACE + RFA: 21/38; TACE alone: 19/30

Child-Pugh Class (patients):

Class A: TACE + RFA: 26; TACE alone: 20

Class B: TACE + RFA: 12; TACE alone: 10

Interventions $\quad$ TACE + RFA group $(n=38)$ :

TACE: Chemotherapeutic drugs: theprubicin $20 \mathrm{mg}$ and carboplatin $1000 \mathrm{mg}$

RFA: The interval between TACE and RFA was 2 weeks. The ablation time of per RFA application was 5-12 minutes.

$\operatorname{TACE}$ group $(\mathrm{n}=30)$ :

Chemotherapeutic drugs: theprubicin $20 \mathrm{mg}$ and carboplatin $1000 \mathrm{mg}$

\begin{tabular}{|c|c|}
\hline \multirow[t]{3}{*}{ Outcomes } & Serum level of AFP \\
\hline & Tumour response: measured by contrast-enhanced CT at 1 month after treatment \\
\hline & 1-, 2-, and 3-year survival rate \\
\hline \multirow[t]{2}{*}{ Notes } & $\begin{array}{l}\text { Country of study: China } \\
\text { Source of funding: None }\end{array}$ \\
\hline & $\begin{array}{l}\text { There was insufficient information available to satisfactorily determine the method of randomisa- } \\
\text { tion and the study data could not be verified. We have attempted to contact the study authors for } \\
\text { more information, but so far, we have not been successful in doing this. }\end{array}$ \\
\hline
\end{tabular}

The combination of transcatheter arterial chemoembolisation (TACE) and thermal ablation versus TACE alone for hepatocellular 
Duration of follow-up: 15 months

Setting: Hospital

\begin{tabular}{l} 
Participants \\
Inclusion criteria: Diagnosed as middle or advanced HCC \\
Male ( $n /$ total): TACE + RFA: 52/90; TACE alone: $49 / 90$ \\
TACE + RFA group ( $n=90):$ \\
TACE: Chemotherapeutic drugs: theprubicin 450 mg \\
RFA: The interval between TACE and RFA was 3-5 weeks. CT-guided RFA \\
TACE group ( $n=90):$ \\
Chemotherapeutic drugs: theprubicin 450 mg \\
Serum level of AFP and CA-199 \\
Survival rate at 5, 10 , and 15 months after treatment \\
Recurrence rate at 15 months after treatment \\
\hline Outcomes \\
$\begin{array}{l}\text { Country of study: China } \\
\text { Source of funding: None } \\
\text { There was insufficient information available to satisfactorily determine the method of randomisa- } \\
\text { tion and the study data could not be verified. We have attempted to contact the study authors for } \\
\text { more information, but so far, we have not been successful in doing this. }\end{array}$ \\
\hline Notes
\end{tabular}

Huang 2017a

\begin{tabular}{|c|c|}
\hline \multirow[t]{4}{*}{ Methods } & Study design: Randomised clinical trial \\
\hline & Study duration: January 2015 to December 2016 \\
\hline & Duration of follow-up: 1 week \\
\hline & Setting: Hospital \\
\hline \multirow[t]{3}{*}{ Participants } & Age (mean \pm SD): TACE + ultrasound ablation: $50.2 \pm 6.3$ years; TACE alone: $50.5 \pm 6.1$ years \\
\hline & Male (n/total): TACE + ultrasound ablation: 22/42; TACE alone: 24/42 \\
\hline & Single/multiple tumours (patients): TACE + ultrasound ablation: 27/15; TACE: 25/17 \\
\hline \multirow[t]{3}{*}{ Interventions } & TACE + ultrasound ablation group $(n=42)$ : \\
\hline & TACE: Chemotherapeutic drugs: mitomycin $10 \mathrm{mg}$, 5-fluorouracil $500 \mathrm{mg}$, and adriamycin $40 \mathrm{mg}$. \\
\hline & Ultrasound ablation: Frequency $0.8 \mathrm{MHz}$, focal length $135 \mathrm{~mm}$, and treatment duration 3000-14000 \\
\hline
\end{tabular}


TACE group $(n=42)$ :

Chemotherapeutic drugs: mitomycin $10 \mathrm{mg}$, 5-fluorouracil $500 \mathrm{mg}$, and adriamycin $40 \mathrm{mg}$

Outcomes Tumour response: measured by contrasted-enhanced CT and liver function at 1 week after treat-
ment

Liver function at 1 week after treatment

Quality of life at 1 week after treatment

Notes Country of study: China

Source of funding: None

There was insufficient information available to satisfactorily determine the method of randomisation and the study data could not be verified. We have attempted to contact the study authors for more information, but so far, we have not been successful in doing this.

\section{Huang 2017b}

\begin{tabular}{ll}
\hline Methods & Study design: Randomised clinical trial \\
Study duration: April 2013 to April 2015 \\
Duration of follow-up: 1 year \\
Setting: Hospital
\end{tabular}

\section{Participants}

Age (mean \pm SD): TACE + RFA: $51.2 \pm 3.6$ years; TACE alone: $51.1 \pm$ years

Male (n/total): TACE + RFA: 23/40; TACE alone: 24/40

Interventions

TACE + RFA group $(n=40)$ :

TACE: Chemotherapeutic drugs: fluorouracil, mitomycin, and cisplatin

RFA: The interval between TACE and RFA was 2 weeks.

$\operatorname{TACE}$ group $(n=40)$ :

Chemotherapeutic drugs: fluorouracil, mitomycin, and cisplatin

Outcomes

Tumour response: measured by image examinations at 12 months after treatment

Adverse events

Survival rate at 6 and 12 months after treatment

Recurrence rate

Country of study: China
Source of funding: None
There was insufficient information available to satisfactorily determine the method of randomisa-
tion and the study data could not be verified. We have attempted to contact the study authors for
more information, but so far, we have not been successful in doing this.

The combination of transcatheter arterial chemoembolisation (TACE) and thermal ablation versus TACE alone for hepatocellular 
Huang 2019

\begin{tabular}{ll}
\hline Methods & Study design: Randomised clinical trial \\
& Study duration: January 2016 to June 2018 \\
& Follow-up: 1 month \\
& Setting: Hospital \\
\hline Participants & Number of participants: 72 \\
\hline Interventions & TACE + RFA group ( $=36)$ \\
& Control group ( $n=36)$ \\
\hline Outcomes & Tumour response: measured by contrast-enhanced CT at 1 month after treatment \\
& TGF- $\beta 1$, CD4+, CD8,+ CD4+/CD8+: measured by blood testing \\
\hline Notes & $\begin{array}{l}\text { Country of study: China } \\
\text { Source of funding: None } \\
\text { There was insufficient information available to satisfactorily determine the method of randomisa- } \\
\text { tion and the study data could not be verified. We have attempted to contact the study authors for } \\
\text { more information, but so far, we have not been successful in doing this. }\end{array}$
\end{tabular}

Study duration: October 2011 to May 2012

Duration of follow-up: 2 years

Setting: Hospital

\section{Participants}

Inclusion criteria: diagnosed as HCC by pathology and images; the number of tumours $\leq 4 \mathrm{~cm}$; tumour maximal diameter of $5-9 \mathrm{~cm}$

Exclusion criteria: With contraindications for intervention therapies

Age (mean \pm SD, range): TACE + RFA: $50 \pm 9$ years, 36-72 years; TACE alone: $52 \pm 10$ years, 32-78 years

Male (n/total): TACE + RFA: 12/21; TACE alone: 14/21

Single/multiple tumour (patients): TACE + RFA: 13/8; TACE: 11/10

TACE: Chemotherapeutic drugs: epirubicin $55 \mathrm{mg}$, cisplatin $50 \mathrm{mg}$, and mitomycin $8 \mathrm{mg}$

RFA: The interval between TACE and RFA was 2 weeks. RANDIONICS system. Output power of $200 \mathrm{~W}$ and 12 minutes per RFA session

TACE group $(n=21)$ :

Chemotherapeutic drugs: epirubicin $55 \mathrm{mg}$, cisplatin $50 \mathrm{mg}$, and mitomycin $8 \mathrm{mg}$

\begin{tabular}{ll}
\hline Outcomes & Tumour response: measured by CT, PET, or DSA \\
6-month, 1-year, and 2-year survival rates
\end{tabular}

The combination of transcatheter arterial chemoembolisation (TACE) and thermal ablation versus TACE alone for hepatocellular carcinoma (Review)

Copyright @ 2021 The Cochrane Collaboration. Published by John Wiley \& Sons, Ltd. 
Jiang 2015a (Continued)

Notes
Country of study: China

Source of funding: None

There was insufficient information available to satisfactorily determine the method of randomisation and the study data could not be verified. We have attempted to contact the study authors for more information, but so far, we have not been successful in doing this.

Jiang 2015b

$\begin{array}{ll}\text { Methods } & \text { Study design: Randomised clinical trial } \\ & \text { Study duration: Not reported } \\ \text { Duration of follow-up: } 2 \text { years } \\ \text { Setting: Hospital }\end{array}$

Participants

Age (mean \pm SD, range): TACE + RFA: $63.65 \pm 9.31$ years, $41-82$ years; TACE alone: $62.18 \pm 9.07$ years, 43-79 years

Male (n/total): TACE + RFA: 17/30; TACE alone: 16/30

Tumour diameter (mean \pm SD, range): TACE + RFA: $5.07 \pm 1.13 \mathrm{~cm}, 3-10.5 \mathrm{~cm}$, TACE: $5.12 \pm 1.04 \mathrm{~cm}$, $2.8-10.6 \mathrm{~cm}$

TNM stage (patients):

Stage I : TACE + RFA: 10; TACE: 9

Stage II : TACE + RFA: 12 ; TACE: 14

Stage III : TACE + RFA: 7; TACE: 7

Child-Pugh Class (patients):

Class A: TACE + RFA: 25; TACE alone: 23

Class B: TACE + RFA: 5; TACE alone: 7

$\operatorname{TACE}+\operatorname{RFA}$ group $(n=30)$ :

TACE: Chemotherapeutic drugs: oxaliplatin 100-150 mg and theprubicin 40-60 mg. Two sessions of TACE were performed, with an interval of one month.

RFA: The interval between TACE and RFA was 2 weeks. RANDIONICS system. Output power of 0-200 W and frequency of $480 \mathrm{kHz}$

TACE group $(n=30)$ :

Chemotherapeutic drugs: oxaliplatin 100-150 mg and theprubicin 40-60 mg. Two sessions of TACE were performed, with an interval of one month.

\begin{tabular}{ll}
\hline Outcomes & Tumour response: measured by contrast-enhanced CT at 1 month after treatment \\
& $\begin{array}{l}\text { 1- and 2-year survival rates } \\
\text { Progression-free survival }\end{array}$ \\
\hline Notes & $\begin{array}{l}\text { Country of study: China } \\
\text { Source of funding: None }\end{array}$
\end{tabular}


There was insufficient information available to satisfactorily determine the method of randomisation and the study data could not be verified. We have attempted to contact the study authors for more information, but so far, we have not been successful in doing this.

Study duration: June 2012 to June 2014

Duration of follow-up: 2 weeks

Setting: Hospital

Participants

All patients were confirmed with hepatic cell carcinoma through biopsy pathology, except for patients who could not receive surgical resection of liver cancer.

Age (mean \pm SD, range): TACE + RFA: $63 \pm 7$ years, 53-76 years; TACE alone: $63 \pm 6$ years, $53-74$ years

Male (n/total): TACE + RFA: 30/53; TACE alone: 31/53

Child-Pugh Class (patients):

Class A: TACE + RFA: 29; TACE: 28

Class B: TACE + RFA: 21 ; TACE: 20

Class C: TACE + RFA: 3; TACE: 5

Interventions $\quad$ TACE + RFA group $(n=53)$ :

The same TACE method was performed as that in control group. After completion, RFA was conducted, the patient's posture was set according to the puncture path under CT guidance, CT scan locating was performed, and a $15 \mathrm{G} \mathrm{RFA}$ needle and RITA $1500 \mathrm{RF}$ emitting device was used to treat the liver cancer lesions of patients. Lesion ablation temperature was set to $105^{\circ} \mathrm{C}$, the diameter of the ablation range might reach $5 \mathrm{~cm}$, and single point puncture and ablation range superposition in different directions were adopted.

$\operatorname{TACE}$ group $(\mathrm{n}=53)$ :

After ensuring that the catheter was in position, $40-80 \mathrm{mg}$ of cisplatin and $30-50 \mathrm{mg}$ of epirubicin was injected. Then, the emulsion of $20 \mathrm{mg}$ of pirarubicin $+5-20 \mathrm{~mL}$ of iodised oil mixture was injected.

Tumour activity-related indicators: measured at two weeks after treatment

Tumour recurrence-related indicators: measured at two weeks after treatment

Serum indicators for inflammation and oxidative stress

Country of study: China
Source of funding: National Natural Science Foundation of China (No.30670612); China Internation-
al Medical Foundation (No.Z-2014-06-15322); Navy Logistics Department (No.HJHQ-20130987)
There was insufficient information available to satisfactorily determine the method of randomisa-
tion and the study data could not be verified. We have attempted to contact the study authors for
more information, but so far, we have not been successful in doing this.


Study design: Randomised clinical trial

Study duration: January 2015 to June 2016

Duration of follow-up: 6 weeks

Setting: Hospital

Participants

Inclusion criteria: Willing to sign a written informed consent document; diagnosed as HCC; Karnofsky score $\geq 60$; life expectancy $>3$ months; no history of interventional treatment; no obvious fistula

Exclusion criteria: not suitable for TACE or MWA; with hepatic metastasis; with serious injuries of other organs; with abnormal haematopoietic function; with mental disorders; with concurrent other tumours

Age (mean \pm SD, range): TACE + MWA: $56.87 \pm 12.70$ years, $38-71$ years; TACE alone: $57.98 \pm 13.05$ years, 32-74 years

Male (n/total): TACE + MWA: 31/46; TACE alone: 28/46

Tumour diameter (mean \pm SD, range): TACE + MWA: $6.97 \pm 3.82 \mathrm{~cm}, 2.50-13.27 \mathrm{~cm}$; TACE: $7.32 \pm 4.05$ $\mathrm{cm}, 2.58-14.19 \mathrm{~cm}$.

TNM stage (patients):

Stage I : TACE + MWA: 8; TACE: 7

Stage II: TACE + MWA: 28; TACE: 26

Stage II : TACE + MWA: 10; TACE: 13

Child-Pugh Class (patients):

Class A: TACE + MWA: 20; TACE: 22

Class B: TACE + MWA: 26; TACE: 24

TACE: Chemotherapeutic drugs: oxaliplatin $130 \mathrm{mg} / \mathrm{m}^{2}$ and epirubicin $35 \mathrm{mg} / \mathrm{m}^{2}$.

MWA: Ultrasound-guided MWA. KV2000 system. Output power of $55 \mathrm{~W}$ and 6 minutes per MWA application

$\operatorname{TACE}$ group $(n=46)$ :

Chemotherapeutic drugs: oxaliplatin $130 \mathrm{mg} / \mathrm{m}^{2}$ andepirubicin $35 \mathrm{mg} / \mathrm{m}^{2}$

\begin{tabular}{ll}
\hline Outcomes & Serum level of AFP: measured at 3 and 6 weeks after treatment; \\
& Serum level of VEGF: measured at 3 and 6 weeks after treatment; \\
& Immune function: measured at 3 and 6 weeks after treatment; \\
\hline Notes & $\begin{array}{l}\text { Country of study: China } \\
\text { Source of funding: None } \\
\text { There was insufficient information available to satisfactorily determine the method of randomisa- } \\
\text { tion and the study data could not be verified. We have attempted to contact the study authors for } \\
\text { more information, but so far, we have not been successful in doing this. }\end{array}$ \\
\hline
\end{tabular}




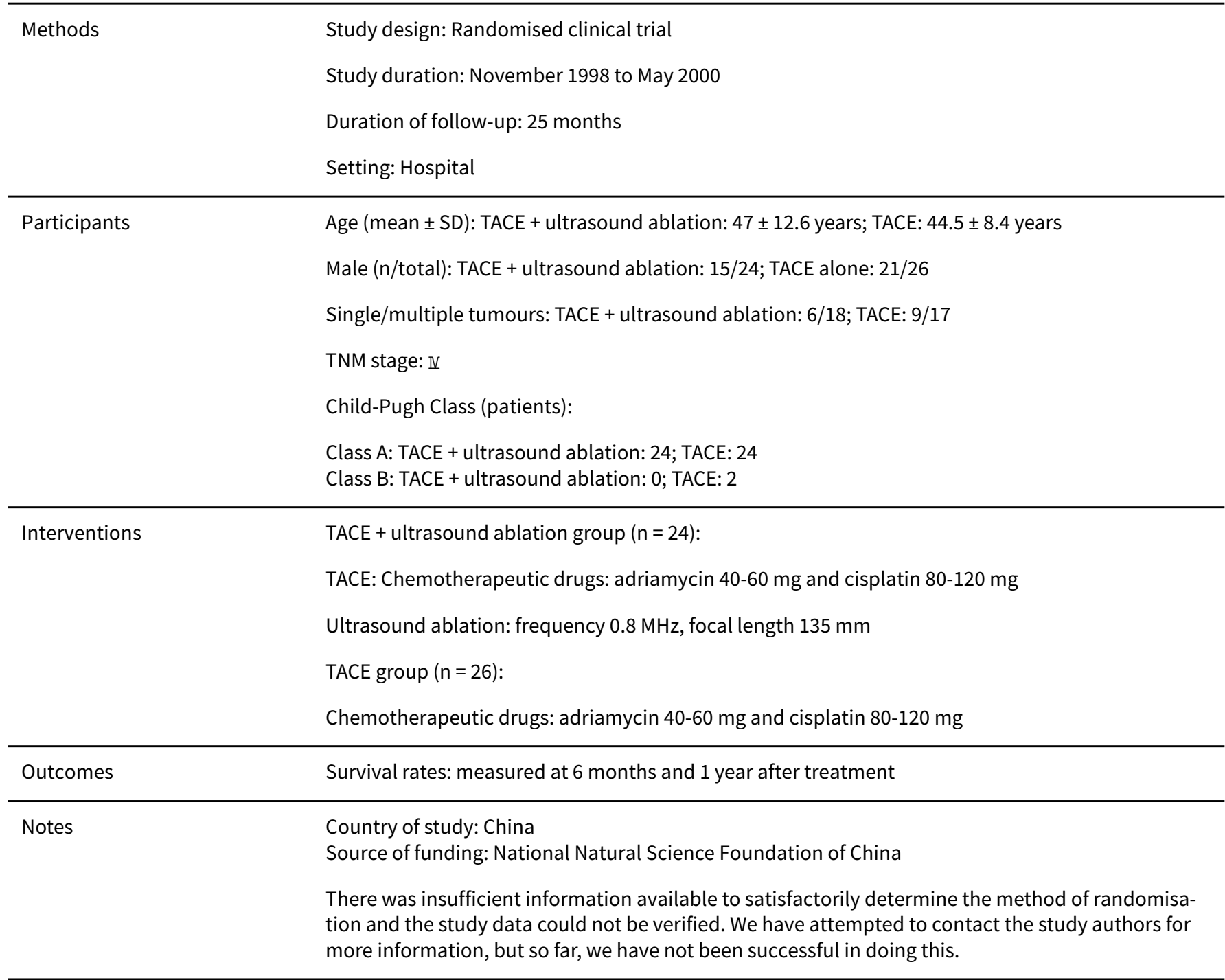

\section{Lai 2019}

\begin{tabular}{ll}
\hline Methods & Study design: Randomised clinical trial \\
& Study duration: March 2017 to March 2018 \\
& Duration of follow-up: 3 weeks \\
& Setting: Hospital \\
\hline Participants & Number of participants: 32 \\
& Inclusion criteria: Diagnosed as HCC; expected survival time $\geq 3$ months \\
\hline Interventions & TACE + MWA group ( $=24):$ \\
TACE: TACE comprised of hepatic arterial infusion chemotherapy and hepatic artery embolisation \\
Chemotherapeutic drugs: carboplatin 300 mg, and epirubicin 30 mg \\
MWA: The interval between TACE and MWA was 1-3 weeks. \\
\hline
\end{tabular}


Lai 2019 (Continued)

$$
\text { Control group }(n=8) \text { : }
$$

TACE comprised of hepatic arterial infusion chemotherapy and hepatic artery embolisation Chemotherapeutic drugs: carboplatin $300 \mathrm{mg}$, and epirubicin $30 \mathrm{mg}$

\begin{tabular}{ll}
\hline Outcomes & Immunological function (CD3, CD4, CD8, and NK cell): measured by blood testing \\
\hline Notes & $\begin{array}{l}\text { Country of study: China } \\
\text { Source of funding: None }\end{array}$ \\
& There was insufficient information available to satisfactorily determine the method of randomisa- \\
& tion and the study data could not be verified. We have attempted to contact the study authors for \\
& more information, but so far, we have not been successful in doing this.
\end{tabular}

Study duration: July 2006 to September 2010.

Duration of follow-up: 2 years

Setting: Hospital

Inclusion criteria: diagnosed as HCC by biopsy and images
Age (mean, range): TACE + ultrasound ablation: 55 years, 31-77 years; TACE: 53 years, 28-69 years
Male (n/total): TACE + ultrasound ablation: 24/33; TACE: 23/33
TNM stage (patients):
TNM II: TACE + ultrasound ablation: 10; TACE: 9
TNM III: TACE + ultrasound ablation: 15; TACE: 16
TNM IV: TACE + ultrasound ablation: 8; TACE: 7

Interventions $\quad$ TACE + ultrasound ablation group $(\mathrm{n}=33)$ :

TACE: TACE was performed 1-2 times. The average sessions of TACE treatment was 1.5 sessions.

Ultrasound ablation: The interval between TACE and ultrasound ablation was 2-3 weeks. Frequency of 0.8 or $1.6 \mathrm{MHz}$, output power of $250-400 \mathrm{~W}$, focal length of $135 \mathrm{~mm}$ and treatment duration of $436-8955 \mathrm{~s}$

$\operatorname{TACE}$ group $(\mathrm{n}=33)$ :

Chemotherapeutic drugs: pingyangmycin $8 \mathrm{mg}$. TACE was performed 1-3 times, with an interval of 3-4 weeks. The average sessions of TACE treatment was 2.3 sessions.

\begin{tabular}{ll}
\hline Outcomes & Serum level of AFP \\
& Liver function \\
& Survival rate: at 6 months and 1 year after treatment \\
\hline Notes & $\begin{array}{l}\text { Country of study: China } \\
\text { Source of funding: National important basic project (2011CB707905) }\end{array}$
\end{tabular}


There was insufficient information available to satisfactorily determine the method of randomisation and the study data could not be verified. We have attempted to contact the study authors for more information, but so far, we have not been successful in doing this.

Study design: Randomised clinical trial
Study duration: August 2013 to August 2014
Duration of follow-up: 1 month
Setting: Hospital

Participants

Inclusion criteria: Diagnosed by Standardisation of Diagnosis and Treatment for Hepatocellular Carcinoma (2011 edition); unsuitable for resection, unwilling to accept surgery or with tumour recurrence after hepatectomy; single tumour with diameter $\leq 5 \mathrm{~cm}$ or multiple tumours (number of tumours $<4$ and tumour diameter $\leq 3 \mathrm{~cm}$ ); no tumour thrombus in hepatic veins or portal veins; with liver function of Child-Pugh Class A or B; no extrahepatic metastasis; no antivascular drugs use history within 6 months; expected life time $>3$ months

Age (mean \pm SD): TACE + cryoablation: $52.2 \pm 3.2$ years; TACE alone: $49.8 \pm 3.2$ years

Male (n/total): TACE + cryoablation: 40/50; TACE alone: 36/50

Interventions $\quad$ TACE + cryoablation group $(n=50)$ :

TACE: Chemotherapeutic drugs: lobaplatin, $50 \mathrm{mg}$; epirubicin, $50 \mathrm{mg}$. 1-month treatment interval.

Cryoablation: CYROCARE-TM-24 system (Endocare)

TACE group $(n=50)$ :

Chemotherapeutic drugs: lobaplatin, 50 mg; epirubicin, 50 mg. 1-month treatment interval

\begin{tabular}{ll}
\hline Outcomes & Serum level of vascular endothelial growth factor: by using ELISA \\
\hline Notes & $\begin{array}{l}\text { Country of study: China } \\
\text { Source of funding: None } \\
\text { There was insufficient information available to satisfactorily determine the method of randomisa- } \\
\text { tion and the study data could not be verified. We have attempted to contact the study authors for } \\
\text { more information, but so far, we have not been successful in doing this. }\end{array}$ \\
\hline
\end{tabular}

\section{Li 2016a}

Methods

Study design: Randomised clinical trial

Study duration: April 2014 to April 2015

Duration of follow-up: Not reported

Setting: Hospital

Participants

Age (mean \pm SD, range): TACE + RFA: $46.38 \pm 11.54$ years, 35 - 81 years; TACE alone: $46.56 \pm 11.48$ years, 36-81 years

Male (n/total): TACE + RFA: 28/43; TACE alone: 29/42 
Li 2016 a (Continued)

Child-Pugh Class (patients):

Class A: TACE + RFA: 18; TACE: 19

Class B: TACE + RFA: 15; TACE: 16

Class C: TACE + RFA: 10; TACE: 7

Interventions $\quad$ TACE + RFA group $(n=43)$ :

TACE: Chemotherapeutic drugs: mitomycin $15 \mathrm{mg}$ and hydroxy camptothecin $15 \mathrm{mg} / \mathrm{m}^{2}$

RFA: The interval between TACE and RFA was 3-5 weeks.

TACE group $(n=42)$ :

Chemotherapeutic drugs: mitomycin $15 \mathrm{mg}$ and hydroxy camptothecin $15 \mathrm{mg} / \mathrm{m}^{2}$

\begin{tabular}{ll}
\hline Outcomes & Serum level of AFP \\
Liver function & Tumour diameter \\
& Adverse events \\
& Recurrence rate \\
\hline Notes & Sountry of study: China \\
& There was insufficient information available to satisfactorily determine the method of randomisa- \\
tion and the study data could not be verified. We have attempted to contact the study authors for \\
more information, but so far, we have not been successful in doing this.
\end{tabular}

\section{Li 2016b}

Study design: Randomised clinical trial
Study duration: January 2013 to December 2015
Duration of follow-up: Not reported
Setting: Hospital

Participants

Age (mean \pm SD): TACE + RFA: $58.7 \pm 6.3$ years; TACE alone: $58.5 \pm 6.2$ years

Male (n/total): TACE + RFA: 27/40; TACE alone: 26/40

Tumour diameter (mean \pm SD): TACE + RFA: $5.1 \pm 1.4 \mathrm{~cm}$; TACE : $5.0 \pm 1.3 \mathrm{~cm}$

Child-Pugh Class (patients):

Class A: TACE + RFA: 29; TACE: 28

Class B: TACE + RFA: 11; TACE: 12

TACE + RFA group $(n=40):$
TACE: Chemotherapeutic drugs: oxaliplatin $200 \mathrm{mg}$ and 5-fluorouracil $2 \mathrm{~g}$
RFA: The interval between TACE and RFA was 2 weeks. Output power of $60 \mathrm{~W}$
TACE group $(n=40):$

The combination of transcatheter arterial chemoembolisation (TACE) and thermal ablation versus TACE alone for hepatocellular 54 carcinoma (Review)

Copyright (c) 2021 The Cochrane Collaboration. Published by John Wiley \& Sons, Ltd. 


\begin{tabular}{ll}
\hline Outcomes & Tumour response: measured by image examinations \\
& Adverse events \\
\hline Notes & Country of study: China \\
Source of funding: None \\
There was insufficient information available to satisfactorily determine the method of randomisa- \\
tion and the study data could not be verified. We have attempted to contact the study authors for \\
more information, but so far, we have not been successful in doing this.
\end{tabular}

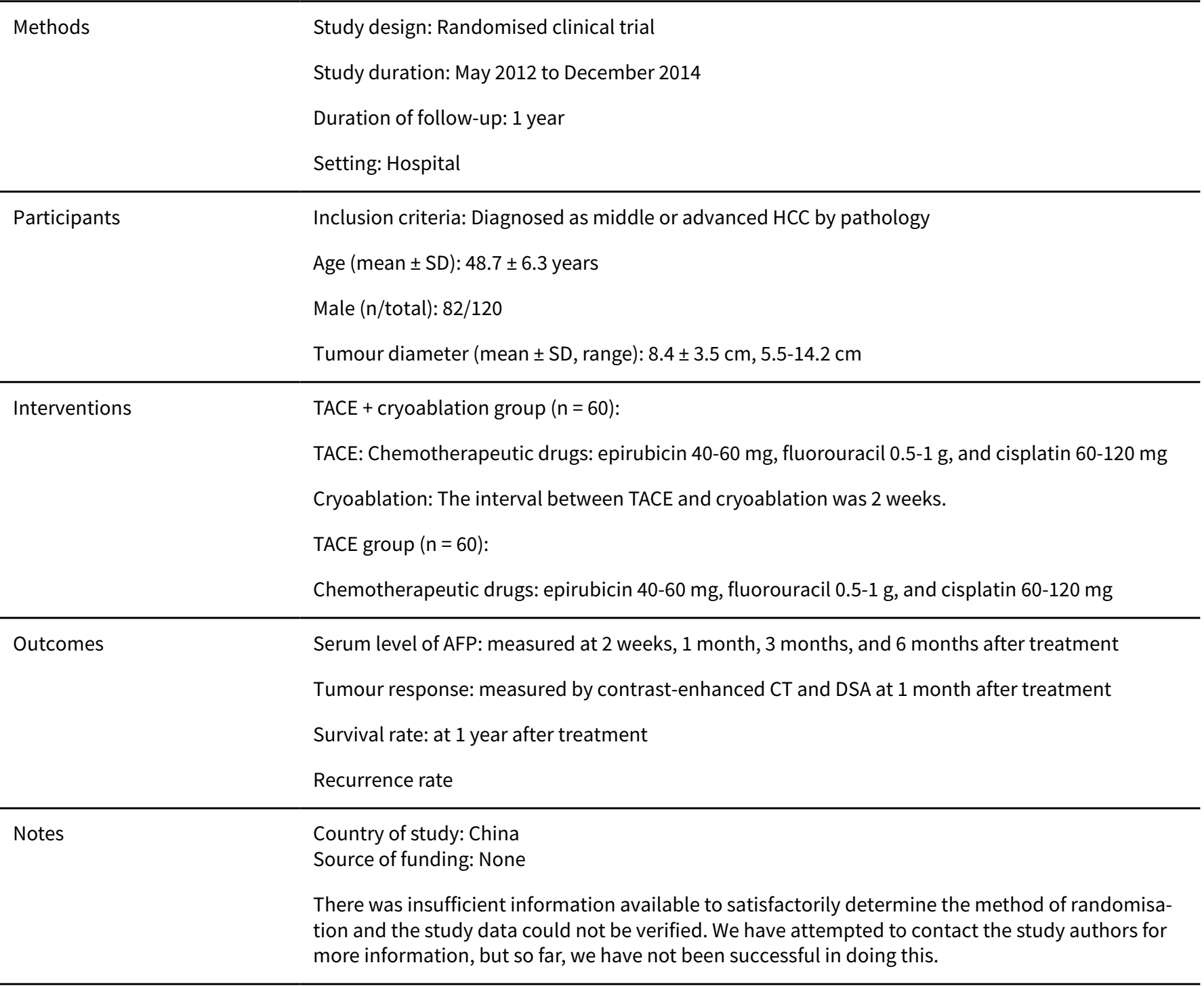




\begin{tabular}{ll}
\hline Methods & Study design: Randomised clinical trial \\
Study duration: February 2014 to February 2017 \\
Duration of follow-up: 1 year \\
Setting: Hospital
\end{tabular}

Participants

Inclusion criteria: Diagnosed as HCC by pathology

Exclusion criteria: Liver function of Child-Pugh Class C; history of gastrointestinal bleeding within 3 months; with extrahepatic metastasis; abnormal haematopoietic function; serious infection; inadequate lung, renal, and cardiac function

Age (mean \pm SD): TACE + MWA: $54.37 \pm 12.94$ years; TACE alone: $54.68 \pm 12.13$ years

Male (n/total): TACE + MWA: 26/36; TACE alone: 27/36

Tumour diameter (mean \pm SD, range): TACE + MWA: $3.74 \pm 1.10 \mathrm{~cm}, 1.12-7.45 \mathrm{~cm}$; TACE: $3.26 \pm 1.31$ $\mathrm{cm}, 1.30-7.39 \mathrm{~cm}$.

Child-Pugh Class (patients):

Class A: TACE + MWA: 28; TACE: 29

Class B: TACE + MWA: 8; TACE: 7

TACE: Chemotherapeutic drugs: oxaliplatin $10 \mathrm{~mL}$

MWA: CT-guided MWA

TACE group $(n=36)$ :

Chemotherapeutic drugs: oxaliplatin $10 \mathrm{~mL}$

Outcomes

Tumour response: Classified as complete necrosis and progression; measured at 6 months after treatment

Adverse events

Survival rate

Recurrence rate

Country of study: China
Source of funding: None
There was insufficient information available to satisfactorily determine the method of randomisa-
tion and the study data could not be verified. We have attempted to contact the study authors for
more information, but so far, we have not been successful in doing this.

\section{Li 2017c}

Methods $\begin{aligned} & \text { Study design: Randomised clinical trial } \\ & \text { Study duration: January } 2010 \text { to January } 2015 \\ & \text { Duration of follow-up: } 1 \text { year }\end{aligned}$

The combination of transcatheter arterial chemoembolisation (TACE) and thermal ablation versus TACE alone for hepatocellular 56 carcinoma (Review)

Copyright $\odot 2021$ The Cochrane Collaboration. Published by John Wiley \& Sons, Ltd. 
Li 2017c (Continued)

Setting: Hospital

$\begin{array}{ll}\text { Participants } & \text { Age }(\text { mean } \pm \mathrm{SD}): 61.3 \pm 2.5 \text { years } \\ & \text { Male }(\mathrm{n} / \text { total }): 100 / 186 \\ & \text { Tumour diameter (mean } \pm \mathrm{SD} \text {, range): } 5.2 \pm 1.4 \mathrm{~cm}, 4.5-8.7 \mathrm{~cm}\end{array}$

Interventions $\quad$ TACE + RFA group $(n=93)$

TACE: Chemotherapeutic drugs: cisplatin $50 \mathrm{mg}$, epirubicin $40 \mathrm{mg}$, and hydroxy camptothecin 30 $\mathrm{mg}$

RFA: The interval between TACE and RFA was 1 week.

TACE group $(\mathrm{n}=93)$ :

TACE: Chemotherapeutic drugs: cisplatin $50 \mathrm{mg}$, epirubicin $40 \mathrm{mg}$, and hydroxy camptothecin 30 $\mathrm{mg}$

Outcomes Tumour response: Classified as obvious effect, moderate effect, and no effect; measured at 12 months after treatment

Adverse events

Quality of life: assessed by QOL questionnaire; assessed at 1 year after treatment

Notes Country of study: China

Source of funding: None

There was insufficient information available to satisfactorily determine the method of randomisation and the study data could not be verified. We have attempted to contact the study authors for more information, but so far, we have not been successful in doing this.

\begin{tabular}{ll} 
Methods & Study design: Randomised clinical trial \\
Study duration: January 2016 to December 2016 \\
Duration of follow-up: 1 month \\
Setting: Hospital \\
\hline Inclusion criteria: Diagnosed as HCC; no serious hepatic disease; no history of liver resection \\
Exclusion criteria: Be allergic to chemotherapeutic drugs or lipiodol oil \\
Age (mean \pm SD, range): TACE + RFA: $51.7 \pm 1.1$ years, $39-67$ years; TACE: $51.8 \pm 1.2$ years, $38-69$ years \\
Male ( $n /$ total): TACE + RFA: $15 / 30 ;$ TACE alone: $14 / 30$ \\
TACE + RFA group ( $\mathrm{n}=30$ ): \\
Chemotherapeutic drugs: mitomycin 5 mg and theprubicin 20 mg \\
RFA: The interval between TACE and RFA was 2 weeks. CT-guided RFA \\
TACE group ( $\mathrm{n}=30$ ): \\
Chemotherapeutic drugs: mitomycin 5 mg and theprubicin 20 mg
\end{tabular}

The combination of transcatheter arterial chemoembolisation (TACE) and thermal ablation versus TACE alone for hepatocellular 
Li 2018 (Continued)

Outcomes Tumour response: measured by area of tumour; assessed at 1 month after treatment Immune function

\section{Notes}

Country of study: China
Source of funding: None

There was insufficient information available to satisfactorily determine the method of randomisation and the study data could not be verified. We have attempted to contact the study authors for more information, but so far, we have not been successful in doing this.

\section{Li 2019a}

Methods $\begin{aligned} & \text { Study design: Randomised clinical trial } \\ & \text { Study duration: June } 2012 \text { to June } 2015 \\ & \text { Duration of follow-up: } 3 \text { years } \\ & \text { Setting: Hospital }\end{aligned}$

\begin{tabular}{ll}
\hline Participants & Age (mean \pm SD, range ): TACE + RFA: $51.22 \pm 2.98$ years, 31-72 years; TACE: $53.46 \pm 3.0$ years, $29-69$ \\
years & Male (n/total): TACE + RFA: $27 / 41 ;$ TACE alone: $31 / 41$ \\
& Child-Pugh Class (patients): \\
& Class A: TACE + RFA: 20; TACE: 21 \\
Class B: TACE + RFA: 18; TACE: 15 & Class C: TACE + RFA: 3 ; TACE: 5
\end{tabular}

Interventions

TACE + RFA group $(n=41)$ :

TACE: A total of 1-3 sessions of TACE, with an interval of 3-4 weeks

RFA: The interval between TACE and RFA was 1 week. Ultrasound-guided RFA

$\operatorname{TACE}$ group $(n=41)$ :

A total of 1-3 sessions of TACE, with an interval of 3-4 weeks

\begin{tabular}{ll}
\hline Outcomes & Serum level of AFP \\
& Liver function \\
& Survival rate \\
& Tumour response: based on mRECIST criteria; measured by images \\
\hline Notes & Country of study: China \\
& Source of funding: None \\
& There was insufficient information available to satisfactorily determine the method of randomisa- \\
tion and the study data could not be verified. We have attempted to contact the study authors for \\
more information, but so far, we have not been successful in doing this.
\end{tabular}




\begin{tabular}{|c|c|}
\hline \multirow[t]{4}{*}{ Methods } & Study design: Randomised clinical trial \\
\hline & Study duration: January 2015 to January 2020 \\
\hline & Duration of follow-up: 3 years \\
\hline & Setting: Hospital \\
\hline \multirow[t]{4}{*}{ Participants } & Number of participants: 66 \\
\hline & $\begin{array}{l}\text { Inclusion criteria: Diagnosed as HCC; number of tumours < } 3 \text {; tumour diameter of 5-10 cm; unre- } \\
\text { sectable tumour }\end{array}$ \\
\hline & Age (mean \pm SD): TACE + MWA: $56.12 \pm 6.59$ years; TACE alone: $57.03 \pm 6.73$ years \\
\hline & Male (n/total): TACE + MWA: 18/33; TACE alone: 19/33 \\
\hline \multirow[t]{5}{*}{ Interventions } & TACE + MWA group $(n=33)$ : \\
\hline & $\begin{array}{l}\text { TACE: TACE comprised of hepatic arterial infusion chemotherapy and hepatic artery embolisation } \\
\text { Chemotherapeutic drugs: mitomycin } 4-10 \mathrm{mg} \text {, epirubicin } 10-50 \mathrm{mg} \text {, and cisplatin } 30-60 \mathrm{mg}\end{array}$ \\
\hline & MWA: Output power of $40-60 \mathrm{~Hz}, 6-9$ minutes per session \\
\hline & Control group $(n=33)$ : \\
\hline & $\begin{array}{l}\text { TACE comprised of hepatic arterial infusion chemotherapy and hepatic artery embolisation } \\
\text { Chemotherapeutic drugs: mitomycin 4-10 mg epirubicin } 10-50 \text { mg and cisplatin } 30-60 \text { mg }\end{array}$ \\
\hline \multirow[t]{2}{*}{ Outcomes } & Survival rates: measured at 1 and 3 years after treatment \\
\hline & AFP: blood testing \\
\hline \multirow[t]{2}{*}{ Notes } & $\begin{array}{l}\text { Country of study: China } \\
\text { Source of funding: None }\end{array}$ \\
\hline & $\begin{array}{l}\text { There was insufficient information available to satisfactorily determine the method of randomisa- } \\
\text { tion and the study data could not be verified. We have attempted to contact the study authors for } \\
\text { more information, but so far, we have not been successful in doing this. }\end{array}$ \\
\hline
\end{tabular}

\section{Lin 2017}

\begin{tabular}{ll} 
Methods & Study design: Randomised clinical trial \\
& Study duration: February 2016 to January 2017 \\
& Duration of follow-up: 3 months \\
& Setting: Hospital \\
\hline Participants & Inclusion criteria: No serious diseases in other organs; tumour numbers <3; no tumour thrombus in \\
& Age (mean \pm SD, range): TACE + RFA: $50.1 \pm 2.5$ years, $34-68$ years; TACE: $49.2 \pm 2.3$ years, $33-67$ years \\
& Male (n/total): TACE + RFA: $22 / 30 ;$ TACE alone: $21 / 30$ \\
& Child-Pugh Class (patients): \\
& Class A: TACE + RFA: 22; TACE: 21 \\
& Class B: TACE + RFA: 5; TACE: 6
\end{tabular}


Lin 2017 (Continued)

Class C: TACE + RFA: 3; TACE: 3

Interventions TACE + RFA group $(\mathrm{n}=30)$ :

TACE: Chemotherapeutic drugs: theprubicin $50 \mathrm{mg}$, mitomycin $10 \mathrm{mg}$, and cisplatin $50 \mathrm{mg}$

RFA: The interval between TACE and RFA was 2 weeks. Output power of $200 \mathrm{~W}$. Total treatment time of 10-30 minutes

$\operatorname{TACE}$ group $(\mathrm{n}=30)$ :

Chemotherapeutic drugs: theprubicin $50 \mathrm{mg}$, mitomycin $10 \mathrm{mg}$, and cisplatin $50 \mathrm{mg}$

\begin{tabular}{ll}
\hline Outcomes & Tumour necrosis: measured by DSA or CT \\
& Tumour recurrence \\
\hline Notes & $\begin{array}{l}\text { Funding source: None } \\
\text { Conducted in China }\end{array}$ \\
& $\begin{array}{l}\text { There was insufficient information available to satisfactorily determine the method of randomisa- } \\
\text { tion and the study data could not be verified. We have attempted to contact the study authors for } \\
\text { more information, but so far, we have not been successful in doing this. }\end{array}$ \\
\hline
\end{tabular}

Liu $2016 a$

\begin{tabular}{ll} 
Methods & Study design: Randomised clinical trial \\
& Study duration: January 2012 to September 2013 \\
& Duration of follow-up: 2 years \\
& Setting: Hospital \\
\hline Inclusion criteria: Tumour diameter $>5 \mathrm{~cm}$; tumour numbers $\leq 4$; liver function of Child-Pugh Class \\
A and B; willing to sign a written informed consent document \\
Exclusion criteria: Not suitable for TACE or MWA; with history of liver function or liver transplanta- \\
tion \\
Age (mean \pm SD, range): TACE + MWA: $58.74 \pm 7.06$ years, $35-81$ years; TACE alone: $58.26 \pm 7.31$ years, \\
34-79 years \\
Male ( $n /$ total): TACE + MWA: 43/62; TACE alone: $45 / 62$
\end{tabular}

Interventions

TACE + MWA group $(n=62)$ :

TACE: Chemotherapeutic drugs: cisplatin 40-60 mg and 5-fluorouracil 0.75-1 g

MWA: The interval between TACE and RFA was 2-4 weeks. Multiple sessions of MWA were performed with an interval of 2 weeks.

$\operatorname{TACE}$ group $(\mathrm{n}=62)$ :

Chemotherapeutic drugs: cisplatin 40-60 mg and 5-fluorouracil 0.75-1 g

Outcomes Tumour response: based on WHO criteria; measured at 4 weeks after treatment

Survival rates

Notes Country of study: China

The combination of transcatheter arterial chemoembolisation (TACE) and thermal ablation versus TACE alone for hepatocellular 
Liu 2016a (Continued)

\section{Source of funding: None}

There was insufficient information available to satisfactorily determine the method of randomisation and the study data could not be verified. We have attempted to contact the study authors for more information, but so far, we have not been successful in doing this.

\section{Liu 2017}

Study design: Randomised clinical trial
Study duration: March 2013 to March 2014
Duration of follow-up: 6 months
Setting: Hospital

\section{Participants}

Age (mean $\pm S D$, range): $52.8 \pm 7.2$ years, $36-68$ years

Male (n/total): 53/72

Tumour diameter (mean \pm SD, range): $6.8 \pm 2.4 \mathrm{~cm}, 3-10.6 \mathrm{~cm}$

BCLC stage (patients):

Stage A: 27; Stage B: 30; Stage C: 15

Child-Pugh Class (patients):

Stage A: 40; Stage B: 32

TACE: Chemotherapeutic drugs: cisplatin 100 mg, epirubicin 100 mg, mitomycin 20 mg

MWA: The interval between TACE and RFA was 1-3 weeks. Output power of 55-70 W, 6-12 minutes per MWA application

TACE group $(n=36)$ :

Chemotherapeutic drugs: cisplatin $100 \mathrm{mg}$, epirubicin $100 \mathrm{mg}$, mitomycin $20 \mathrm{mg}$

\begin{tabular}{ll}
\hline Outcomes & Tumour response: measured by contrast-enhanced CT \\
& Serum level of AFP \\
& Survival rate \\
& Adverse events \\
\hline Notes & $\begin{array}{l}\text { Country of study: China } \\
\text { Source of funding: None } \\
\text { There was insufficient information available to satisfactorily determine the method of randomisa- } \\
\text { tion and the study data could not be verified. We have attempted to contact the study authors for } \\
\text { more information, but so far, we have not been successful in doing this. }\end{array}$ \\
\hline
\end{tabular}


Liu 2018b (Continued)

Study duration: January 2015 to Novermber 2016

Duration of follow-up: 3 months

Setting: Hospital

Participants

Age (mean \pm SD, range): TACE + MWA: $54.3 \pm 3.64$ years, $31-81$ years; TACE alone: $54.32 \pm 3.68$ years, 30-82 years

Male (n/total): TACE + MWA: 28/40; TACE alone: 26/40

Interventions

TACE + MWA group $(n=40)$ :

TACE: Chemotherapeutic drugs: epirubicin

MWA: The interval between TACE and MWA was 2 weeks. Output power of 40-70 W, 6-8 minutes per MWA session

TACE group $(n=40)$ :

Chemotherapeutic drugs: epirubicin

\begin{tabular}{ll}
\hline Outcomes & Serum level of AFP \\
& Quality of life: measured by KPS score; measured at 3 months after treatment \\
& Serum level of VEGF \\
& Adverse events \\
\hline Notes & $\begin{array}{l}\text { Country of study: China } \\
\text { Source of funding: None } \\
\text { There was insufficient information available to satisfactorily determine the method of randomisa- } \\
\text { tion and the study data could not be verified. We have attempted to contact the study authors for } \\
\text { more information, but so far, we have not been successful in doing this. }\end{array}$
\end{tabular}

Liu 2019b

\begin{tabular}{ll}
\hline Methods & Study design: Randomised clinical trial \\
Study duration: January 2014 to December 2018 \\
Duration of follow-up: 1 month \\
Setting: Hospital \\
\hline
\end{tabular}

Participants

Number of participants: 100

Inclusion criteria: Diagnosed as HCC

Age (mean \pm SD, range ): TACE + RFA: $43.6 \pm 3.7$ years; TACE alone: $42.8 \pm 3.2$ years

Male (n/total): TACE + RFA: 26/50; TACE alone: 29/50

Interventions

TACE + RFA group $(n=50)$ :

TACE: TACE comprised of hepatic arterial infusion chemotherapy and hepatic artery embolisation Chemotherapeutic drugs: 5-fluorouracil 40-60 mg, cisplatin 40-60 mg, and epirubicin 10-30 mg

RFA: CT-guided

The combination of transcatheter arterial chemoembolisation (TACE) and thermal ablation versus TACE alone for hepatocellular 
Liu 2019b (Continued)

$$
\text { Control group }(n=50) \text { : }
$$

TACE comprised of hepatic arterial infusion chemotherapy and hepatic artery embolisation Chemotherapeutic drugs: 5-fluorouracil 30-40 mL, cisplatin 40-60 mg, and epirubicin 10-30 mg

\begin{tabular}{ll}
\hline Outcomes & Tumour response: measured by contrast-enhanced CT at 1 month after treatment \\
\hline Notes & $\begin{array}{l}\text { Country of study: China } \\
\text { Source of funding: None } \\
\text { There was insufficient information available to satisfactorily determine the method of randomisa- } \\
\text { tion and the study data could not be verified. We have attempted to contact the study authors for } \\
\text { more information, but so far, we have not been successful in doing this. }\end{array}$ \\
\end{tabular}

\section{Liu $2019 c$}

\begin{tabular}{|c|c|}
\hline \multirow[t]{4}{*}{ Methods } & Study design: Randomised clinical trial \\
\hline & Study duration: January 2012 to December 2013 \\
\hline & Duration of follow-up: 5 years \\
\hline & Setting: Hospital \\
\hline \multirow[t]{4}{*}{ Participants } & Number of participants: 83 \\
\hline & Inclusion criteria: Diagnosed as HCC \\
\hline & Age (mean \pm SD, range ): TACE + RFA: $57.1 \pm 7.5$ years; TACE alone: $55.3 \pm 7.1$ years \\
\hline & Male (n/total): TACE + RFA: 25/41; TACE alone: 25/42 \\
\hline \multirow[t]{2}{*}{ Interventions } & TACE + RFA group $(n=41)$ \\
\hline & Control group $(n=42)$ \\
\hline \multirow[t]{3}{*}{ Outcomes } & Tumour response: measured by contrast-enhanced CT at 1 month after treatment \\
\hline & Survival rates: measured at 1,3 , and 5 years after treatment \\
\hline & Liver function and the level of AFP: measured by blood testing \\
\hline \multirow[t]{2}{*}{ Notes } & $\begin{array}{l}\text { Country of study: China } \\
\text { Source of funding: None }\end{array}$ \\
\hline & $\begin{array}{l}\text { There was insufficient information available to satisfactorily determine the method of randomisa- } \\
\text { tion and the study data could not be verified. We have attempted to contact the study authors for } \\
\text { more information, but so far, we have not been successful in doing this. }\end{array}$ \\
\hline
\end{tabular}

\section{Liu 2019d}

\section{Methods}

Study design: Randomised clinical trial

Study duration: January 2016 to January 2018

Duration of follow-up: 3 months 
Liu 2019d (Continued)

\section{Setting: Hospital}

\begin{tabular}{|c|c|}
\hline \multirow[t]{4}{*}{ Participants } & Number of participants: 76 \\
\hline & Inclusion criteria: Diagnosed as HCC; advanced tumour; Child-Pugh Class A or B \\
\hline & Age (mean \pm SD, range ): TACE + MWA: $58.4 \pm 4.5$ years; TACE alone: $58.2 \pm 4.4$ years \\
\hline & Male (n/total): TACE + MWA: 27/38; TACE alone: $26 / 38$ \\
\hline \multirow[t]{2}{*}{ Interventions } & TACE + MWA group $(n=38)$ \\
\hline & Control group $(n=38)$ \\
\hline Outcomes & Tumour response: measured by contrast-enhanced CT at 4 and 12 weeks after treatment \\
\hline \multirow[t]{2}{*}{ Notes } & $\begin{array}{l}\text { Country of study: China } \\
\text { Source of funding: None }\end{array}$ \\
\hline & $\begin{array}{l}\text { There was insufficient information available to satisfactorily determine the method of randomisa- } \\
\text { tion and the study data could not be verified. We have attempted to contact the study authors for } \\
\text { more information, but so far, we have not been successful in doing this. }\end{array}$ \\
\hline
\end{tabular}

\section{Liu 2020}

\begin{tabular}{|c|c|}
\hline \multirow[t]{4}{*}{ Methods } & Study design: Randomised clinical trial \\
\hline & Study duration: January 2018 to April 2019 \\
\hline & Duration of follow-up: 1 month \\
\hline & Setting: Hospital \\
\hline \multirow[t]{4}{*}{ Participants } & Number of participants: 72 \\
\hline & Inclusion criteria: Diagnosed as HCC; expected survival time $>6$ months; Child-Pugh Class A or B \\
\hline & Age (mean \pm SD, range ): TACE + MWA: $52.61 \pm 10.04$ years; TACE alone: $51.49 \pm 10.14$ years \\
\hline & Male (n/total): TACE + MWA: 29/36; TACE alone: $27 / 36$ \\
\hline \multirow[t]{2}{*}{ Interventions } & TACE + MWA group $(n=36)$ \\
\hline & Control group $(n=36)$ \\
\hline \multirow[t]{2}{*}{ Outcomes } & Tumour response: measured by contrast-enhanced CT at 1 month after treatment \\
\hline & Immunological function: measured by blood testing \\
\hline \multirow[t]{2}{*}{ Notes } & $\begin{array}{l}\text { Country of study: China } \\
\text { Source of funding: None }\end{array}$ \\
\hline & $\begin{array}{l}\text { There was insufficient information available to satisfactorily determine the method of randomisa- } \\
\text { tion and the study data could not be verified. We have attempted to contact the study authors for } \\
\text { more information, but so far, we have not been successful in doing this. }\end{array}$ \\
\hline
\end{tabular}

The combination of transcatheter arterial chemoembolisation (TACE) and thermal ablation versus TACE alone for hepatocellular 


\begin{tabular}{|c|c|}
\hline Methods & $\begin{array}{l}\text { Study design: Randomised clinical trial } \\
\text { Study duration: October } 2014 \text { to October } 2017 \\
\text { Duration of follow-up: Not reported } \\
\text { Setting: Hospital }\end{array}$ \\
\hline Interventions & $\begin{array}{l}\text { TACE + RFA group }(\mathrm{n}=40) \text { : } \\
\text { TACE: Chemotherapeutic drugs: mitomycin } 10-20 \mathrm{mg} \text {, cisplatin } 40-80 \mathrm{mg} \text {, and 5-fluorouracil 0.5-1 g } \\
\text { RFA: The interval between TACE and RFA was } 2 \text { weeks. Total treatment time of } 30 \text { minutes } \\
\text { TACE group }(\mathrm{n}=40) \text { : } \\
\text { Chemotherapeutic drugs: mitomycin } 10-20 \mathrm{mg} \text {, cisplatin } 40-80 \mathrm{mg} \text {, and 5-fluorouracil } 0.5-1 \mathrm{~g}\end{array}$ \\
\hline Outcomes & $\begin{array}{l}\text { Tumour response: Classified as obvious effect, moderate effect, and no effect } \\
\text { Duration of hospital stay } \\
\text { Quality of life }\end{array}$ \\
\hline Notes & $\begin{array}{l}\text { Country of study: China } \\
\text { Source of funding: None } \\
\text { There was insufficient information available to satisfactorily determine the method of randomisa- } \\
\text { tion and the study data could not be verified. We have attempted to contact the study authors for } \\
\text { more information, but so far, we have not been successful in doing this. }\end{array}$ \\
\hline
\end{tabular}

Luo 2019

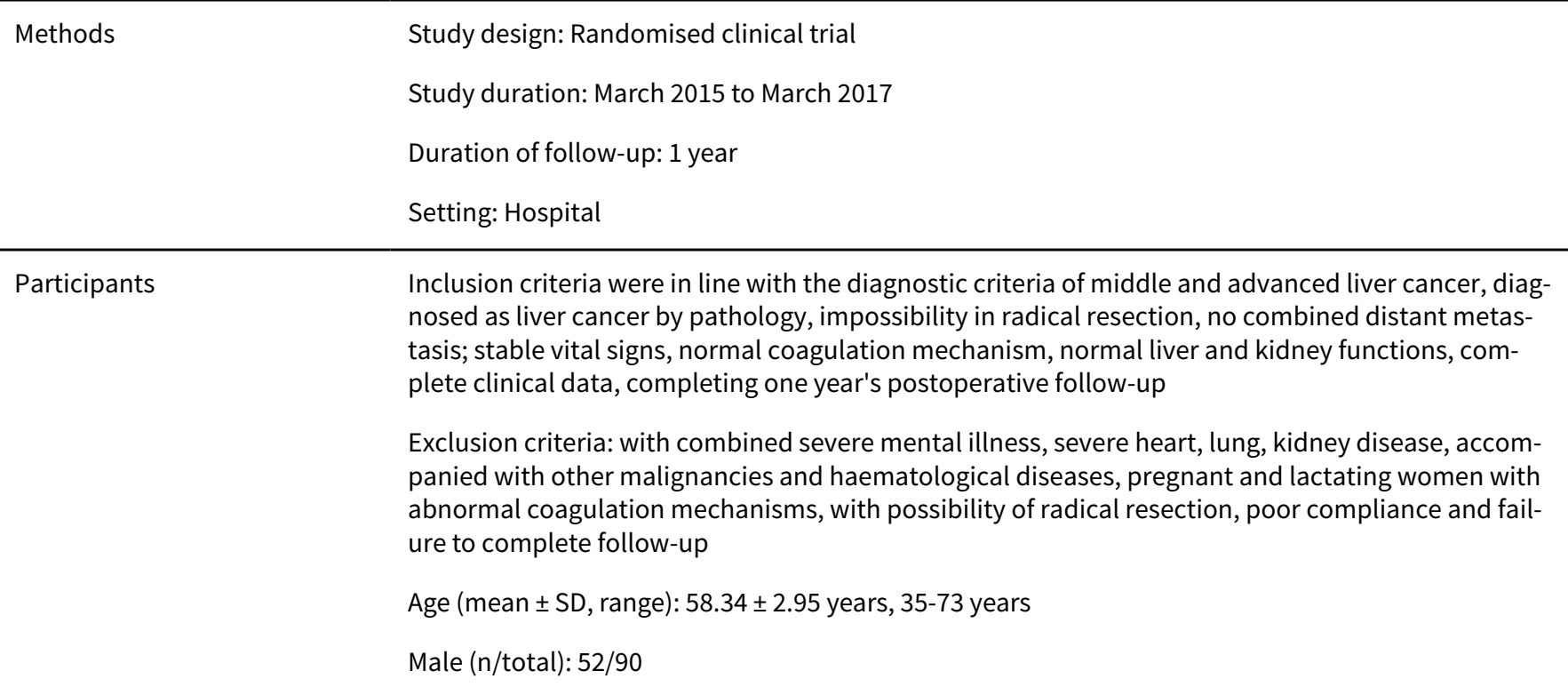

The combination of transcatheter arterial chemoembolisation (TACE) and thermal ablation versus TACE alone for hepatocellular 
Luo 2019 (Continued)

Interventions

TACE + HIFU group $(n=45)$ :

HIFU was performed 2-4 weeks after TACE treatment. The parameters of HIFU tumour treatment system were: frequency $0.8 \mathrm{MHz}$, focal length $150 \mathrm{~mm}$ and treatment duration 4946-16223 s. The therapeutic range and therapeutic dose were adjusted by monitoring B-mode ultrasound images during the treatment.

Forty-five patients were treated with HIFU for at least 2 times and up to 6 times, with an average of 3.16 times.

TACE group $(n=45)$ :

The chemotherapy drugs included 5-fluorouracil $1.0 \mathrm{~g}$ and epirubicin $30 \mathrm{mg}$ ( $10 \mathrm{mg}$ of which was mixed with an appropriate amount of ultra-liquid iodised oil to form emulsion). The dose of lipiodol emulsion varied depending on the size of the lesion and intraoperative tolerability of the patient, with an average dose at $10.5 \mathrm{~mL}$. TACE treatment was performed 1-2 times depending on the patient's tolerability, with intervals of 3-4 weeks.

\begin{tabular}{ll}
\hline Outcomes & $\begin{array}{l}\text { Tumour response: After six months of treatment, the efficacy was evaluated according to WHO cri- } \\
\text { teria. }\end{array}$ \\
Liver function & Adverse events \\
Recurrence rate & $\begin{array}{l}\text { Country of study: China } \\
\text { Source of funding: None } \\
\text { There was insufficient information available to satisfactorily determine the method of randomisa- } \\
\text { tion and the study data could not be verified. We have attempted to contact the study authors for } \\
\text { more information, but so far, we have not been successful in doing this. }\end{array}$ \\
\end{tabular}

Duration of follow-up: 2 years

Setting: Hospital

Participants

Age (mean \pm SD, range): TACE + RFA: $52.25 \pm 2.12$ years, $34-76$ years; TACE alone: $52.61 \pm 2.13$ years, 34-77 years

Male (n/total): TACE + RFA: 27/30; TACE: 25/30

Interventions

TACE + RFA group $(n=30)$ :

TACE: Chemotherapeutic drugs: 5-fluorouracil 0.5-1 g, hydroxy camptothecin $10 \mathrm{~g}$, and epirubicin 10-40 mg. Total sessions of TACE ranged between 1-3, with an interval of 4-5 weeks.

RFA: The interval between TACE and RFA was 3-4 weeks. CT-guided RFA

$\operatorname{TACE}$ group $(\mathrm{n}=30)$ :

Chemotherapeutic drugs: 5-fluorouracil 0.5-1 g, hydroxy camptothecin $10 \mathrm{~g}$, and epirubicin 10-40 $\mathrm{mg}$. Total sessions of TACE ranged between 1-3, with an interval of 4-5 weeks.

The combination of transcatheter arterial chemoembolisation (TACE) and thermal ablation versus TACE alone for hepatocellular carcinoma (Review)

Copyright (C) 2021 The Cochrane Collaboration. Published by John Wiley \& Sons, Ltd. 
Lv 2016 (Continued)

Outcomes
Serum level of AFP

Tumour response, classified as complete response, partial response, stable, and progression

2-year survival rate

Adverse events

Source of funding: None

There was insufficient information available to satisfactorily determine the method of randomisation and the study data could not be verified. We have attempted to contact the study authors for more information, but so far, we have not been successful in doing this.

Ma 2017

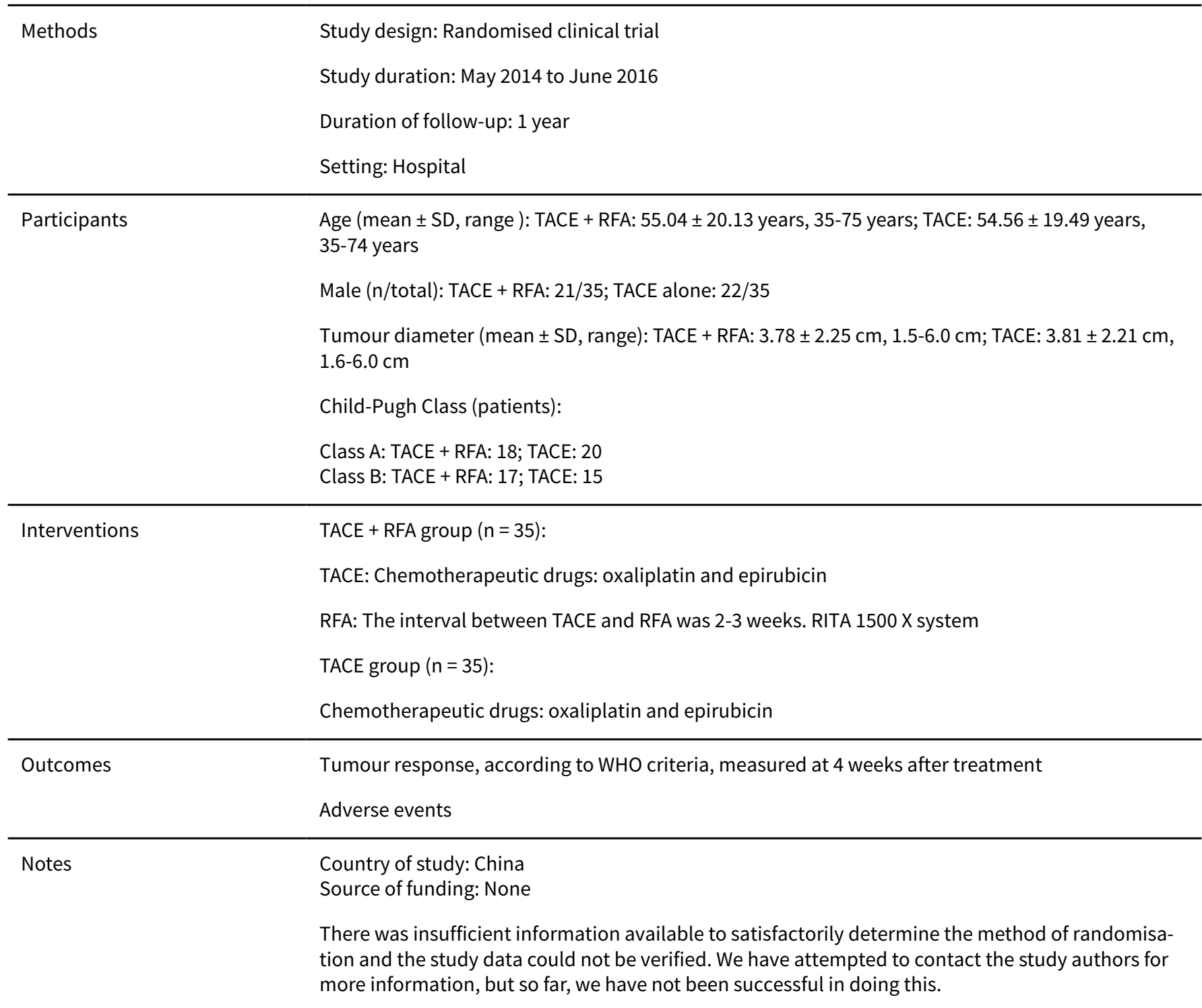

The combination of transcatheter arterial chemoembolisation (TACE) and thermal ablation versus TACE alone for hepatocellular 
Ma 2019a

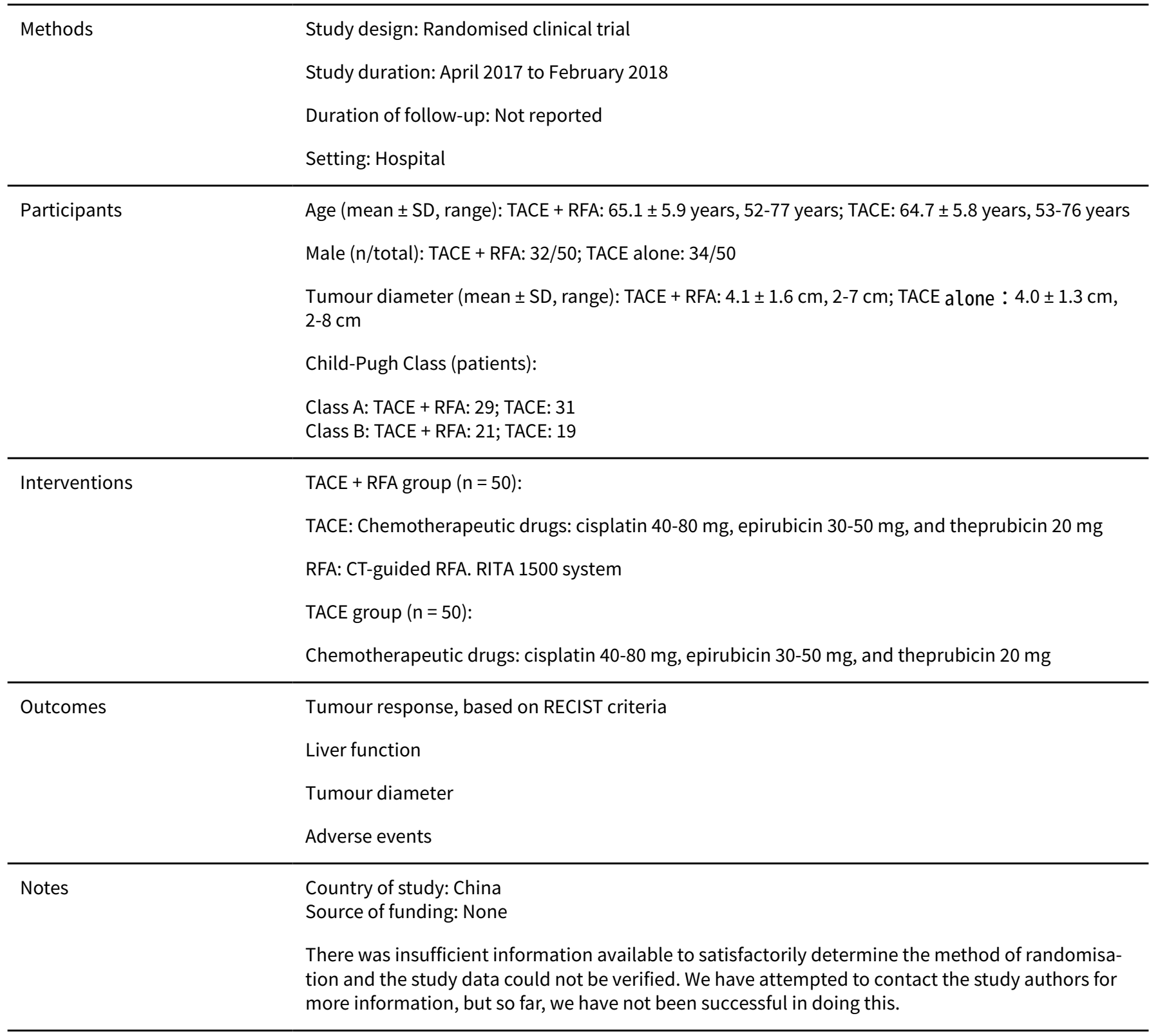

Ma 2019b

\begin{tabular}{ll}
\hline Methods & Study design: Randomised clinical trial \\
& Study duration: January 2013 to February 2016 \\
& Duration of follow-up: 2 years \\
\hline Participants & Age (mean \pm SD): TACE + MWA: $53.72 \pm 8.72$ years; TACE alone: $53.24 \pm 8.45$ years \\
& Male (n/total): TACE + MWA: 26/41; TACE alone: $24 / 41$ \\
& Tumour diameter (mean \pm SD): TACE + MWA: $49.82 \pm 11.27 \mathrm{~mm}$; TACE: $50.15 \pm 11.62 \mathrm{~mm}$ \\
\hline Interventions & TACE + MWA group: \\
\hline
\end{tabular}

The combination of transcatheter arterial chemoembolisation (TACE) and thermal ablation versus TACE alone for hepatocellular 
TACE: Chemotherapeutic drugs: oxaliplatin $100 \mathrm{mg}$. 1-2 sessions of TACE, with an interval of 4 weeks

RFA: The interval between TACE and RFA was 1 week. CT-guided RFA

TACE group:

Chemotherapeutic drugs: oxaliplatin $100 \mathrm{mg}$. 1-2 sessions of TACE, with an interval of 4 weeks

\begin{tabular}{ll}
\hline Outcomes & Tumour response: measured by CT image \\
& Survival rate \\
& Recurrence rate \\
\hline Notes & $\begin{array}{l}\text { Country of study: China } \\
\text { Source of funding: None } \\
\text { There was insufficient information available to satisfactorily determine the method of randomisa- } \\
\text { tion and the study data could not be verified. We have attempted to contact the study authors for } \\
\text { more information, but so far, we have not been successful in doing this. }\end{array}$ \\
\end{tabular}

\begin{tabular}{ll}
\hline Methods & Study design: Randomised clinical trial \\
Study duration: January 2017 to December 2019 \\
Duration of follow-up: 1 month \\
Setting: Hospital
\end{tabular}

Inclusion criteria: Diagnosed as HCC; no metastasis; no history of other anti-cancer treatments

Age (mean \pm SD): TACE + MWA: $58.75 \pm 7.65$ years; TACE alone: $55.65 \pm 8.17$ years

Male (n/total): TACE + MWA: 30/43; TACE alone: 28/43

Interventions $\quad$ TACE + MWA group $(n=43)$ :

TACE: TACE comprised of hepatic arterial infusion chemotherapy and hepatic artery embolisation Chemotherapeutic drugs: theprubicin

MWA: The interval between TACE and MWA was 2 weeks. Output power of 40-60 W

Control group $(n=43)$ :

TACE comprised of hepatic arterial infusion chemotherapy and hepatic artery embolisation Chemotherapeutic drugs: theprubicin

Outcomes

Tumour response: measured by contrast-enhanced CT at 1 month after treatment

Adverse events: measured at 1 month after treatment

TBIL, DBIL, and ALT: measured by blood testing

$\begin{array}{ll}\text { Notes } & \text { Country of study: China } \\ \text { Source of funding: None }\end{array}$

The combination of transcatheter arterial chemoembolisation (TACE) and thermal ablation versus TACE alone for hepatocellular 
There was insufficient information available to satisfactorily determine the method of randomisation and the study data could not be verified. We have attempted to contact the study authors for more information, but so far, we have not been successful in doing this.

\section{Mo 2017}

Methods
Study design: Randomised clinical trial
Study duration: May 2011 to May 2013
Setting: Hospital

Participants

Inclusion criteria: Diagnosed as primary liver cancer; aged $\geq 18$ years; with liver function of ChildPugh A or B; unsuitable for resection or unwilling to accept surgery; abnormal haematopoietic function; no portal vein tumour thrombus; no extrahepatic metastasis.

Exclusion criteria: Intrahepatic dissemination; huge liver cancer with intrahepatic or extrahepatic metastasis; with liver, cardiac, or kidney function damage; with the liver function of Child-Pugh Class C; inadequate haematopoietic function; with systematic infection; allergic to contrast agent

Male (n/total): TACE + RFA: 39/61; TACE alone: 35/56

Child-Pugh Class (patients):

Class A: TACE + RFA: 28; TACE: 20

Class B: TACE + RFA: 33; TACE: 36

\section{Interventions}

TACE + RFA group $(n=61)$ :

TACE: Chemotherapeutic drugs: theprubicin, 5-fluorouracil, and oxaliplatin

RFA: The interval between TACE and RFA was 2-4 weeks. CT/Ultrasound-guided RFA, with the ablation margin of $5-10 \mathrm{~mm}$

TACE group $(n=56)$ :

Chemotherapeutic drugs: theprubicin, 5-fluorouracil, and oxaliplatin. A total of 1-3 sessions of TACE, with an interval of $1-2$ months

\section{Outcomes}

Serum level of AFP, VEGF, and CA-199

Tumour response, according to the mRECIST criteria

1-, 2-, and 3-year survival rates

$\begin{array}{ll}\text { Notes } & \text { Country of study: China } \\ \text { Source of funding: None }\end{array}$

There was insufficient information available to satisfactorily determine the method of randomisation and the study data could not be verified. We have attempted to contact the study authors for more information, but so far, we have not been successful in doing this. 
Pan 2016 (Continued)

Study duration: February 2012 to February 2013

Duration of follow-up: 3 years

Setting: Hospital

Participants

Age (mean \pm SD, range): TACE + RFA: $55.4 \pm 11.7$ years, $29-75$ years; TACE alone: $53.3 \pm 10.8$ years, 28-53 years

Male (n/total): TACE + RFA: 29/56; TACE alone: 32/56

Tumour diameter: TACE + RFA: $2.5-11 \mathrm{~cm}$; TACE: $2-10 \mathrm{~cm}$

\begin{tabular}{|c|c|}
\hline \multirow[t]{5}{*}{ Interventions } & TACE + RFA group $(n=56)$ : \\
\hline & TACE: Chemotherapeutic drugs: epirubicin $60 \mathrm{mg}$ and carboplatin $300 \mathrm{mg}$ \\
\hline & RFA: The interval between TACE and RFA was 1 week. LDRF-12S system. CT-guided RFA \\
\hline & TACE group $(n=56)$ : \\
\hline & Chemotherapeutic drugs: epirubicin $60 \mathrm{mg}$ and carboplatin $300 \mathrm{mg}$ \\
\hline \multirow[t]{3}{*}{ Outcomes } & Tumour response, according to WHO criteria \\
\hline & 6-month recurrence rate \\
\hline & 1-, 2-, and 3-year survival rates \\
\hline \multirow[t]{2}{*}{ Notes } & $\begin{array}{l}\text { Country of study: China } \\
\text { Source of funding: None }\end{array}$ \\
\hline & $\begin{array}{l}\text { There was insufficient information available to satisfactorily determine the method of randomisa- } \\
\text { tion and the study data could not be verified. We have attempted to contact the study authors for } \\
\text { more information, but so far, we have not been successful in doing this. }\end{array}$ \\
\hline
\end{tabular}

Peng 2017

\begin{tabular}{ll} 
Methods & Study design: Randomised clinical trial \\
& Study duration: December 2013 to June 26 \\
& Duration of follow-up: 1 month \\
& Setting: Hospital \\
\hline Participants & Age (mean \pm SD, range): $65.5 \pm 3.5$ years, 21-80 years \\
& Male (n/total): $34 / 64$ \\
\hline Interventions & TACE + MWA group ( $=32):$ \\
& TACE: Chemotherapeutic drugs: cisplatin 30-60 mg, mitomycin 4-10 mg, and adriamycin 10-50 mg. \\
MWA: DSA/CT-guided MWA. Frequency of 40-60 Hz, 6-10 minutes per MWA session \\
TACE group ( $n=32):$ \\
Chemotherapeutic drugs: cisplatin 30-60 mg, mitomycin 4-10 mg, and adriamycin 10-50 mg
\end{tabular}

The combination of transcatheter arterial chemoembolisation (TACE) and thermal ablation versus TACE alone for hepatocellular 71 
Peng 2017 (Continued)

Outcomes
Tumour response, classified as complete response, partial response, stable disease, and progression, measured at 4 weeks after treatment

Adverse events

Liver function

2-year survival rate and metastasis rate

Country of study: China

Source of funding: Maoming Medical Project

There was insufficient information available to satisfactorily determine the method of randomisation and the study data could not be verified. We have attempted to contact the study authors for more information, but so far, we have not been successful in doing this.

Study design: Randomised clinical trial
Study duration: January 2009 to January 2013
Duration of follow-up: 6 months
Setting: Hospital

Participants Inclusion criteria: Diagnosed as HCC by biopsy or images

Exclusion criteria: Inadequate haematopoietic function; with history of other tumours; abnormal immune function; platelet less than $5 \times 10 \% / \mathrm{L}$

Age (mean $\pm S D$, range ): $58.2 \pm 6.2$ years, $47-75$ years

Tumour diameter (range): $5.1-7.3 \mathrm{~cm}$

Interventions $\quad$ TACE + RFA group $(n=40)$ :

TACE: Chemotherapeutic drugs: 5-fluorouracil $2 \mathrm{~g}$ and oxaliplatin $200 \mathrm{mg}$

RFA: The interval between TACE and RFA was 2 weeks. Output power of $60 \mathrm{~W}$, ablation margin of 1 $\mathrm{cm}$

$\operatorname{TACE}$ group $(n=40)$ :

Chemotherapeutic drugs: 5-fluorouracil $2 \mathrm{~g}$ and oxaliplatin $200 \mathrm{mg}$

Outcomes Serum level of AFP and CEA, measured at 3 days, 7 days, and 21 days after treatment

Tumour response, measured at 6 months after treatment

Recurrence rate

Survival rate, measured at 6 months after treatment

There was insufficient information available to satisfactorily determine the method of randomisation and the study data could not be verified. We have attempted to contact the study authors for more information, but so far, we have not been successful in doing this.

The combination of transcatheter arterial chemoembolisation (TACE) and thermal ablation versus TACE alone for hepatocellular carcinoma (Review)

Copyright (c) 2021 The Cochrane Collaboration. Published by John Wiley \& Sons, Ltd. 
Study duration: April 2012 to April 2014

Duration of follow-up: 1 month

Setting: Hospital

Participants

Age (mean \pm SD, range ): TACE + RFA: $58.8 \pm 13.4$ years, $45-77$ years; TACE: $59.3 \pm 15.7$ years, $47-75$ years

Male (n/total): TACE + RFA: 26/50; TACE alone: 28/50

Tumour diameter $($ mean \pm SD): TACE + RFA: $3.9 \pm 1.7 \mathrm{~cm}$; TACE: $3.6 \pm 1.9 \mathrm{~cm}$

TACE: Chemotherapeutic drugs: 5-fluorouracil $1 \mathrm{~g}$ and oxaliplatin $100 \mathrm{mg}$

RFA: The interval between TACE and RFA was 6 weeks. Output power of 50-120 W, 12-16 minutes per RFA session

TACE group $(n=50)$ :

Chemotherapeutic drugs: 5-fluorouracil $1 \mathrm{~g}$ and oxaliplatin $100 \mathrm{mg}$

\begin{tabular}{ll}
\hline Outcomes & Serum level of brain-derived neurotrophic factor \\
& Tumour response, according to the RECIST criteria, measured at 4 weeks after treatment \\
& Adverse events \\
\hline Notes & $\begin{array}{l}\text { Country of study: China } \\
\text { Source of funding: National Natural Science Foundation of China, No. } 81172365\end{array}$ \\
& $\begin{array}{l}\text { There was insufficient information available to satisfactorily determine the method of randomisa- } \\
\text { tion and the study data could not be verified. We have attempted to contact the study authors for } \\
\text { more information, but so far, we have not been successful in doing this. }\end{array}$ \\
\hline
\end{tabular}

Shen 2015

Methods

Study design: Randomised clinical trial

Study duration: January 2012 to November 2013

Duration of follow-up: 2 years

Setting: Hospital

Participants

Age (mean $\pm S D$, range): $40.23 \pm 8.23$ years, $32-59$ years

Male (n/total): 66/96

Tumour diameter (mean \pm SD, range): $6.23 \pm 2.45 \mathrm{~cm}, 2.5-11.4 \mathrm{~cm}$

Child-Pugh Class (patients):

Child-A 50, Child-B 40, Child-C 6 
Shen 2015 (Continued)

Interventions $\quad$ TACE + RFA group $(n=48)$ :

TACE: TACE comprised of hepatic arterial infusion chemotherapy and hepatic artery embolisation

RFA: The interval between TACE and RFA was 2-4 weeks. In total of 20-30 minutes

TACE group $(n=48)$ :

TACE comprised of hepatic arterial infusion chemotherapy and hepatic artery embolisation

\begin{tabular}{ll}
\hline Outcomes & Tumour response, according to RECIST criteria, measured at 6 months \\
& 1- and 2- year survival rates \\
& Adverse events \\
\hline Notes & $\begin{array}{l}\text { Country of study: China } \\
\text { Source of funding: None } \\
\text { There was insufficient information available to satisfactorily determine the method of randomisa- } \\
\text { tion and the study data could not be verified. We have attempted to contact the study authors for } \\
\text { more information, but so far, we have not been successful in doing this. }\end{array}$ \\
\hline
\end{tabular}

\section{Shen 2020}

\begin{tabular}{|c|c|}
\hline \multirow[t]{4}{*}{ Methods } & Study design: Randomised clinical trial \\
\hline & Study duration: January 2015 to February 2017 \\
\hline & Duration of follow-up: 2 years \\
\hline & Setting: Hospital \\
\hline \multirow[t]{4}{*}{ Participants } & Number of participants: 67 \\
\hline & Inclusion criteria: Diagnosed as HCC \\
\hline & Age (mean \pm SD): TACE + RFA: $59.62 \pm 5.05$ years; TACE alone: $59.63 \pm 5.02$ years \\
\hline & Male (n/total): TACE + MWA: 21/33; TACE alone: $24 / 34$ \\
\hline \multirow[t]{2}{*}{ Interventions } & TACE + RFA group $(n=33)$ \\
\hline & Control group $(n=34)$ \\
\hline \multirow[t]{2}{*}{ Outcomes } & Sleep: measured by a score system for sleeping \\
\hline & Survival rates and recurrence: measured at 2 years after treatment \\
\hline \multirow[t]{2}{*}{ Notes } & $\begin{array}{l}\text { Country of study: China } \\
\text { Source of funding: None }\end{array}$ \\
\hline & $\begin{array}{l}\text { There was insufficient information available to satisfactorily determine the method of randomisa- } \\
\text { tion and the study data could not be verified. We have attempted to contact the study authors for } \\
\text { more information, but so far, we have not been successful in doing this. }\end{array}$ \\
\hline
\end{tabular}

The combination of transcatheter arterial chemoembolisation (TACE) and thermal ablation versus TACE alone for hepatocellular 


\begin{tabular}{ll}
\hline Methods & Study design: Randomised clinical trial \\
& Study duration: January 2008 to June 2012 \\
Duration of follow-up: 3 years \\
Setting: Hospital
\end{tabular}

Participants

Inclusion criteria: Diagnosed as HCC by images; no history of liver resection, liver transplantation, and ablation; with liver function of Child-Pugh Class A or B; maximal tumour diameter $>5 \mathrm{~cm}$; tumour number $<5$; willing to sign a written informed consent document

Exclusion criteria: With history of upper gastrointestinal bleeding; with abnormal haematopoietic function; with liver function of Child-Pugh C; with liver abscess or biliary system infection

Age (mean \pm SD, range): TACE + MWA: $56.7 \pm 8.5$ years, $32-86$ years; TACE: $57.6 \pm 7.6$ years, 33-85 years

Male (n/total): TACE + MWA: 32/50; TACE alone: 33/50

Tumour diameter (mean \pm SD, range): TACE + MWA: $8.45 \pm 2.34 \mathrm{~cm}, 5-15 \mathrm{~cm}$; TACE: $9.25 \pm 3.15 \mathrm{~cm}$, $5.2-16.3 \mathrm{~cm}$

Child-Pugh Class (patients):

Class A: TACE + MWA: 34; TACE: 35

Class B: TACE + MWA: 16; TACE: 15

Interventions

TACE + MWA group $(n=50)$ :

TACE: Chemotherapeutic drugs: 5-fluorouracil $1 \mathrm{mg}$ and oxaliplatin $120 \mathrm{mg}$

MWA: The interval between TACE and RFA was 2-4 weeks. Ultrasound-guided MWA. In total of 6-10 minutes per MWA session, with the ablation margin of $1 \mathrm{~cm}$

TACE group $(n=50)$ :

Chemotherapeutic drugs: 5-fluorouracil $1 \mathrm{mg}$ and oxaliplatin $120 \mathrm{mg}$

\begin{tabular}{ll}
\hline Outcomes & $\begin{array}{l}\text { Tumour response, classified as complete response, partial response, stable disease, and progres- } \\
\text { sion }\end{array}$ \\
Adverse events \\
1-, 2-, and 3-year survival rates \\
\hline Country of study: China \\
Source of funding: None \\
There was insufficient information available to satisfactorily determine the method of randomisa- \\
tion and the study data could not be verified. We have attempted to contact the study authors for \\
more information, but so far, we have not been successful in doing this.
\end{tabular}

Song 2018

$\begin{array}{ll}\text { Methods } & \text { Study design: Randomised clinical trial } \\ \text { Study duration: January } 2016 \text { to January } 2017 \\ \text { Duration of follow-up: } 6 \text { months }\end{array}$

The combination of transcatheter arterial chemoembolisation (TACE) and thermal ablation versus TACE alone for hepatocellular 75 carcinoma (Review)

Copyright $\odot 2021$ The Cochrane Collaboration. Published by John Wiley \& Sons, Ltd. 
Song 2018 (Continued)

\section{Setting: Hospital}

Participants Age (mean \pm SD, range): TACE + MWA: $53.01 \pm 4.54$ years; TACE alone: $53.64 \pm 3.65$ years

Male (n/total): TACE + MWA: 19/24; TACE alone: 20/24

TACE + MWA group $(n=24):$
TACE: Chemotherapeutic drugs: epirubicin 20-80 mg and oxaliplatin 100-150 mg. One to three ses-
sions of TACE were performed for each patient.
MWA: The interval between TACE and MWA was 2-4 weeks. Output power of 40-60 W, 15-20 minutes
per MWA session
TACE group ( $n=24):$
Chemotherapeutic drugs: epirubicin 20-80 mg and oxaliplatin 100-150 mg. One to three sessions of
TACE were performed for each patient.
Tumour response
Survival rate at 0.5 year after treatment
Serum level of AFP
Country of study: China
Source of funding: None
There was insufficient information available to satisfactorily determine the method of randomisa-
tion and the study data could not be verified. We have attempted to contact the study authors for
more information, but so far, we have not been successful in doing this.

\section{Song 2019}

Methods

Study design: Randomised clinical trial

Study duration: March 2015 to February 2016

Duration of follow-up: 2 years

Setting: Hospital

Participants

Inclusion criteria: Diagnosed as HCC by images; be willing to sign a written informed consent document

Age (mean \pm SD, range): TACE + RFA: $57.86 \pm 5.42$ years, $25-70$ years; TACE alone: $57.96 \pm 5.85$ years, 26-71 years

Male (n/total): TACE + RFA: 19/32; TACE alone: 20/32

Interventions

TACE + RFA group $(n=32)$ :

TACE: TACE comprised of hepatic arterial infusion chemotherapy and hepatic artery embolisation

RFA: CT-guided RFA. Multiple RFA treatments were performed for each patient, with an interval of 1-2 weeks

TACE group $(n=32)$ :

TACE comprised of hepatic arterial infusion chemotherapy and hepatic artery embolisation

The combination of transcatheter arterial chemoembolisation (TACE) and thermal ablation versus TACE alone for hepatocellular carcinoma (Review)

Copyright $\odot 2021$ The Cochrane Collaboration. Published by John Wiley \& Sons, Ltd. 
Song 2019 (Continued)

Outcomes

Serum level of AFP

Tumour diameter

1- and 2-year survival rate

\section{Notes}

Country of study: China

Source of funding: None

There was insufficient information available to satisfactorily determine the method of randomisation and the study data could not be verified. We have attempted to contact the study authors for more information, but so far, we have not been successful in doing this.

\section{Tong 2018}

\begin{tabular}{ll}
\hline Methods & Study design: Randomised clinical trial \\
Study duration: July 2014 to July 2016 \\
Duration of follow-up: 2 weeks \\
Setting: Hospital
\end{tabular}

Participants Inclusion criteria: Diagnosed as HCC, at TNM II-II stage; with no history of chemotherapy or radiotherapy; be willing to sign a written informed consent document

Exclusion criteria: With serious disease of other organs; with mental disease; abnormal haematopoietic or immune function

Age (mean \pm SD, range): TACE + RFA: $62.34 \pm 7.4$ years, $52-75$ years; TACE: $62.14 \pm 7.5$ years, 53-75 years

Male (n/total): TACE + RFA: 33/54; TACE alone: 32/54

TNM stage (patients):

TNMII : TACE + RFA: 38; TACE: 37

TNMIII : TACE + RFA:16, TACE:17

Child-Pugh Class (patients):

Class A: TACE + RFA: 34; TACE: 35

Class B: TACE + RFA: 20; TACE: 19

TACE: Chemotherapeutic drugs: cisplatin 40-80 mg, theprubicin $20 \mathrm{mg}$, and epirubicin 30-50 mg

RFA: The interval between TACE and RFA was 2-4 weeks. CT-guided RFA. RITA 1550 system

TACE group $(n=54)$ :

Chemotherapeutic drugs: cisplatin 40-80 mg, theprubicin $20 \mathrm{mg}$, and epirubicin 30-50 mg

\section{Outcomes}

Serum level of VEGF and MMP

Serum level of AFP, CA-199, and GGT

Tumour response, according to RECIST criteria, measured at 2 weeks after treatment 
Tong 2018 (Continued)

Notes
Country of study: China

Source of funding: None

There was insufficient information available to satisfactorily determine the method of randomisation and the study data could not be verified. We have attempted to contact the study authors for more information, but so far, we have not been successful in doing this.

Wang 2013

$\begin{array}{ll}\text { Methods } & \text { Study design: Randomised clinical trial } \\ \text { Study duration: March } 2008 \text { to March } 2010 \\ \text { Duration of follow-up: } 3 \text { years } \\ \text { Setting: Hospital }\end{array}$

Participants Inclusion criteria: Unresectable HCC; tumour number $\leq 4$; tumour maximal diameter $\leq 10 \mathrm{~cm}$; Karnofsky score $\geq 70$; with liver function of Child-Pugh Class A or B; without inferior vena cava or portal vein tumour thrombus; with no extrahepatic metastasis

Child-Pugh Class (patients): Class A: 41, Class B: 23

Interventions TACE + RFA group $(n=35)$ :

TACE: Chemotherapeutic drugs: mitomycin 4-10 mg, carboplatin 25-100 mg, and adriamycin 10-30 mg. In total, 2-3 sessions of TACE were performed for each patient, with an interval of 3-4 weeks.

RFA: The interval between TACE and RFA was 2 weeks. 10-15 minutes per RFA session

TACE group $(n=29)$ :

Chemotherapeutic drugs: mitomycin 4-10 mg, carboplatin 25-100 mg, and adriamycin 10-30 mg. In total, 2-3 sessions of TACE were performed for each patient, with an interval of 3-4 weeks.

\begin{tabular}{ll}
\hline Outcomes & Tumour response, according to WHO criteria \\
$1-, 2-$, and 3-year survival rates & Adverse events \\
\hline Notes & Country of study: China \\
Source of funding: None & $\begin{array}{l}\text { There was insufficient information available to satisfactorily determine the method of randomisa- } \\
\text { tion and the study data could not be verified. We have attempted to contact the study authors for } \\
\text { more information, but so far, we have not been successful in doing this. }\end{array}$
\end{tabular}

Study design: Randomised clinical trial
Study duration: January 2008 to June 2011
Duration of follow-up: 3 years
Setting: Hospital

The combination of transcatheter arterial chemoembolisation (TACE) and thermal ablation versus TACE alone for hepatocellular 
Wang 2015a (Continued)

Participants
Age (mean \pm SD): TACE + RFA: $52.97 \pm 9.23$ years; TACE alone: $51.68 \pm 9.87$ years

Male (n/total): TACE + RFA: 36/45; TACE alone: 32/45

Child-Pugh Class (patients):

Class A: TACE + RFA: 26; TACE: 29

Class B: TACE + RFA: 19; TACE: 16

Interventions TACE + RFA group $(n=45)$ :

TACE: Chemotherapeutic drugs: 5-fluorouracil 1-1.5 g, oxaliplatin 80-100 mg, and adriamycin 10-20 $\mathrm{mg}$. In total, 3 sessions of TACE were performed, with an interval of 4 weeks.

RFA: The interval between TACE and RFA was 2 weeks. Output power of 100-150 W, 30-60 minutes per RFA treatment

TACE group $(n=45)$ :

Chemotherapeutic drugs: 5-fluorouracil 1-1.5 g, oxaliplatin 80-100 mg, and adriamycin 10-20 mg. In total, 3 sessions of TACE were performed, with an interval of 4 weeks.

Outcomes

Tumour response, according to WHO criteria, measured at 4 months after treatment

Serum level of ALT, AST, TBIL, and $\gamma$ GT

Serum level of AFP, CEA, CA-199, and VEGF

1-year and 3-year survival rate

Notes Country of study: China

Source of funding: None

There was insufficient information available to satisfactorily determine the method of randomisation and the study data could not be verified. We have attempted to contact the study authors for more information, but so far, we have not been successful in doing this.

\begin{tabular}{|c|c|}
\hline \multirow[t]{4}{*}{ Methods } & Study design: Randomised clinical trial \\
\hline & Study duration: January 2011 to September 2014 \\
\hline & Duration of follow-up: 6 months \\
\hline & Setting: Hospital \\
\hline
\end{tabular}

Participants Inclusion criteria: Diagnosed as HCC by images and pathology

Exclusion criteria: Abnormal haematopoietic and immune function; with other tumours

Age (mean \pm SD): TACE + RFA: $58.6 \pm 6.2$ years; TACE alone: $58.3 \pm 6.5$ years

Male (n/total): TACE + RFA: 32/50; TACE alone: 31/50

Tumour diameter (mean \pm SD): TACE + RFA: $5.1 \pm 1.2 \mathrm{~cm}$, TACE: $5.0 \pm 1.3 \mathrm{~cm}$

TNM stage (patients):

Stage I : TACE + RFA: 13; TACE: 13

StageII : TACE + RFA: 31 ; TACE: 30

The combination of transcatheter arterial chemoembolisation (TACE) and thermal ablation versus TACE alone for hepatocellular carcinoma (Review)

Copyright (c) 2021 The Cochrane Collaboration. Published by John Wiley \& Sons, Ltd. 
Wang 2015b (Continued)

StageII : TACE + RFA: 6; TACE: 7

Child-Pugh Class (patients):

Class A: TACE + RFA: 36; TACE: 35

Class B: TACE + RFA: 14; TACE: 15

\begin{tabular}{|c|c|}
\hline \multirow[t]{5}{*}{ Interventions } & TACE + RFA group $(n=50)$ : \\
\hline & TACE: Chemotherapeutic drugs: 5-fluorouracil $2 \mathrm{~g}$ and oxaliplatin $200 \mathrm{mg}$ \\
\hline & $\begin{array}{l}\text { RFA: The interval between TACE and RFA was } 2 \text { weeks. Output power of } 60 \mathrm{~W} \text {, ablation margin of } 1 \\
\mathrm{~cm}\end{array}$ \\
\hline & TACE group $(n=50)$ : \\
\hline & Chemotherapeutic drugs: 5-fluorouracil $2 \mathrm{~g}$ and oxaliplatin $200 \mathrm{mg}$ \\
\hline \multirow[t]{4}{*}{ Outcomes } & $\begin{array}{l}\text { Tumour response, classified as complete response, partial response, stable disease, and progres- } \\
\text { sion }\end{array}$ \\
\hline & 6-month survival rate \\
\hline & 6-month recurrence rate \\
\hline & Adverse events \\
\hline \multirow[t]{2}{*}{ Notes } & $\begin{array}{l}\text { Country of study: China } \\
\text { Source of funding: None }\end{array}$ \\
\hline & $\begin{array}{l}\text { There was insufficient information available to satisfactorily determine the method of randomisa- } \\
\text { tion and the study data could not be verified. We have attempted to contact the study authors for } \\
\text { more information, but so far, we have not been successful in doing this. }\end{array}$ \\
\hline
\end{tabular}

Wang 2017a

\begin{tabular}{ll} 
Methods & Study design: Randomised clinical trial \\
& Study duration: January 2015 to December 2015 \\
& Duration of follow-up: Not reported \\
& Setting: Hospital \\
\hline Inclusion criteria: Diagnosed as HCC by pathology; expected survival > 3 months; Karnofsky score $\geq$ \\
70 \\
Exclusion criteria: With cognitive disorder; with abnormal liver, renal, or cardiac function \\
Age (mean \pm SD, range): TACE + RFA: $53.42 \pm 4.1$ years, $39-79$ years; TACE alone: $53.25 \pm 4.09$ years, \\
44-78 years \\
Male (n/total): TACE + RFA: $28 / 42 ;$ TACE alone: $26 / 42$
\end{tabular}

TACE + RFA group $(n=42)$ :

TACE: Chemotherapeutic drugs: cisplatin $50 \mathrm{mg}$, epirubicin $30 \mathrm{mg}$, and mitomycin $10 \mathrm{mg}$

RFA: Radio Therapeutics TMRF 2000 system

TACE group $(n=42)$ : 
Wang 2017a (Continued)

Chemotherapeutic drugs: cisplatin $50 \mathrm{mg}$, epirubicin $30 \mathrm{mg}$, and mitomycin $10 \mathrm{mg}$

\begin{tabular}{ll}
\hline Outcomes & Serum level of ALT \\
& Serum level of AFP \\
& Tumour response, classified as complete response, partial response, stable disease, and progres- \\
sion & Adverse events \\
Notes & $\begin{array}{l}\text { Country of study: China } \\
\text { There was insufficient information available to satisfactorily determine the method of randomisa- } \\
\text { tion and the study data could not be verified. We have attempted to contact the study authors for } \\
\text { more information, but so far, we have not been successful in doing this. }\end{array}$
\end{tabular}

Wang 2017b

\begin{tabular}{ll}
\hline Methods & Study design: Randomised clinical trial \\
& Study duration: October 2014 to October 2016 \\
& Duration of follow-up: Not reported \\
& Setting: Hospital \\
\hline Participants & Age (mean \pm SD, range): TACE + RFA: $52.07 \pm 2.12$ years, $34-75$ years; TACE alone: $52.13 \pm 2.16$ years, \\
& Male (n/total): TACE + RFA: $21 / 36$; TACE alone: $21 / 36$ \\
\hline
\end{tabular}

Interventions

$\operatorname{TACE}+\operatorname{RFA}$ group $(\mathrm{n}=36)$ :

TACE: Chemotherapeutic drugs: theprubicin $20 \mathrm{mg}$, oxaliplatin $150 \mathrm{mg}$, and mitomycin $8 \mathrm{mg}$

RFA: Ultrasould-guided RFA.

$\operatorname{TACE}$ group $(\mathrm{n}=36)$ :

Chemotherapeutic drugs: theprubicin $20 \mathrm{mg}$, oxaliplatin $150 \mathrm{mg}$, and mitomycin $8 \mathrm{mg}$

\begin{tabular}{ll} 
Outcomes & $\begin{array}{l}\text { Tumour response, classified as complete response, partial response, stable disease, and progres- } \\
\text { sion }\end{array}$ \\
& Adverse events \\
\hline Notes & Country of study: China \\
Source of funding: None & \\
There was insufficient information available to satisfactorily determine the method of randomisa- \\
tion and the study data could not be verified. We have attempted to contact the study authors for \\
more information, but so far, we have not been successful in doing this.
\end{tabular}

Wang 2017c

Methods Study design: Randomised clinical trial

The combination of transcatheter arterial chemoembolisation (TACE) and thermal ablation versus TACE alone for hepatocellular carcinoma (Review)

Copyright (c) 2021 The Cochrane Collaboration. Published by John Wiley \& Sons, Ltd. 
Wang 2017c (Continued)

Study duration: May 2012 to September 2014

Duration of follow-up: 2 years

Setting: Hospital

Participants

Inclusion criteria: Diagnosed as HCC by pathology and images; single tumour, with tumour diameter $\leq 5 \mathrm{~cm}$ or multiple tumours $(\leq 3)$ with tumour diameter $\leq 3 \mathrm{~cm}$; AFP $>200 \mu \mathrm{g} / \mathrm{L}$; with liver function of Child-Pugh Class A or B; unwilling to receive liver resection

Exclusion criteria: With the tumour near major vessels or organs; serious hypertension; tumour diameter $\geq 5 \mathrm{~cm}$; with disseminated metastasis; abnormal haematopoietic function; with liver function of Child-Pugh Class C

Age (mean \pm SD, range): TACE + RFA: $50.13 \pm 8.75$ years, 28-65 years; TACE: $49.47 \pm 9.13$ years, 31-66 years

Male (n/total): TACE + RFA: 28/36; TACE alone: 26/36

\begin{tabular}{|c|c|}
\hline \multirow[t]{4}{*}{ Interventions } & $\begin{array}{l}\text { TACE + RFA group }(n=36) \text { : } \\
\text { TACE: Chemotherapeutic drugs: 5-fluorouracil 1-1.5 g, oxaliplatin 50-100 mg, and adriamycin 20-40 } \\
\text { mg }\end{array}$ \\
\hline & RFA: The interval between TACE and RFA was 4 weeks. Ablation margin of 5-10 mm \\
\hline & TACE group $(n=36)$ : \\
\hline & Chemotherapeutic drugs: 5-fluorouracil 1-1.5 g, oxaliplatin 50-100 mg, and adriamycin 20-40 mg \\
\hline \multirow[t]{3}{*}{ Outcomes } & Serum level of AFP \\
\hline & 1- and 2-year survival rates \\
\hline & Adverse events \\
\hline \multirow[t]{2}{*}{ Notes } & $\begin{array}{l}\text { Country of study: China } \\
\text { Source of funding: None }\end{array}$ \\
\hline & $\begin{array}{l}\text { There was insufficient information available to satisfactorily determine the method of randomisa- } \\
\text { tion and the study data could not be verified. We have attempted to contact the study authors for } \\
\text { more information, but so far, we have not been successful in doing this. }\end{array}$ \\
\hline
\end{tabular}

Wang 2017d

\begin{tabular}{ll}
\hline Methods & Study design: Randomised clinical trial \\
& Study duration: October 2012 to July 2016 \\
& Duration of follow-up: Not reported \\
& Setting: Hospital \\
\hline Participants & Age (mean \pm SD, range): TACE + RFA: $55.9 \pm 5.72$ years, $43-70$ years; TACE: $56.2 \pm 5.02$ years, $45-68$ \\
& years \\
& Male ( $n /$ total): TACE + RFA: $13 / 20 ;$ TACE alone: $11 / 20$ \\
\hline Interventions & TACE + RFA group ( $=20):$ \\
& TACE: Chemotherapeutic drugs: cisplatin 50 mg, mitomycin 8 mg, and adriamycin 10 mg
\end{tabular}

The combination of transcatheter arterial chemoembolisation (TACE) and thermal ablation versus TACE alone for hepatocellular 
Wang 2017d (Continued)

RFA: The interval between TACE and RFA was 2 weeks. 15-20 minutes per RFA session

TACE group $(n=20)$ :

Chemotherapeutic drugs: cisplatin $50 \mathrm{mg}$, mitomycin $8 \mathrm{mg}$, and adriamycin $10 \mathrm{mg}$

\begin{tabular}{|c|c|}
\hline Outcomes & $\begin{array}{l}\text { Serum level of AFP } \\
\text { Tumour response, classified as complete response, partial response, stable disease, and progres- } \\
\text { sion }\end{array}$ \\
\hline Notes & $\begin{array}{l}\text { Country of study: China } \\
\text { Source of funding: None } \\
\text { There was insufficient information available to satisfactorily determine the method of randomisa- } \\
\text { tion and the study data could not be verified. We have attempted to contact the study authors for } \\
\text { more information, but so far, we have not been successful in doing this. }\end{array}$ \\
\hline
\end{tabular}

\section{Wang 2018a}

Methods

Study design: Randomised clinical trial

Study duration: January 2013 to June 2016

Duration of follow-up: 3 years

Setting: Hospital

Participants

Inclusion criteria: Diagnosed as HCC by biopsy and images; unsuitable for resection; with liver function of Child-Pugh Class A or B; no history of radiotherapy or chemotherapy

Exclusion criteria: Abnormal haematopoietic function; with serious immune, digestive or nervous system diseases; with no history of other tumours

Age (mean \pm SD, range): TACE + RFA: $56.97 \pm 7.49$ years, 31-69 years; TACE: $55.26 \pm 7.82$ years, 34-68 years

Male (n/total): TACE + RFA: 29/45; TACE alone: 30/45

Tumour diameter (mean \pm SD, range): TACE + RFA: $5.17 \pm 1.12 \mathrm{~cm}$; TACE: $5.03 \pm 1.21 \mathrm{~cm}$

Child-Pugh Class (patients):

Class A: TACE + RFA: 32; TACE: 30

Class B: TACE + RFA: 13; TACE: 15

Interventions

TACE + RFA group $(n=45)$ :

TACE: Chemotherapeutic drugs: 5-fluorouracil $2 \mathrm{~g}$ and oxaliplatin $200 \mathrm{mg}$. Multiple sessions of TACE were performed, with an interval of 1-1.5 months.

RFA: The interval between TACE and RFA was 2 weeks. Output power of $60 \mathrm{w}$, ablation margin of 1 $\mathrm{cm}$

TACE group $(n=45)$ :

Chemotherapeutic drugs: 5-fluorouracil $2 \mathrm{~g}$ and oxaliplatin $200 \mathrm{mg}$. Multiple sessions of TACE were performed, with an interval of 1-1.5 months

\section{Outcomes}

Tumour response, classified as complete response, partial response, stable disease, and progression, measured at 4 weeks after treatment

The combination of transcatheter arterial chemoembolisation (TACE) and thermal ablation versus TACE alone for hepatocellular 


\section{1-, 2-, and 3-year survival rates}

Recurrence rate

Country of study: China
Source of funding: Luohe City Medical Project (1400134)
There was insufficient information available to satisfactorily determine the method of randomisa-
tion and the study data could not be verified. We have attempted to contact the study authors for
more information, but so far, we have not been successful in doing this.

Wang 2018b

Methods
Study design: Randomised clinical trial
Study duration: January 2013 to January 2017
Duration of follow-up: 1 year
Setting: Hospital

Participants

Inclusion criteria: Diagnosed as HCC by biopsy and images; with liver function of Child-Pugh Class A or B; adequate haematopoietic function; tumour number $\leq 3$; no extrahepatic metastasis

Exclusion criteria: With hepatic arterio-venous fistula; abnormal renal or cardiac function

Age (mean \pm SD, range): TACE + RFA: $43.02 \pm 7.14$ years, 41-63 years; TACE: $40.48 \pm 7.26$ years, 37-59 years

Male (n/total): TACE + RFA: 14/27; TACE alone: 15/27

Child-Pugh Class (patients):

Class A: TACE + RFA: 18; TACE: 15

Class B: TACE + RFA: 9; TACE: 12

Interventions

TACE + RFA group $(n=27)$ :

TACE: Chemotherapeutic drugs: oxaliplatin and 5-fluorouracil

RFA: The interval between TACE and RFA was 1 week.

$\operatorname{TACE}$ group $(\mathrm{n}=27)$ :

Chemotherapeutic drugs: oxaliplatin and 5-fluorouracil

\begin{tabular}{ll}
\hline Outcomes & Serum level of AFP \\
& Liver function \\
Tumour response, classified as complete response, partial response, stable disease, and progres- \\
sion \\
1-year survival, recurrence, and metastasis rate \\
Country of study: China \\
Source of funding: None \\
There was insufficient information available to satisfactorily determine the method of randomisa- \\
tion and the study data could not be verified. We have attempted to contact the study authors for \\
more information, but so far, we have not been successful in doing this.
\end{tabular}

The combination of transcatheter arterial chemoembolisation (TACE) and thermal ablation versus TACE alone for hepatocellular 
Wang 2018c

$\begin{array}{ll}\text { Methods } & \text { Study design: Randomised clinical trial } \\ \text { Study duration: January } 2016 \text { to January } 2017 \\ \text { Duration of follow-up: } 1 \text { year } \\ \text { Setting: Hospital }\end{array}$

Participants

Inclusion criteria: Tumour number $\leq 3$; tumour diameter of $5-9 \mathrm{~cm}$

Exclusion criteria: With mental diseases; abnormal cardiac function

Age (mean \pm SD, range): TACE + RFA: $47.6 \pm 6.8$ years, $23-66$ years; TACE alone: $48.7 \pm 6.5$ years, 22-68 years

Male (n/total): TACE + RFA: 40/50; TACE alone: 36/50

Child-Pugh Class (patients):

Class A: TACE + RFA: 11; TACE: 10

Class B: TACE + RFA: 4; TACE: 5

TACE + RFA group $(n=50)$ :

TACE: Chemotherapeutic drugs: oxaliplatin, mitomycin, and adriamycin

RFA: Ultrasound-guided RFA

TACE group $(n=50)$ :

Chemotherapeutic drugs: oxaliplatin, mitomycin, and adriamycin

\begin{tabular}{ll}
\hline Outcomes & $\begin{array}{l}\text { Tumour response, classified as complete response, partial response, stable disease, and progres- } \\
\text { sion }\end{array}$ \\
Quality of life \\
1-year survival rate \\
Adverse events \\
Country of study: China \\
Source of funding: None \\
There was insufficient information available to satisfactorily determine the method of randomisa- \\
tion and the study data could not be verified. We have attempted to contact the study authors for \\
more information, but so far, we have not been successful in doing this.
\end{tabular}

Wen 2018

$\begin{array}{ll}\text { Methods } & \text { Study design: Randomised clinical trial } \\ & \text { Study duration: March } 2013 \text { to March } 2015 \\ & \text { Duration of follow-up: } 2 \text { years } \\ & \text { Setting: Hospital }\end{array}$

The combination of transcatheter arterial chemoembolisation (TACE) and thermal ablation versus TACE alone for hepatocellular 
Wen 2018 (Continued)

Participants
Inclusion criteria: Diagnosed as HCC by pathology; huge HCC; tumour volume $<70 \%$ of whole liver volume; with liver function of Child-Pugh Class A or B; ECOG $\leq 2$

Exclusion criteria: With liver function of Child-Pugh Class C; abnormal haematopoietic function; life expectancy $<6$ months; with serious disease of other organs

Age (mean \pm SD): TACE + cryoablation: $53.2 \pm 12.3$ years; TACE alone: $54.8 \pm 10.2$ years

Male (n/total): TACE + cryoablation: 35/43; TACE alone: 37/43

Vascular invasion (patients): TACE + cryoablation: 6; TACE: 4
TACE + cryoablation group $(n=43)$ :

TACE: Chemotherapeutic drugs: lobaplatin

Cryoablation: The interval between TACE and RFA was 1 week. Ultrasound-guided cryoablation.

TACE group $(n=43)$ :

Chemotherapeutic drugs: lobaplatin

Tutcomes
sion
Adverse events
1- and 2-year survival rates
Country of study: China
Source of funding: None
There was insufficient information available to satisfactorily determine the method of randomisa-
tion and the study data could not be verified. We have attempted to contact the study authors for
more information, but so far, we have not been successful in doing this.

\section{Wu 2011b}

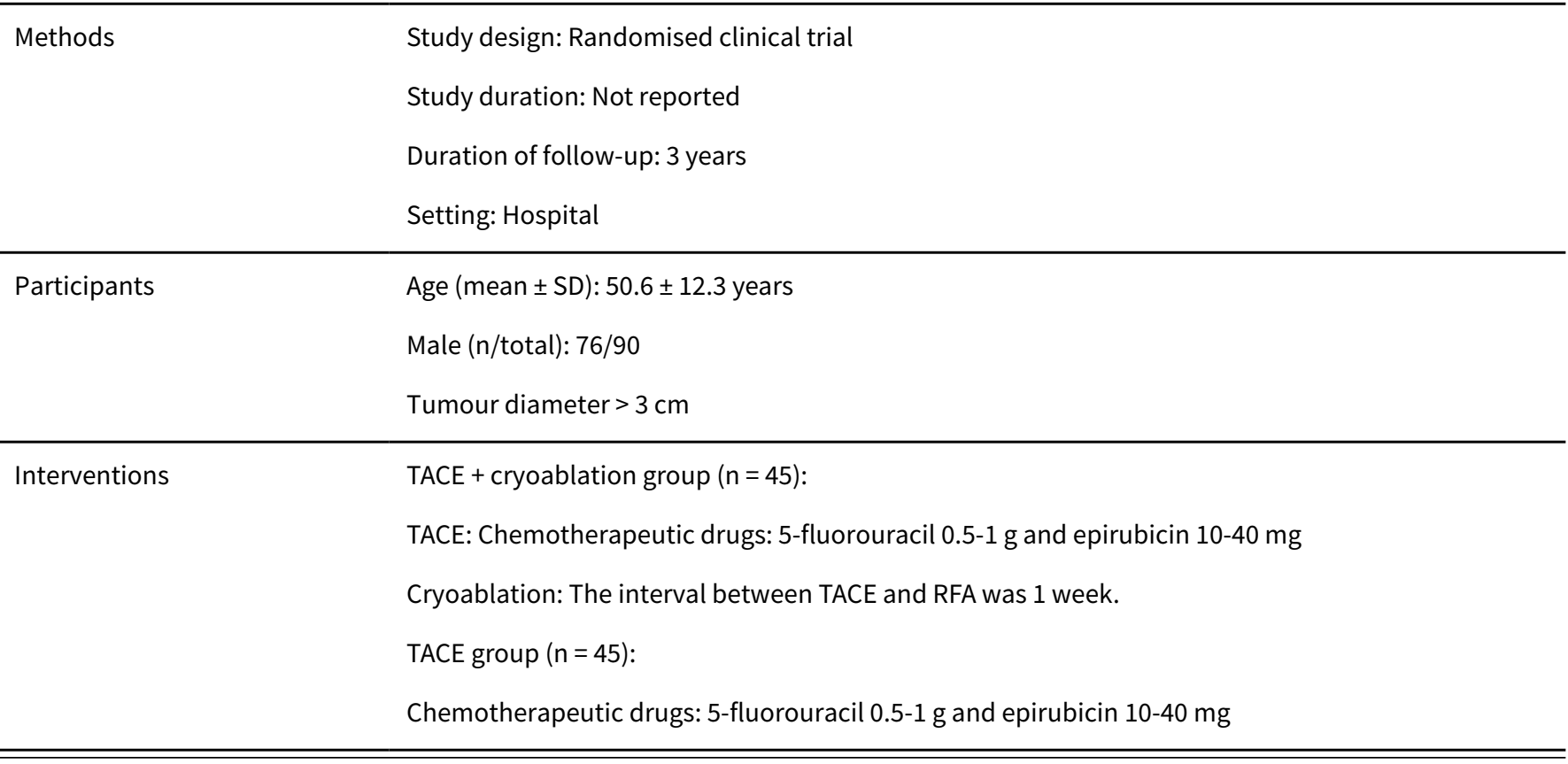


Wu 2011b (Continued)

Outcomes
Serum level of AFP

Tumour diameter

1-, 2-, and 3-year survival rates

\section{Notes}

Country of study: China

Source of funding: None

There was insufficient information available to satisfactorily determine the method of randomisation and the study data could not be verified. We have attempted to contact the study authors for more information, but so far, we have not been successful in doing this.

Wu 2017b

Methods
Study design: Randomised clinical trial
Suration of follow-up: Not reported
Setting: Hospital

Participants Inclusion criteria: Diagnosed as HCC by pathology and images; with normal renal and haematopoietic function; tumour number $\leq 5$; no extrahepatic metastasis

Exclusion criteria: With other serious diseases; with mental disease

Age (mean \pm SD, range): TACE + MWA: $42.1 \pm 1.5$ years, $25-60$ years; TACE alone: $43.1 \pm 1.3$ years, 26-60 years

Male (n/total): TACE + MWA: 20/35; TACE alone: $21 / 35$

\begin{tabular}{ll}
\hline Interventions & TACE + MWA group $(n=35):$ \\
& TACE: Chemotherapeutic drugs: cisplatin and epirubicin. Three sessions of TACE treatment were \\
performed for each patient, with an interval of 4 weeks.
\end{tabular}

MWA: CT-guided MWA. Output power of $50 \mathrm{~W}$

$\operatorname{TACE}$ group $(\mathrm{n}=35)$ :

Chemotherapeutic drugs: cisplatin and epirubicin. Three sessions of TACE treatment were performed for each patient, with an interval of 4 weeks.

\begin{tabular}{ll}
\hline Outcomes & Recurrence rate, classified as complete response, partial response, stable disease, and progression \\
& Tumour response rate \\
\hline Notes & $\begin{array}{l}\text { Country of study: China } \\
\text { Source of funding: None } \\
\text { There was insufficient information available to satisfactorily determine the method of randomisa- } \\
\text { tion and the study data could not be verified. We have attempted to contact the study authors for } \\
\text { more information, but so far, we have not been successful in doing this. }\end{array}$ \\
\hline
\end{tabular}

The combination of transcatheter arterial chemoembolisation (TACE) and thermal ablation versus TACE alone for hepatocellular 


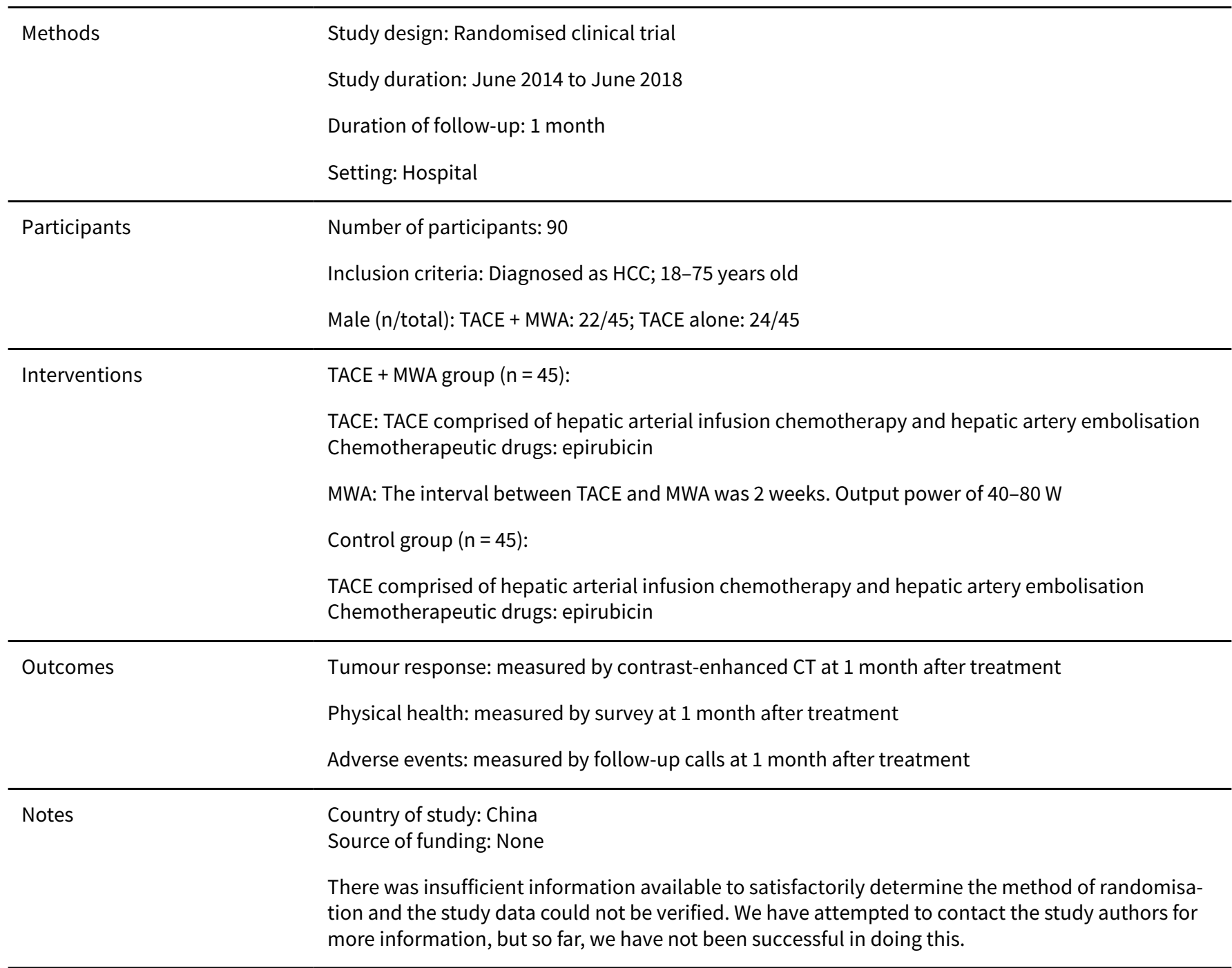

\section{Xie 2017}

\section{Methods}

Study design: Randomised clinical trial

Study duration: February 2012 to February 2014

Duration of follow-up: 3 years

Setting: Hospital

\section{Participants}

Inclusion criteria: Diagnosed as HCC; aged $\geq 50$ years; willing to sign a written informed consent document

Exclusion criteria: Abnormal immune and haematopoietic function; with history of organ transplantation; with serious infection

Age (mean \pm SD, range): TACE + HIFU: $55.03 \pm 3.97$ years, 50-75 years; TACE: $54.85 \pm 3.64$ years, 50-76 years

Male (n/total): TACE + HIFU: 25/42; TACE alone: 24/42 
Xie 2017 (Continued)

Tumour diameter (mean \pm SD, range): TACE + RFA: $8.46 \pm 1.9 \mathrm{~cm}, 1.2-13.8 \mathrm{~cm}$; TACE: $8.52 \pm 2.36 \mathrm{~cm}$, $1.1-14 \mathrm{~cm}$

Interventions

TACE + HIFU group $(n=42)$ :

TACE: Chemotherapeutic drugs: cisplatin and theprubicin

HIFU: The interval between TACE and HIFU was 1-2 weeks.

TACE group ( $n=42)$ : Chemotherapeutic drugs: cisplatin and theprubicin

\begin{tabular}{ll}
\hline Outcomes & Tumour volume \\
Tumour response, according to WHO criteria \\
Immune function \\
1-, 2, and 3-year survival rates \\
Country of study: China \\
Source of funding: Guangdong Province Science Project \\
There was insufficient information available to satisfactorily determine the method of randomisa- \\
tion and the study data could not be verified. We have attempted to contact the study authors for \\
more information, but so far, we have not been successful in doing this.
\end{tabular}

Xiong 2013

Methods

Study design: Randomised clinical trial

Study duration: January 2009 to May 2011

Duration of follow-up: Not reported

Setting: Hospital

Participants

Inclusion criteria: Aged $\geq 60$ years; diagnosed as HCC by pathology; unsuitable for resection or unwilling to accept surgery; Karnofsky score $\geq 60$; life expectancy $\geq 3$ months; no contraindications for TACE or HIFU; no extrahepatic metastasis; tumour volume $\leq 70 \%$ of whole liver volume

Age (mean \pm SD, range): TACE + RFA: $73.4 \pm 4.5$ years; TACE alone: $74.2 \pm 5.6$ years

Male (n/total): TACE + RFA: 20/35; TACE alone: 21/35

Tumour diameter (mean \pm SD): TACE + RFA: $6.3 \pm 2.1 \mathrm{~cm}$; TACE: $6.5 \pm 2.0 \mathrm{~cm}$

Child-Pugh Class (patients):

Class A: TACE + RFA: 27; TACE: 28

Class B: TACE + RFA: 8; TACE: 7

Interventions

TACE + RFA group $(n=35)$ :

TACE: Chemotherapeutic drugs: 5-fluorouracil, epirubicin, and mitomycin

RFA: The interval between TACE and RFA was 1-2 weeks. Ablation margin of $0.5-1 \mathrm{~cm}$

$\operatorname{TACE}$ group $(\mathrm{n}=35)$ :

Chemotherapeutic drugs: 5-fluorouracil, epirubicin, and mitomycin 
Xiong 2013 (Continued)

Outcomes Serum level of AFP

Tumour response, assessed at 6 weeks after treatment, measured by contrast-enhanced CT or MRI

\section{Notes}

\section{Country of study: China \\ Source of funding: None}

There was insufficient information available to satisfactorily determine the method of randomisation and the study data could not be verified. We have attempted to contact the study authors for more information, but so far, we have not been successful in doing this.

\title{
Xiong 2017
}

Methods

\author{
Study design: Randomised clinical trial \\ Study duration: February 2013 to January 2014 \\ Duration of follow-up: 3 years \\ Setting: Hospital
}

Participants

Inclusion criteria: diagnosed in line with the Criteria for Clinical Diagnosis of Primary Hepatic Carcinoma; they were diagnosed as having PHC, as demonstrated by serum alpha fetoprotein (AFP), CT or MRI; the Karnofsky Performance Status score $\geq 70$; the Child-Pugh scores or TNM stages of liver function were accurate; no previous systemic chemotherapy or radiotherapy.

Exclusion criteria: with obvious hepatic arteriovenous fistula; had hepatic tumour which exceeded $70 \%$ of the volume of the liver; had obvious cachexia, jaundice, ascites or distant metastasis or a contraindication to chemotherapy

Age (mean \pm SD): TACE + RFA: $59.45 \pm 5.34$ years; TACE alone: $60.06 \pm 5.41$ years

Male (n/total): TACE + RFA: 21/37; TACE alone: 24/37

Tumour diameter (mean \pm SD, range): TACE + RFA: $5.08 \pm 0.84 \mathrm{~cm}$; TACE: $5.09 \pm 0.86 \mathrm{~cm}$

TNM stage (patients):

Stage I : TACE+RFA: $11 ;$ TACE: 13

StageII: TACE+RFA: 18; TACE: 19

StageII : TACE+RFA: 8; TACE: 5

Child-Pugh Class (patients):

Class A: TACE + RFA: 25; TACE: 23

Class B: TACE + RFA: 12; TACE: 14

Interventions

TACE + RFA group $(n=37)$ :

The procedures of RFA were initiated at $15 \mathrm{~d}$ after TACE. The electrode was inserted into the tumour tissue under the guidance of CT, with the ablation power at $60 \mathrm{~W}$ for 10-15 min. Single needle ablation was administered for 1-3 bulbous focus, bilateral focal ablation for 4-6 bulbous focus, and fractional ablation for patients with poor toleration. The RFA range can be extended to $1 \mathrm{~cm}$ inside the normal tissues to ensure full ablation.

TACE group $(n=37)$ : 
Xiong 2017 (Continued)

A catheter was inserted into the feeding artery, into which nonionic contrast agent lipiodol ( $5 \mathrm{~mL})$, 5-fluorouracil (2 g), and oxaliplatin (200 mg) were injected.

\begin{tabular}{ll}
\hline Outcomes & Serum level of GGT and AFP \\
& Clinical response, according to RECIST criteria, measured at 3 years after treatment \\
& Tumour necrosis \\
& Recurrence and survival at 3-year \\
& Adverse events \\
\hline Cotes & Sountry of study: China \\
& There was insufficient information available to satisfactorily determine the method of randomisa- \\
tion and the study data could not be verified. We have attempted to contact the study authors for \\
more information, but so far, we have not been successful in doing this.
\end{tabular}

\begin{tabular}{ll}
\hline Methods & Study design: Randomised clinical trial \\
Study duration: December 2010 to July 2012 \\
Duration of follow-up: 3 years \\
Setting: Hospital
\end{tabular}

\section{Participants}

Age (mean \pm SD): TACE + RFA: $52.9 \pm 5.4$ years; TACE alone: $53.4 \pm 6.8$ years

Male (n/total): TACE + RFA: 28/38; TACE alone: 27/34

Child-Pugh Class (patients):

Class A: TACE + RFA: 20; TACE: 19

Class B: TACE + RFA: 18; TACE: 15

TACE + RFA group $(n=38)$ :

TACE: Chemotherapeutic drugs: 5-fluorouracil, theprubicin, and epirubicin

RFA: The interval between TACE and RFA was 2 weeks. Output power of 50-100 W

TACE group $(n=34)$ :

Chemotherapeutic drugs: 5-fluorouracil, theprubicin, and epirubicin

\begin{tabular}{ll}
\hline Outcomes & Serum level of AFP \\
& Liver function \\
& Tumour response, measured by contrast-enhanced CT or MRI; measured at 3 months after treat- \\
ment & $1-, 2-$, and 3-year survival rates \\
\hline Notes & Country of study: China \\
& Source of funding: Qinhuangdao Science and Develoment Funding
\end{tabular}


There was insufficient information available to satisfactorily determine the method of randomisation and the study data could not be verified. We have attempted to contact the study authors for more information, but so far, we have not been successful in doing this.

\section{Xue 2019}

\begin{tabular}{ll}
\hline Methods & Study design: Randomised clinical trial \\
& Study duration: February 2017 to February 2018 \\
& Duration of follow-up: 2 years \\
& Setting: Hospital
\end{tabular}

Number of participants: 122
Inclusion criteria: Diagnosed as HCC; tumour diameter $<5 \mathrm{~cm}$; number of tumours < 3; no metasta-
sis
Age (mean \pm SD): TACE + MWA: $47.56 \pm 4.71$ years; TACE alone: $47.63 \pm 4.62$ years
Male (n/total): TACE + MWA: $37 / 61 ;$ TACE alone: $36 / 61$

Interventions

TACE + MWA group $(n=61)$ :

TACE: TACE comprised of hepatic arterial infusion chemotherapy and hepatic artery embolisation Chemotherapeutic drugs: 20-30 mg theprubicin and $80 \mathrm{mg}$ cisplatin

MWA: The interval between TACE and MWA was 2 weeks. Output power of $60 \mathrm{~W}$

Control group $(n=61)$ :

TACE comprised of hepatic arterial infusion chemotherapy and hepatic artery embolisation Chemotherapeutic drugs: 20-30 mg theprubicin and $80 \mathrm{mg}$ cisplatin

\begin{tabular}{ll}
\hline Outcomes & Tumour response: measured by contrast-enhanced CT at 1 month after treatment \\
Survival rates: measured at 1 and 2 years after treatment \\
Adverse events \\
Liver function and AFP: blood testing \\
\hline Country of study: China \\
Source of funding: None \\
There was insufficient information available to satisfactorily determine the method of randomisa- \\
tion and the study data could not be verified. We have attempted to contact the study authors for \\
more information, but so far, we have not been successful in doing this.
\end{tabular}


Yao 2018 (Continued)

Setting: Hospital

Inclusion criteria: Diagnosed as HCC by pathology or images; willing to sign a written informed consent document

Exclusion criteria: With serious diseases of other organs; abnormal haematopoietic and cardiac function

Age (mean \pm SD): TACE + RFA: $42.18 \pm 5.31$ years; TACE alone: $41.76 \pm 5.62$ years

Male (n/total): TACE + RFA: 26/42; TACE alone: 25/42

Child-Pugh Class (patients):

Class A: TACE + RFA: 34; TACE: 33

Class B: TACE + RFA: 8; TACE: 9

TACE + RFA group:

TACE: Chemotherapeutic drugs: 5-fluorouracil 0.75-1 g, cisplatin 40-60 mg, and epirubicin 10-30 mg RFA: CT-guided RFA

TACE group: Chemotherapeutic drugs: 5-fluorouracil 0.75-1 g, cisplatin 40-60 mg, and epirubicin 10-30 mg

\begin{tabular}{ll}
\hline Outcomes & Serum level of AFP \\
& Tumour response \\
& Survival rate \\
& Adverse events \\
\hline Notes & $\begin{array}{l}\text { Country of study: China } \\
\text { Source of funding: None } \\
\text { There was insufficient information available to satisfactorily determine the method of randomisa- } \\
\text { tion and the study data could not be verified. We have attempted to contact the study authors for } \\
\text { more information, but so far, we have not been successful in doing this. }\end{array}$
\end{tabular}

Duration of follow-up: 3 years

Setting: Hospital

Participants

Inclusion criteria: Diagnosed as HCC by images; tumour number < 4; maximal tumour diameter $\leq 10$ $\mathrm{cm}$; Karnofsky score $\geq 70$; with liver function of Child-Pugh Class A or B

Exclusion criteria: With history of other tumours; with extrahepatic metastasis; with inferior vena cava or portal vein tumour thrombus

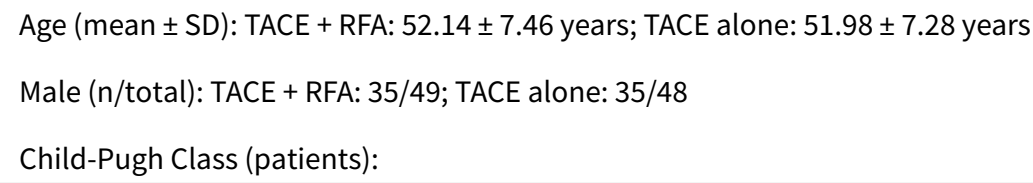

The combination of transcatheter arterial chemoembolisation (TACE) and thermal ablation versus TACE alone for hepatocellular carcinoma (Review)

Copyright @ 2021 The Cochrane Collaboration. Published by John Wiley \& Sons, Ltd. 
Yi 2015 (Continued)

Class A: TACE + RFA: 32; TACE: 33

Class B: TACE + RFA: 17; TACE: 15

\begin{tabular}{|c|c|}
\hline \multirow[t]{4}{*}{ Interventions } & TACE + RFA group $(n=49)$ : \\
\hline & TACE: Chemotherapeutic drugs: mitomycin and adriamycin \\
\hline & $\begin{array}{l}\text { RFA: The interval between TACE and RFA was } 2 \text { weeks. } 10-15 \text { minutes per RFA session, ablation mar- } \\
\text { gin of } 1 \mathrm{~cm}\end{array}$ \\
\hline & TACE group ( $n=48$ ): Chemotherapeutic drugs: mitomycin and adriamycin \\
\hline \multirow[t]{3}{*}{ Outcomes } & Tumour response, according to WHO criteria \\
\hline & Adverse events \\
\hline & 1-, 2-, and 3-year survival rates \\
\hline \multirow[t]{2}{*}{ Notes } & $\begin{array}{l}\text { Country of study: China } \\
\text { Source of funding: None }\end{array}$ \\
\hline & $\begin{array}{l}\text { There was insufficient information available to satisfactorily determine the method of randomisa- } \\
\text { tion and the study data could not be verified. We have attempted to contact the study authors for } \\
\text { more information, but so far, we have not been successful in doing this. }\end{array}$ \\
\hline
\end{tabular}

\begin{tabular}{ll}
\hline Methods & Study design: Randomised clinical trial \\
& Study duration: May 2013 to May 2016 \\
& Duration of follow-up: 2 years \\
Setting: Hospital
\end{tabular}

\section{Participants}

Inclusion criteria: Diagnosed as HCC by biopsy or images; with liver function of Child-Pugh Class A or $\mathrm{B}$; tumour diameter $\geq 5 \mathrm{~cm}$

Exclusion criteria: With abnormal haematopoietic function; with portal vein tumour thrombus or extrahepatic metastasis; with abnormal renal or cardiac function

Age (mean \pm SD): TACE + RFA: $55.9 \pm 4.3$ years; TACE alone: $55.6 \pm 4.1$ years

Male (n/total): TACE + RFA: 23/34; TACE alone: 22/34

Tumour diameter (mean \pm SD): TACE + RFA: $6.23 \pm 0.35 \mathrm{~cm}$; TACE: $6.2 \pm 0.35 \mathrm{~cm}$

Child-Pugh Class (patients):

Class A: TACE + RFA: 17; TACE: 15

Class B: TACE + RFA: 17; TACE: 19

TACE: Chemotherapeutic drugs: theprubicin 20-60 mg and oxaliplatin 60-100 mg. Multiple sessions of TACE can be performed for each patient, with an interval of 4-6 weeks

RFA: The interval between TACE and RFA was 1-2 weeks. LDRF-20S ablation system. With tumour margin of $0.5-1 \mathrm{~cm}$ 
Yu 2019 (Continued)

TACE group ( $\mathrm{n}=34$ ): Chemotherapeutic drugs: theprubicin 20-60 mg and oxaliplatin $60-100 \mathrm{mg}$ Multiple sessions of TACE can be performed for each patient, with an interval of 4-6 weeks.

\begin{tabular}{ll}
\hline Outcomes & Tumour response, according to mRECIST criteria \\
& Adverse events \\
& 1- and 2-year survival rates \\
\hline Notes & $\begin{array}{l}\text { Country of study: China } \\
\text { Source of funding: None } \\
\text { There was insufficient information available to satisfactorily determine the method of randomisa- } \\
\text { tion and the study data could not be verified. We have attempted to contact the study authors for } \\
\text { more information, but so far, we have not been successful in doing this. }\end{array}$
\end{tabular}

\section{Yuan 2015}

\begin{tabular}{|c|c|}
\hline \multirow[t]{4}{*}{ Methods } & Study design: Randomised clinical trial \\
\hline & Study duration: March 2011 to December 2014 \\
\hline & Duration of follow-up: 2 years \\
\hline & Setting: Hospital \\
\hline \multirow[t]{2}{*}{ Participants } & Age (mean): TACE + MWA: 54 years; TACE: 53 years \\
\hline & Male (n/total): TACE + MWA: 39/55; TACE alone: 41/55 \\
\hline \multirow[t]{4}{*}{ Interventions } & TACE + MWA group $(n=55)$ : \\
\hline & TACE: Chemotherapeutic drugs: mitomycin $10 \mathrm{mg}$ and adriamycin $50 \mathrm{mg}$ \\
\hline & MWA: The interval between TACE and RFA was 2 weeks. Tumour margin of $1 \mathrm{~cm}$ \\
\hline & TACE group ( $n=55$ ): Chemotherapeutic drugs: mitomycin $10 \mathrm{mg}$ and adriamycin $50 \mathrm{mg}$ \\
\hline \multirow[t]{3}{*}{ Outcomes } & $\begin{array}{l}\text { Tumour response, classified as complete response, partial response, stable disease, and progres- } \\
\text { sion }\end{array}$ \\
\hline & Adverse events \\
\hline & 1- and 2-year survival rates \\
\hline \multirow[t]{2}{*}{ Notes } & $\begin{array}{l}\text { Country of study: China } \\
\text { Source of funding: None }\end{array}$ \\
\hline & $\begin{array}{l}\text { There was insufficient information available to satisfactorily determine the method of randomisa- } \\
\text { tion and the study data could not be verified. We have attempted to contact the study authors for } \\
\text { more information, but so far, we have not been successful in doing this. }\end{array}$ \\
\hline
\end{tabular}

\begin{tabular}{ll}
\hline Methods & Study design: Randomised clinical trial \\
& Study duration: March 2009 to September 2011
\end{tabular}


Zhang 2013 (Continued)

Duration of follow-up: 35 months

Setting: Hospital

Participants

Inclusion criteria: Diagnosed as HCC by liver biopsy; tumour maximal diameter of 5-10 cm; with liver function of Child-Pugh Class A or B; unsuitable for resection or unwilling to accept surgery; with no history of treatments on HCC

Age (mean \pm SD): TACE + MWA: $52.1 \pm 1.64$ years; TACE alone: $55.57 \pm 1.76$ years

Male (n/total): TACE + MWA: 48/60; TACE alone: $33 / 42$

Tumour diameter (mean \pm SD): TACE + MWA: $7.8 \pm 1.37 \mathrm{~cm}$; TACE: $7.34 \pm 1.23 \mathrm{~cm}$

Child-Pugh Class (patients):

Class A: TACE + MWA: 42; TACE: 25

Class B: TACE + MWA: 18; TACE: 17

TACE + MWA group ( $\mathrm{n}=60):$
TACE: Chemotherapeutic drugs: adriamycin 30-50 mg. Multiple sessions of TACE were performed,
with an interval of 3-4 weeks.
MWA: Output power of 50-60 W; 10-15 minutes per MWA session
TACE group ( $\mathrm{n}=42$ ):
Chemotherapeutic drugs: adriamycin 30-50 mg. Multiple sessions of TACE were performed, with an
interval of 3-4 weeks.
Serum level of AFP
Tumour response, according to mRECIST criteria, measured at 2 months after treatment
1- and 2-year survival rates
Adverse events
Country of study: China
Source of funding: None
There was insufficient information available to satisfactorily determine the method of randomisa-
tion and the study data could not be verified. We have attempted to contact the study authors for
more information, but so far, we have not been successful in doing this.

Study duration: May 2008 to May 2013

Duration of follow-up: 2 years

Setting: Hospital 


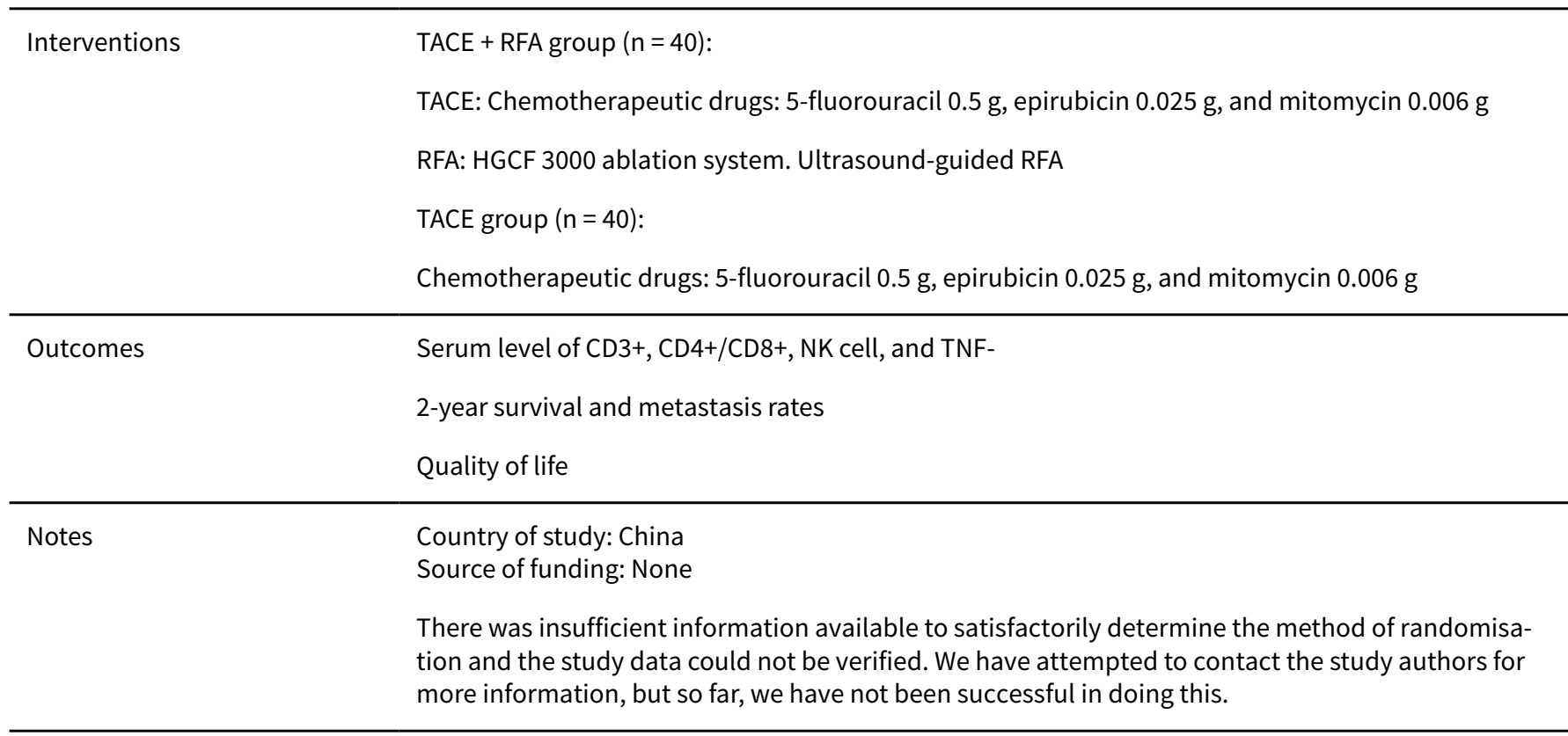

\begin{tabular}{ll}
\hline Methods & Study design: Randomised clinical trial \\
& Study duration: March 2011 to January 2014 \\
Duration of follow-up: 2 years \\
Setting: Hospital
\end{tabular}

Participants

Inclusion criteria: Diagnosed as middle or advanced HCC

Exclusion criteria: With serious infection; with metal disease; with serious systematic diseases

Age (mean \pm SD): TACE + cryoablation: $64.39 \pm 4.25$ years; TACE alone: $65.02 \pm 4.72$ years

Male (n/total): TACE + cryoablation: 16/28; TACE alone: 17/28

Interventions

TACE + cryoablation group $(n=28)$ :

TACE: Chemotherapeutic drugs: epirubicin and oxaliplatin

Cryoablation: CT-guided cryoablation. 30 minutes per ablation session

TACE group ( $n=28)$ : Chemotherapeutic drugs: epirubicin and oxaliplatin

\section{Outcomes}

Tumour response, classified as complete response, partial response, stable disease, and progression, measured at 4 weeks after treatment, measured by contrast-enhanced CT or MRI;

2-, 6-, 9-, 12-, and 24-month survival rates

$\begin{array}{ll}\text { Notes } & \text { Country of study: China } \\ & \text { Source of funding: None }\end{array}$


There was insufficient information available to satisfactorily determine the method of randomisation and the study data could not be verified. We have attempted to contact the study authors for more information, but so far, we have not been successful in doing this.

Study design: Randomised clinical trial
Study duration: June 2011 to June 2014
Duration of follow-up: 2 years
Setting: Hospital

Participants

Inclusion criteria: Diagnosed as HCC by pathology; no extrahepatic metastasis and tumour thrombus; unresectable for liver resection; with liver function of Child-Pugh Class A or B; no history of radiotherapy or chemotherapy; life expectancy $\geq 3$ months; willing to sign a written informed consent document

Exclusion criteria: With other serious diseases; disseminated tumour; abnormal renal or cardiac function; with contraindications for TACE or ablation

Age (mean \pm SD): TACE + MWA: $57.4 \pm 6.5$ years; TACE alone: $58.2 \pm 6.3$ years

Male (n/total): TACE + MWA: 54/117; TACE alone: 52/117

BCLC stage (patients):

Stage B: TACE + MWA: 66 ; TACE: 64

Stage C: TACE + MWA: 33; TACE: 39

Stage D: TACE + MWA: 13; TACE: 14

\section{Interventions}

TACE + MWA group $(n=117)$ :

TACE: Allura Xper FD20 guiding system. Oxaliplatin $100 \mathrm{mg}$. Multiple sessions of TACE can be performed.

MWA: The interval between TACE and MWA was 2 weeks. KY-2000 ablation system. CT-guided MWA. Ablation margin of $0.5-1 \mathrm{~cm}, 5-15$ minutes per ablation session

TACE group ( $n=117$ ): Allura Xper FD20 guiding system. Oxaliplatin $100 \mathrm{mg}$. Multiple sessions of TACE can be performed.

\begin{tabular}{ll}
\hline Outcomes & $\begin{array}{l}\text { Tumour response, according to mRECIST criteria, measured at } 4 \text { weeks after treatment, measured } \\
\text { by contrast-enhanced CT }\end{array}$ \\
$6-, 12-, 18-$, and 24-month survival rates \\
\hline Notes & $\begin{array}{l}\text { Country of study: China } \\
\text { Source of funding: None }\end{array}$ \\
& $\begin{array}{l}\text { There was insufficient information available to satisfactorily determine the method of randomisa- } \\
\text { tion and the study data could not be verified. We have attempted to contact the study authors for } \\
\text { more information, but so far, we have not been successful in doing this. }\end{array}$ \\
\hline
\end{tabular}


Zhang 2017b

\begin{tabular}{|c|c|}
\hline \multirow[t]{4}{*}{ Methods } & Study design: Randomised clinical trial \\
\hline & Study duration: April 2012 to March 2013 \\
\hline & Duration of follow-up: 3 years \\
\hline & Setting: Hospital \\
\hline \multirow[t]{5}{*}{ Participants } & $\begin{array}{l}\text { Inclusion criteria: Tumour number }<4 \text {; maximal tumour diameter } \leq 15 \mathrm{~cm} \text {; with liver function of } \\
\text { Child-Pugh Class A or B }\end{array}$ \\
\hline & Exclusion criteria: With history of other tumours; with extrahepatic metastasis; with metal diseases \\
\hline & Age $($ mean $\pm S D): 44.07 \pm 7.56$ years, $27-66$ years \\
\hline & Male (n/total): $33 / 60$ \\
\hline & Child-Pugh Class (patients): Class A: 44; Class B: 16 \\
\hline \multirow[t]{5}{*}{ Interventions } & TACE + RFA group $(n=30)$ : \\
\hline & TACE: Chemotherapeutic drugs: mitomycin and adriamycin \\
\hline & $\begin{array}{l}\text { RFA: The interval between TACE and RFA was } 2 \text { weeks. RITA ablation system. 10-15 minutes per ab- } \\
\text { lation session, ablation margin of } 1 \mathrm{~cm}\end{array}$ \\
\hline & TACE group $(n=30)$ : \\
\hline & Chemotherapeutic drugs: mitomycin and adriamycin \\
\hline \multirow[t]{3}{*}{ Outcomes } & Tumour response, according to WHO criteria \\
\hline & Serum level of AFP \\
\hline & 1-, 2-, and 3-year of survival rates \\
\hline \multirow[t]{2}{*}{ Notes } & $\begin{array}{l}\text { Country of study: China } \\
\text { Source of funding: Jinan Science Project (J115N009); Taian Science Project (2015NS1132) }\end{array}$ \\
\hline & $\begin{array}{l}\text { There was insufficient information available to satisfactorily determine the method of randomisa- } \\
\text { tion and the study data could not be verified. We have attempted to contact the study authors for } \\
\text { more information, but so far, we have not been successful in doing this. }\end{array}$ \\
\hline
\end{tabular}

Study duration: 2012 to 2014

Duration of follow-up: 2 years

Setting: Hospital

Participants

Inclusion criteria: Diagnosed as HCC by liver biopsy or images; maximal tumour diameter $>5 \mathrm{~cm}$; tumour number $\leq 4$; with liver function of Child-Pugh Class A or B; willing to sign a written informed consent document

Exclusion criteria: With history of liver resection or liver transplantation

Age (mean \pm SD): TACE + MWA: $56.9 \pm 7.7$ years; TACE alone: $58.2 \pm 7.3$ years

The combination of transcatheter arterial chemoembolisation (TACE) and thermal ablation versus TACE alone for hepatocellular 


\begin{tabular}{|c|c|}
\hline \multirow[t]{4}{*}{ Interventions } & TACE + MWA group $(n=30)$ : \\
\hline & TACE: Chemotherapeutic drugs: 5-fluorouracil 0.075-1 g and cisplatin 40-60 mg \\
\hline & $\begin{array}{l}\text { MWA: The interval between TACE and RFA was 2-4 weeks. Multiple sessions of MWA were per- } \\
\text { formed, with an interval of } 2 \text { weeks. }\end{array}$ \\
\hline & TACE group $(n=30)$ : Chemotherapeutic drugs: 5-fluorouracil 0.075-1 g and cisplatin 40-60 mg \\
\hline \multirow[t]{3}{*}{ Outcomes } & $\begin{array}{l}\text { Tumour response, classified as complete response, partial response, stable disease, and progres- } \\
\text { sion, measured at } 4 \text { weeks after treatment }\end{array}$ \\
\hline & 1- and 2-year survival rates \\
\hline & Adverse events \\
\hline \multirow[t]{2}{*}{ Notes } & $\begin{array}{l}\text { Country of study: China } \\
\text { Source of funding: None }\end{array}$ \\
\hline & $\begin{array}{l}\text { There was insufficient information available to satisfactorily determine the method of randomisa- } \\
\text { tion and the study data could not be verified. We have attempted to contact the study authors for } \\
\text { more information, but so far, we have not been successful in doing this. }\end{array}$ \\
\hline
\end{tabular}

\section{Zhang 2018a}

Study design: Randomised clinical trial
Study duration: January 2014 to January 2017
Duration of follow-up: 2 months
Setting: Hospital

$\begin{array}{ll}\text { Participants } & \text { Age (mean } \pm \text { SD): TACE + RFA: } 58.62 \pm 4.19 \text { years; TACE alone: } 57.21 \pm 3.98 \text { years } \\ & \text { Male }(n / \text { total): TACE + RFA: } 30 / 48 ; \text { TACE alone: } 29 / 48 \\ & \text { Tumour diameter (mean } \pm \text { SD, range): TACE + RFA: } 6.32 \pm 1.24 \mathrm{~cm}, 5-15 \mathrm{~cm} ; \text { TACE: } 6.25 \pm 1.19 \mathrm{~cm}, \\ & 4-14 \mathrm{~cm}\end{array}$

Interventions $\quad$ TACE + RFA group $(n=48)$ :

TACE: Chemotherapeutic drugs: cisplatin $80 \mathrm{mg}$, theprubicin $30 \mathrm{mg}$, and epirubicin $20 \mathrm{mg}$

RFA: The interval between TACE and RFA was 2 weeks. RADION-ICS ablation system. Output power of 40 W, 5-10 minutes per RFA session. Multiple sessions of RFA were performed, with an interval of $1-2$ weeks.

TACE group ( $n=48$ ): Chemotherapeutic drugs: cisplatin $80 \mathrm{mg}$, theprubicin $30 \mathrm{mg}$, and epirubicin $20 \mathrm{mg}$

\begin{tabular}{ll}
\hline Outcomes & Tumour response, according to WHO criteria \\
& Liver function \\
& Immune function \\
\hline Notes & $\begin{array}{l}\text { Country of study: China } \\
\text { Source of funding: None }\end{array}$ \\
\hline
\end{tabular}

The combination of transcatheter arterial chemoembolisation (TACE) and thermal ablation versus TACE alone for hepatocellular 
There was insufficient information available to satisfactorily determine the method of randomisation and the study data could not be verified. We have attempted to contact the study authors for more information, but so far, we have not been successful in doing this.

\section{Zhang 2018b}

Methods Study design: Randomised clinical trial
Study duration: January 2014 to December 2015
Duration of follow-up: 1 year
Setting: Hospital

Participants

Inclusion criteria: Diagnosed as HCC by pathology; tumour number $\leq 3$; tumour diameter of $5-9 \mathrm{~cm}$

Age (mean \pm SD): TACE + RFA: $49.21 \pm 3.45$ years; TACE alone: $49.11 \pm 3.42$ years

Male (n/total): TACE + RFA: 24/42; TACE alone:26/42

\begin{tabular}{|c|c|}
\hline \multirow[t]{4}{*}{ Interventions } & TACE + RFA group $(n=42)$ : \\
\hline & TACE: Chemotherapeutic drugs: 5-fluorouracil, oxaliplatin, and mitomycin \\
\hline & $\begin{array}{l}\text { RFA: The interval between TACE and RFA was } 2 \text { weeks. Ultrasound-guided RFA, } 15 \text { minutes per abla- } \\
\text { tion session }\end{array}$ \\
\hline & TACE group ( $n=42$ ): Chemotherapeutic drugs: 5-fluorouracil, oxaliplatin, and mitomycin \\
\hline \multirow[t]{4}{*}{ Outcomes } & $\begin{array}{l}\text { Tumour response, classified as complete response, partial response, stable disease, and progres- } \\
\text { sion }\end{array}$ \\
\hline & Adverse events \\
\hline & Quality of life, measured by self-designed questionnaire, with the total score of 100 \\
\hline & 1-year survival rate \\
\hline \multirow[t]{2}{*}{ Notes } & $\begin{array}{l}\text { Country of study: China } \\
\text { Source of funding: None }\end{array}$ \\
\hline & $\begin{array}{l}\text { There was insufficient information available to satisfactorily determine the method of randomisa- } \\
\text { tion and the study data could not be verified. We have attempted to contact the study authors for } \\
\text { more information, but so far, we have not been successful in doing this. }\end{array}$ \\
\hline
\end{tabular}

\section{Zhang 2018c}

Study design: Randomised clinical trial
Study duration: January 2015 to September 2016
Duration of follow-up: 1 year
Setting: Hospital

Participants

Inclusion criteria: Diagnosed as HCC by pathology or images; Karnofsky score $\geq 70$; with no history of radiotherapy or chemotherapy 
Exclusion criteria: With obvious arteriovenous fistula; tumour volume more than $70 \%$ of whole liver volume; with extrahepatic metastasis; with contraindications for TACE

Age (mean \pm SD): TACE + RFA: $60 \pm 5$ years; TACE alone: $59 \pm 5$ years

Male (n/total): TACE +RFA: 14/25; TACE alone: 16/25

TNM stage (patients):

Stage I : TACE + RFA: 7; TACE: 9

StageII : TACE + RFA: 12; TACE: 13

StageII : TACE + RFA: 6; TACE: 2
TACE + RFA group $(n=25)$ :

TACE: Chemotherapeutic drugs: 5-fluorouracil $2 \mathrm{~g}$ and oxaliplatin $200 \mathrm{mg}$

RFA: The interval between TACE and RFA was 15 days. Output power of $60 \mathrm{~W}, 10-15$ minutes per ablation session, ablation margin of $1 \mathrm{~cm}$

TACE group $(n=25)$ :

Chemotherapeutic drugs: 5-fluorouracil $2 \mathrm{~g}$ and oxaliplatin $200 \mathrm{mg}$

1-year survival rate and recurrence rate

Notes

Country of study: China

Source of funding: None

There was insufficient information available to satisfactorily determine the method of randomisation and the study data could not be verified. We have attempted to contact the study authors for more information, but so far, we have not been successful in doing this.

Methods
Study design: Randomised clinical trial
Duration of follow-up: 3 months
Setting: Hospital

Participants

Age (mean $\pm S D$, range): $52.6 \pm 7.2$ years, $31-80$ years

Male (n/total): 49/86

Tumour diameter (mean $\pm \mathrm{SD}$, range): $3.8 \pm 0.6,3-5 \mathrm{~cm}$

Child-Pugh Class (patients): Class A: 52; Class B: 34

TACE: Chemotherapeutic drugs: 5-fluorouracil, theprubicin, and epirubicin. Two sessions of TACE treatment were performed for each patient, with an interval of 4 weeks.

MWA: The interval between TACE and RFA was 2 weeks. Output power of $60-90 \mathrm{~W}$ 
TACE group $(n=43)$ : Chemotherapeutic drugs: 5-fluorouracil, theprubicin, and epirubicin. Two sessions of TACE treatment were performed for each patient, with an interval of 4 weeks.

\begin{tabular}{ll}
\hline Outcomes & Serum level of AST and ALT \\
& Serum level of AFP \\
& Tumour response, measured by ultrasound or CT, assessed by the reduction of tumour diameter \\
& Adverse events \\
\hline Notes & $\begin{array}{l}\text { Country of study: China } \\
\text { Source of funding: None } \\
\text { There was insufficient information available to satisfactorily determine the method of randomisa- } \\
\text { tion and the study data could not be verified. We have attempted to contact the study authors for } \\
\text { more information, but so far, we have not been successful in doing this. }\end{array}$ \\
\hline
\end{tabular}

\begin{tabular}{ll}
\hline Methods & Study design: Randomised clinical trial \\
Study duration: May 2011 to April 2014 \\
Duration of follow-up: 5 years \\
Setting: Hospital
\end{tabular}

\section{Participants}

Age (mean \pm SD): TACE + RFA: 55. $04 \pm 20.13$ years; TACE alone: $54.56 \pm 19.49$ years

Male (n/total): TACE + RFA: 18/30; TACE alone: 22/30

Tumour diameter (mean \pm SD, range): TACE + RFA: $3.78 \pm 2.25 \mathrm{~cm}, 1.5-6 \mathrm{~cm}$; TACE: $3.81 \pm 2.21 \mathrm{~cm}$, $1.6-6 \mathrm{~cm}$

Child-Pugh Class (patients):

Class A: TACE + RFA: 18; TACE: 20

Class B: TACE + RFA: 12; TACE: 10

TACE + RFA group $(n=30):$
TACE: TACE comprised of hepatic arterial infusion chemotherapy and hepatic artery embolisation
RFA: The interval between TACE and RFA was 1-2 weeks. RITA 1500X ablation system
TACE group $(n=30)$ : TACE comprised of hepatic arterial infusion chemotherapy and hepatic artery
embolisation

Outcomes Tumour response, according to WHO criteria, measured at 4 weeks after treatment

1-, 2-, 3-, and 5-year survival rates

Adverse events

\begin{tabular}{ll}
\hline Notes & Country of study: China \\
Source of funding: None
\end{tabular}


There was insufficient information available to satisfactorily determine the method of randomisation and the study data could not be verified. We have attempted to contact the study authors for more information, but so far, we have not been successful in doing this.

\section{Zhang 2020}

\begin{tabular}{ll}
\hline Methods & Study design: Randomised clinical trial \\
Study duration: January 2017 to May 2019 \\
Setting: Hospital
\end{tabular}

Participants Number of participants: 70

Inclusion criteria: Diagnosed as HCC; not invading into portal veins

Age (mean \pm SD): TACE + MWA: $61.44 \pm 4.33$ years; TACE alone: $61.38 \pm 4.39$ years

Male (n/total): TACE + MWA: 23/35; TACE alone: 22/35

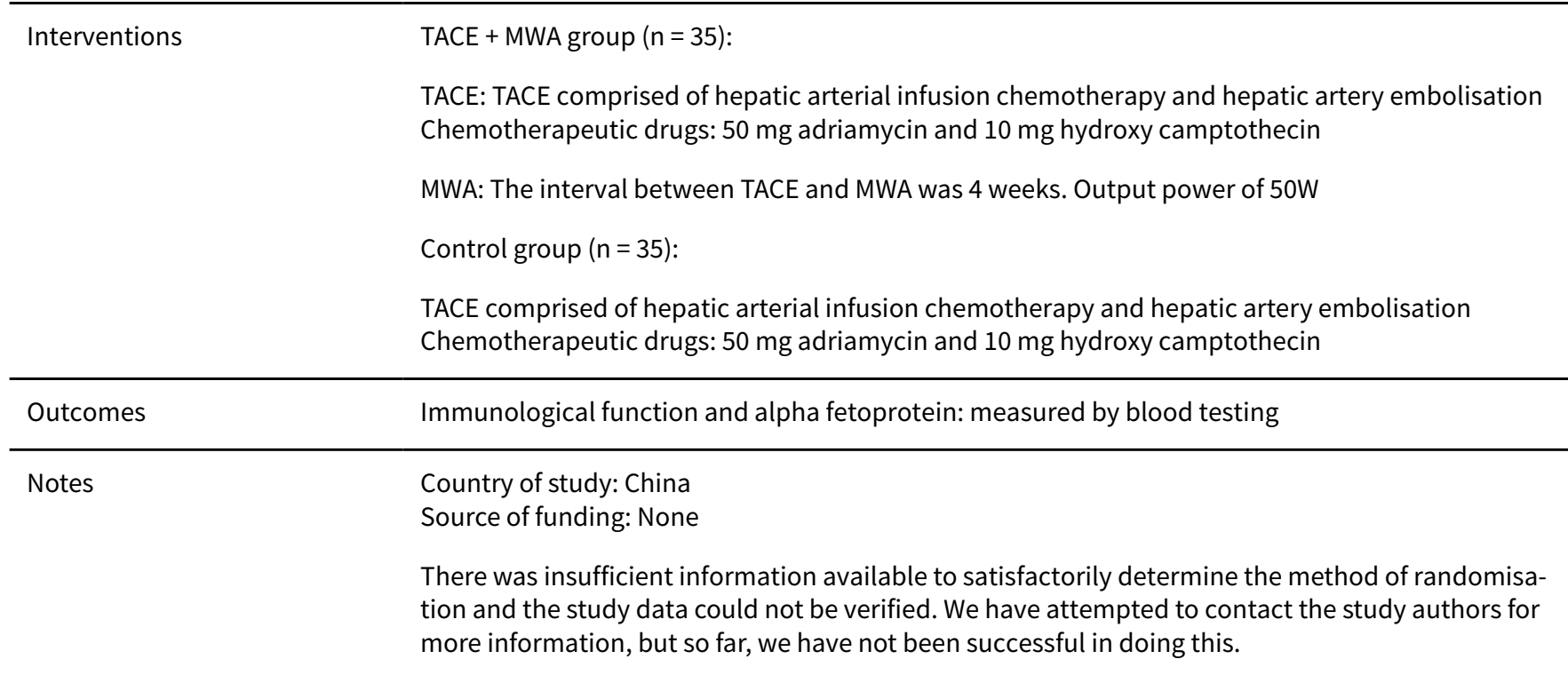

\begin{tabular}{|c|c|}
\hline \multirow[t]{4}{*}{ Methods } & Study design: Randomised clinical trial \\
\hline & Study duration: February 2007 to October 2010 \\
\hline & Duration of follow-up: 5 years \\
\hline & Setting: Hospital \\
\hline
\end{tabular}


Zhao 2014b (Continued)

Interventions $\quad$ TACE + RFA group $(n=40)$ :

TACE: Chemotherapeutic drugs: 5-fluorouracil 0.5-1 g and theprubicin 20-40 g

RFA: CT-guided RFA, 10 minutes per ablation session

TACE group $(n=40)$ :

Chemotherapeutic drugs: 5-fluorouracil 0.5-1 g and theprubicin 20-40 g

\begin{tabular}{ll}
\hline Outcomes & Tumour necrosis, measured by CT \\
$1-$, 3-, and 5-year survival rates \\
Adverse events \\
\hline Country of study: China \\
Source of funding: None \\
$\begin{array}{l}\text { There was insufficient information available to satisfactorily determine the method of randomisa- } \\
\text { tion and the study data could not be verified. We have attempted to contact the study authors for } \\
\text { more information, but so far, we have not been successful in doing this. }\end{array}$ \\
\hline
\end{tabular}

\section{Zhao 2015a}

\begin{tabular}{|c|c|}
\hline \multirow[t]{4}{*}{ Methods } & Study design: Randomised clinical trial \\
\hline & Study duration: July 2014 to July 2015 \\
\hline & Duration of follow-up: 3 years \\
\hline & Setting: Hospital \\
\hline \multirow[t]{2}{*}{ Participants } & Age (range): $31-64$ years \\
\hline & Male (n/total): $63 / 120$ \\
\hline \multirow[t]{4}{*}{ Interventions } & TACE + RFA group $(n=60):$ \\
\hline & TACE: Chemotherapeutic drugs: epirubicin $40 \mathrm{mg}$ and oxaliplatin $100 \mathrm{mg}$ \\
\hline & $\begin{array}{l}\text { RFA: The interval between TACE and RFA was } 2 \text { weeks. Cool-tip ablation system. Ablation margin of } \\
1 \mathrm{~cm}\end{array}$ \\
\hline & TACE group ( $n=60)$ : Chemotherapeutic drugs: epirubicin $40 \mathrm{mg}$ and oxaliplatin $100 \mathrm{mg}$ \\
\hline \multirow[t]{2}{*}{ Outcomes } & Tumour necrosis rate, measured at 4 weeks after treatment by contrast-enhanced CT \\
\hline & 1-, 2-, and 3-year disease progression rate \\
\hline \multirow[t]{2}{*}{ Notes } & $\begin{array}{l}\text { Country of study: China } \\
\text { Source of funding: None }\end{array}$ \\
\hline & $\begin{array}{l}\text { There was insufficient information available to satisfactorily determine the method of randomisa- } \\
\text { tion and the study data could not be verified. We have attempted to contact the study authors for } \\
\text { more information, but so far, we have not been successful in doing this. }\end{array}$ \\
\hline
\end{tabular}


Zhao 2016

\begin{tabular}{|c|c|}
\hline \multirow[t]{4}{*}{ Methods } & Study design: Randomised clinical trial \\
\hline & Study duration: January 2010 to December 2012 \\
\hline & Duration of follow-up: $29-62$ months \\
\hline & Setting: Hospital \\
\hline \multirow[t]{5}{*}{ Participants } & Age (mean \pm SD): TACE + RFA: $65.89 \pm 9.3$ years; TACE alone: $66.85 \pm 9.35$ years \\
\hline & Male (n/total): TACE + RFA: 37/ 47; TACE alone: $34 / 47$ \\
\hline & Child-Pugh Class (patients): \\
\hline & Class A: TACE + RFA: 45; TACE: 44 \\
\hline & Class B: TACE + RFA: 2; TACE: 3 \\
\hline \multirow[t]{4}{*}{ Interventions } & TACE + RFA group $(n=47):$ \\
\hline & $\begin{array}{l}\text { TACE: Chemotherapeutic drugs: 5-fluorouracil 0.25-1 g, theprubicin } 30-50 \mathrm{mg} \text {, and oxaliplatin } \\
\text { 100-150 mg }\end{array}$ \\
\hline & $\begin{array}{l}\text { RFA: The interval between TACE and RFA was } 2 \text { weeks. CT-guided RFA. HGCF- } 3000 \text { ablation system, } \\
\text { output power of } 60 \mathrm{~W}\end{array}$ \\
\hline & $\begin{array}{l}\text { TACE group }(n=47) \text { : Chemotherapeutic drugs: } 5 \text {-fluorouracil } 0.25-1 \mathrm{~g} \text {, theprubicin } 30-50 \mathrm{mg} \text {, and } \\
\text { oxaliplatin } 100-150 \mathrm{mg}\end{array}$ \\
\hline \multirow[t]{2}{*}{ Outcomes } & 1-, 3, and 5-year survival rates \\
\hline & Adverse events \\
\hline \multirow[t]{2}{*}{ Notes } & $\begin{array}{l}\text { Country of study: China } \\
\text { Source of funding: None }\end{array}$ \\
\hline & $\begin{array}{l}\text { There was insufficient information available to satisfactorily determine the method of randomisa- } \\
\text { tion and the study data could not be verified. We have attempted to contact the study authors for } \\
\text { more information, but so far, we have not been successful in doing this. }\end{array}$ \\
\hline
\end{tabular}

$\begin{array}{ll}\text { Methods } & \text { Study design: Randomised clinical trial } \\ & \text { Study duration: February } 2017 \text { to April } 2018 \\ & \text { Duration of follow-up: Not reported } \\ & \text { Setting: Hospital }\end{array}$

Participants

Age (mean \pm SD): TACE + MWA: $55.26 \pm 1.24$ years; TACE alone: $55.21 \pm 1.25$ years

Male (n/total): TACE + MWA: 18/24; TACE alone: 17/24

Interventions

TACE + MWA group $(n=24)$ :

TACE: Chemotherapeutic drugs: 5-fluorouracil 0.75-1 g, cisplatin 40-60 mg, and mitomycin

MWA: The interval between TACE and RFA was 21 days. CT-guided MWA 
Zhao 2018 (Continued)

TACE group ( $n=24$ ): Chemotherapeutic drugs: 5-fluorouracil 0.75-1 g, cisplatin 40-60 mg, and mitomycin

\begin{tabular}{ll}
\hline Outcomes & $\begin{array}{l}\text { Tumour response, classified as obvious efficacy, moderate efficacy, and no efficacy; assessed by } \\
\text { the symptoms of pain and poor appetite. }\end{array}$ \\
\hline Notes & $\begin{array}{l}\text { Country of study: China } \\
\text { Source of funding: None }\end{array}$ \\
& There was insufficient information available to satisfactorily determine the method of randomisa- \\
tion and the study data could not be verified. We have attempted to contact the study authors for \\
more information, but so far, we have not been successful in doing this.
\end{tabular}

\section{Zhao 2020}

\begin{tabular}{ll}
\hline Methods & Study design: Randomised clinical trial \\
Study duration: August 2016 to July 2018 \\
Duration of follow-up: 1 year \\
Setting: Hospital
\end{tabular}

\begin{tabular}{ll}
\hline Participants & Number of participants: 84 \\
& Inclusion criteria: Diagnosed as HCC; Child-Pugh Class A or B; tumour diameter $>5 \mathrm{~cm}$; unre- \\
& sectable tumour \\
& Age (mean \pm SD): TACE + MWA: $44.31 \pm 6.07$ years; TACE alone: $45.62 \pm 5.85$ years \\
& Male (n/total): TACE + MWA: $27 / 42 ;$ TACE alone: $29 / 42$
\end{tabular}

Interventions

TACE + MWA group $(n=42)$ :

TACE: TACE comprised of hepatic arterial infusion chemotherapy and hepatic artery embolisation Chemotherapeutic drugs: 5-fluorouracil, oxaliplatin, and epirubicin

MWA: The interval between TACE and MWA was 1-2 weeks. Output power of 50-70 W

Control group $(n=42)$ :

TACE comprised of hepatic arterial infusion chemotherapy and hepatic artery embolisation Chemotherapeutic drugs: 5-fluorouracil, oxaliplatin, and epirubicin

\begin{tabular}{l} 
Tutcomes \\
Recurrence: measured by CT at 1 year after treatment \\
AFP: measured by blood testing \\
\hline Country of study: China \\
Source of funding: None \\
There was insufficient information available to satisfactorily determine the method of randomisa- \\
tion and the study data could not be verified. We have attempted to contact the study authors for \\
more information, but so far, we have not been successful in doing this.
\end{tabular}




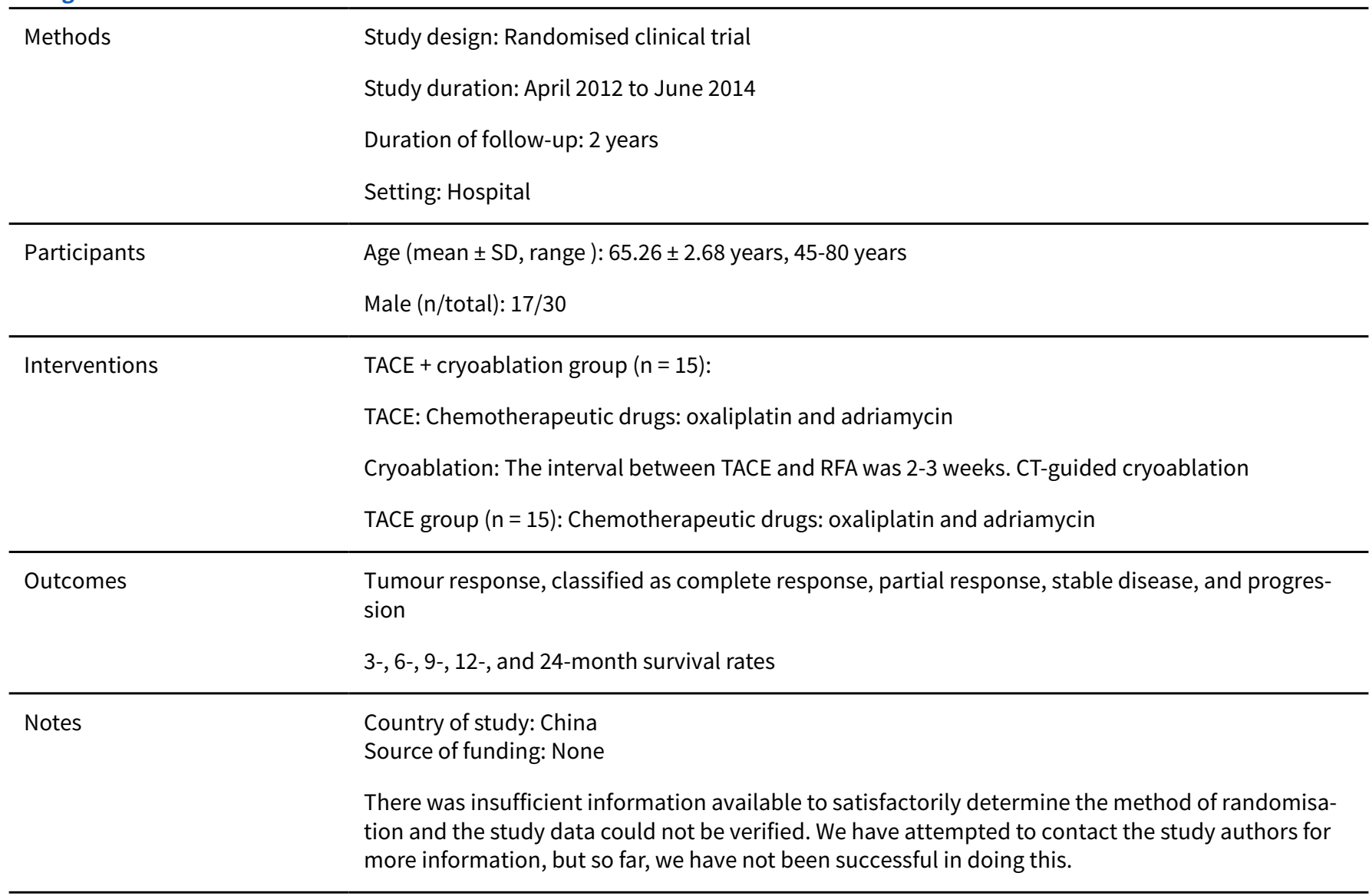

\begin{tabular}{ll}
\hline Methods & Study design: Randomised clinical trial \\
Study duration: March 2008 to June 2009 \\
Duration of follow-up: 3 years \\
Setting: Hospital \\
\hline Age (mean \pm SD, range): TACE + MWA: 53.6 years, 27-80 years; TACE alone: 51.2 years, 28-79 years \\
Male ( $n /$ total): TACE + MWA: 12/18; TACE alone: $11 / 18$ \\
\hline TACE + MWA group ( $=18$ ): \\
TACE: TACE comprised of hepatic arterial infusion chemotherapy and hepatic artery embolisation A \\
total of 2-4 sessions of TACE were performed, with an interval of 3-4 weeks. \\
MWA: Output power of 50-80 W, 4-10 minutes per ablation session \\
TACE group ( $n=18):$ \\
TACE comprised of hepatic arterial infusion chemotherapy and hepatic artery embolisation. A total \\
of 2-4 episodes of TACE were performed, with an interval of 3-4 weeks.
\end{tabular}


Zhu 2013b (Continued)

1-, 2-, and 3-year survival rates

Notes Country of study: China

Source of funding: None

There was insufficient information available to satisfactorily determine the method of randomisation and the study data could not be verified. We have attempted to contact the study authors for more information, but so far, we have not been successful in doing this.

\begin{tabular}{ll}
\hline Methods & Study design: Randomised clinical trial \\
& Study duration: February 2003 to July 2015 \\
& Duration of follow-up: 6 months \\
& Setting: Hospital
\end{tabular}

Participants

Inclusion criteria: Diagnosed as HCC by pathology or images; no other serious diseases; Karnofsky score $\geq 60$; life expectancy $\geq 6$ months

Exclusion criteria: With abnormal renal or liver function; with serious mental diseases

Age (mean \pm SD): TACE + RFA: $51.86 \pm 9.43$ years; TACE alone: $51.65 \pm 9.55$ years

Male (n/total): TACE + RFA: 20/30; TACE alone: 22/30

Child-Pugh Class (patients):

Class A: TACE + RFA: 17 ; TACE: 18

Class B: TACE + RFA: 11; TACE: 9

Class C: TACE + RFA: 2; TACE: 3

Interventions $\quad$ TACE + RFA group $(n=30)$ :

TACE: Chemotherapeutic drugs: 5-fluorouracil $0.5 \mathrm{~g}$, oxaliplatin 100-150 mg, and adriamycin $2.5 \mathrm{mg}$

RFA: The interval between TACE and RFA was 2 weeks. Ablation margin of $1 \mathrm{~cm}$

TACE group $(n=30)$ :

Chemotherapeutic drugs: 5-fluorouracil $0.5 \mathrm{~g}$, oxaliplatin 100-150 mg, and adriamycin $2.5 \mathrm{mg}$

\begin{tabular}{ll}
\hline Outcomes & Tumour response, according to WHO criteria \\
6-month survival and recurrence rates \\
Adverse events \\
\hline Cotes \\
$\begin{array}{l}\text { Country of study: China } \\
\text { There was insufficient information available to satisfactorily determine the method of randomisa- } \\
\text { tion and the study data could not be verified. We have attempted to contact the study authors for } \\
\text { more information, but so far, we have not been successful in doing this. }\end{array}$ \\
\end{tabular}


Zhuang 2016

\begin{tabular}{|c|c|}
\hline \multirow[t]{4}{*}{ Methods } & Study design: Randomised clinical trial \\
\hline & Study duration: November 2014 to April 2016 \\
\hline & Duration of follow-up: 2 years \\
\hline & Setting: Hospital \\
\hline \multirow[t]{3}{*}{ Participants } & $\begin{array}{l}\text { Inclusion criteria: Diagnosed as HCC; with liver function of Child-Pugh Class A or B; with normal re- } \\
\text { nal function; life expectancy > } 3 \text { months }\end{array}$ \\
\hline & Age (mean, range): 63 years, $34-80$ years \\
\hline & Male (n/total): 54/70 \\
\hline \multirow[t]{4}{*}{ Interventions } & TACE + cryoablation group $(n=35)$ : \\
\hline & TACE: Chemotherapeutic drugs: cisplatin 20-50 mg and adriamycin $10-40 \mathrm{mg}$ \\
\hline & $\begin{array}{l}\text { Cryoablation: The interval between TACE and RFA was } 2-4 \text { weeks. Multiple sessions of cryoablation } \\
\text { can be performed with an interval of } 4-6 \text { weeks. }\end{array}$ \\
\hline & TACE group ( $n=35$ ): Chemotherapeutic drugs: cisplatin $20-50 \mathrm{mg}$ and adriamycin $10-40 \mathrm{mg}$ \\
\hline Outcomes & $\begin{array}{l}\text { 1-month, 6-month, 1-year, and 2-year response rate, measured by CT or DSA (DSA: digital subtrac- } \\
\text { tion angiography) }\end{array}$ \\
\hline \multirow[t]{2}{*}{ Notes } & $\begin{array}{l}\text { Country of study: China } \\
\text { Source of funding: Guangdong Province Science Project }\end{array}$ \\
\hline & $\begin{array}{l}\text { There was insufficient information available to satisfactorily determine the method of randomisa- } \\
\text { tion and the study data could not be verified. We have attempted to contact the study authors for } \\
\text { more information, but so far, we have not been successful in doing this. }\end{array}$ \\
\hline
\end{tabular}

AFP: alpha foetoprotein

ALT: alanine aminotransferase

BCLC B: Barcelona Clinic Liver Cancer Stage B (Intermediate Stage)

CA199: carbohydrate antigen 19-9

CEA: carcinoembryonic antigen

CD (3+/4+/8+): lymphocytes CD3-CD4-CD8 - whole blood (test)

$\mathrm{CT}$ : computed tomography

DBIL: direct bilirubin

DSA: digital subtraction angiography

ECOG: Eastern Cooperative Oncology Group

ELISA: enzyme-linked immunosorbent assay

GGT: gamma-glutamyl transferase

HCC: hepatocellular carcinoma

HIFU: high-intensity focused ultrasound

KPS: Karnofsky score

mRECIST: modified Response Evaluation Criteria in Solid Tumors (guideline)

MMP: matrix metalloproteinase

MRI: magnetic resonance imaging

MTI-5DT: a tumor microwave therapy system

MWA: microwave ablation

NK: natural killer (cells)

PET: positron emission tomography

PHC: primary hepatic carcinoma

PVTT: portal vein tumour trombosis

QOL: quality of life

RFA: radiofrequency ablation

RFG(-4): RET fused gene (RFG)

The combination of transcatheter arterial chemoembolisation (TACE) and thermal ablation versus TACE alone for hepatocellular carcinoma (Review)

Copyright $\odot 2021$ The Cochrane Collaboration. Published by John Wiley \& Sons, Ltd. 
SD: standard deviation

$\mathrm{SSC}(-\mathrm{Ag})$ : squamous cell carcinoma

TACE: transcatheter arterial chemoembolisation

TBIL: total bilirubin (test)

TGF- $\beta 1$ : transforming growth factor beta 1

TNF- $\alpha$ : tumour necrosis factor alpha

TNM: Classification of Malignant Tumors standard for classifying the extent of spread of cancer (T: size or direct extent of the primary tumour; $\mathbf{N}$ : degree of spread to regional lymph nodes; M: presence of distant metastasis)

VEGF: vascular endothelial growth factor

yGT: gamma-glutamyl transpeptidase (y-GT)

WHO: World Health Organization

Characteristics of ongoing studies [ordered by study ID]

\section{ChicTR-IOR-16007915}

Study name

Transarterial chemoembolization (TACE) with or without sequential cryoablation in hepatocellular carcinoma of BCLC B: a multicentral randomised controlled trial

\begin{tabular}{|c|c|}
\hline Methods & Interventional study \\
\hline Participants & $\begin{array}{l}\text { Inclusion criteria: } \\
\text { 1. CT, MRI, and AFP combined with clinical or pathological diagnosis of hepatocellular carcinoma } \\
\text { 2. Prior informed consent; be able to follow the visit/treatment rules according to the research pro- } \\
\text { grammes } \\
\text { 3. Generally in good condition, adequate bone marrow, liver and renal function } \\
\text { 4. ECOG Performance Status of } 0-2 \\
\text { 5. Advanced stage HCC/BCLC B stage } \\
\text { 6. Hepatitis B history or HBsAg positive } \\
\text { 7. Patients without previous surgery, local-regional therapies (radiofrequency ablation, etc.), or liv- } \\
\text { er transplantation } \\
\text { 8. Aged } 18 \text { to } 65 \text { years } \\
\text { 9. Child Pugh class A/B ( }=<7 \text { ) } \\
\text { 10. Baseline laboratory tests meeting the following criteria: platelet count }>=100 \text { * } 10 \wedge 9 / L \text {; ALT and } \\
\text { AST }<3 \text { * upper limit of normal; BUN and creatinine }<1.5^{*} \text { upper limit of normal; INR }<1.5 \text {, or PT }<4 \\
\text { seconds above control. ALB }>=30 \mathrm{~g} / \mathrm{L} \text {; total bilirubin }=<34 \text { mmol/L } \\
\text { Exclusion criteria : } \\
\text { 1. Pregnant or lactating women } \\
\text { 2. Extrahepatic metastasis, or tumour thrombosis invasive venous system } \\
\text { 3. Any contraindications for hepatic embolisation procedures (known renal failure/insufficiency re- } \\
\text { quiring hemo-or peritoneal dialysis) } \\
\text { 4. Patients with prior malignancy were ineligible for the study, with the exception of those who had } \\
\text { been disease-free for longer than } 5 \text { years } \\
\text { 5. Patients with liver transplantation }\end{array}$ \\
\hline
\end{tabular}

Interventions

Group A: Transarterial chemoembolisation

Group B: Transarterial chemoembolisation (TACE) with sequential cryoablation

\begin{tabular}{ll}
\hline Outcomes & 3-year overall survival rate \\
& Postoperative complication \\
& Time to progression \\
& Distant metastasis rate \\
\hline Starting date & $2016-04-01$ \\
\hline
\end{tabular}


ChicTR-IOR-16007915 (Continued)

Contact information

Notes

\section{ChiCTR-IOR-17013743}

Study name

Treatment of BCLC medium-term hepatocellular carcinoma (HCC) of randomised controlled study of conventional TACE sequential microwave ablation (MWA) and conventional TACE alone

\begin{tabular}{|c|c|}
\hline Methods & Parallel study \\
\hline Participants & $\begin{array}{l}\text { Subjects who meet the following criteria can be included in this study: } \\
\text { 1. Gender, age } 18-70 \text { (inclusive) } \\
\text { 2. HCC meets the clinical diagnostic criteria of AASLD or EASL } \\
\text { 3. Subjects were not willing to have surgical excision } \\
\text { 4. BCLC medium liver cancer, numbers of tumours less than } 5 \text {, maximum diameter is less than } 10 \\
\mathrm{~cm} \\
\text { 5. Good liver reserve function (Child-Pugh A level) } \\
\text { 6. The ECOG score is } 0 . \\
\text { Exclusion criteria: } \\
\text { 1. Waiting for surgical resection or liver transplantation } \\
\text { 2. Visible portal vein, hepatic vein, bile duct invasion } \\
\text { 3. Extrahepatic metastasis } \\
\text { 4. History of liver cancer treatment (transplantation, excision, TACE, ablation, radiotherapy) } \\
\text { 5. Uncorrected clotting disorder (platelet count } 50 x 109 / L \text { or thrombin activity }<50 \% \text { ) } \\
\text { 6. Normal blood flow results in normal range } \\
\text { 7. Unstable coronary artery disease or recent myocardial infarction (within } 1 \text { year) } \\
\text { 8. Echocardiography of left ventricular ejection fraction }<50 \% \\
\text { 9. Active infection requiring antibiotic treatment } \\
\text { 10. Current anticoagulation therapy or have known haemorrhagic disease } \\
\text { 11. Renal insufficiency (serum creatinine }>176.8 \text { mu mol/L) } \\
\text { 12. AST and/or ALT > } 3 \text { times normal limit } \\
\text { 13. Pregnant or lactating subjects, women of childbearing age receiving a serum pregnancy test } \\
\text { within } 72 \text { hours of the start of treatment } \\
\text { 14. Allergy to known iodine contrast agents }\end{array}$ \\
\hline Interventions & $\begin{array}{l}\text { Experimental group: TACE + MWA } \\
\text { Control group: TACE }\end{array}$ \\
\hline Outcomes & Safety and efficacy \\
\hline Starting date & $2017-12-06$ \\
\hline Contact information & zhengjiasheng6@163.com \\
\hline Notes & \\
\hline
\end{tabular}


NCT02301091 (Continued)

\begin{tabular}{ll} 
Methods & Interventional (clinical trial) \\
\hline Participants & Inclusion Criteria: \\
- & HCC with portal vein tumour thrombus in the first or second branch \\
- Refused sorafenib or could not tolerate the adverse effect of sorafenib & A solitary HCC $\leq 5.0 \mathrm{~cm}$ in diameter, or multiple $\mathrm{HCC} \leq 3$ lesions, each $\leq 5.0 \mathrm{~cm}$ in diameter \\
- Eastern Cooperative Oncology Group Performance Status $0-1$ & Child-Pugh Score $\leq 8$ \\
- Platelet counts of $>60,000 / \mathrm{mm}^{3}$, haemoglobin $>8.5 \mathrm{~g} / \mathrm{dL}$, prothrombin time prolonged $<6 \mathrm{~s}$ \\
- Albumin $>2.8 \mathrm{~g} / \mathrm{dL}$, total bilirubin $<51.3$ umol/L; alanine aminotransferase (ALT) and aspartate \\
transaminase (AST) $<5$ times of upper limit \\
- Signed informed consent \\
Exclusion Criteria: \\
- Presence of extrahepatic metastasis except lymph node metastasis \\
- The blood supply of tumour lesions is absolutely poor or arterial-venous shunt that TACE can not \\
- be performed \\
- Uncontrolled or refractory ascites, ongoing variceal bleeding or encephalopathy \\
- Seve heart, brain or kidney diseases \\
- Pregnant women or lactating women
\end{tabular}

2 sessions of TACE first, RFA for residual viable tumours and PVTT within 1 month

Active Comparator: TACE alone

Repeated TACE and 1 to 2 months interval between two sessions of TACE

\begin{tabular}{|c|c|}
\hline Outcomes & $\begin{array}{l}\text { Primary outcome measures: } \\
\text { 1. Overall survival rates [time frame: } 1 \text { year] } \\
\text { Secondary outcome measures: } \\
\text { 1. Progression-free survival rates [time frame: } 6 \text { months] } \\
\text { 2. Response rate of PVTT [time frame: } 6 \text { months] } \\
\text { 3. Number of participants with adverse events [time frame: } 1 \text { month] }\end{array}$ \\
\hline Starting date & October 2014 \\
\hline Contact information & Ming Zhao, doctor+86 020 87343272zhaoming@sysucc.org.cn \\
\hline
\end{tabular}

Study name TACE + RFA versus TACE alone for intermediate-stage hepatocellular carcinoma

Methods Experimental: TACE-RFA

1-2 sessions of TACE treatment, then followed by RFA treatment 
NCT02435953 (Continued)

Participants

Inclusion Criteria:

- Multiple HCC (2-3 lesions), largest lesion 3-7 cm in diameter, or multiple HCC (4-10 lesions), each $\leq 7 \mathrm{~cm}$ in diameter

- No vascular invasion or extrahepatic metastases

- Eastern Cooperative Oncology Group Performance Status 0-1

- Child-Pugh Stage A or B

- Treatment-naive

Exclusion Criteria:

- Platelet counts of $<40 \times 109 / \mathrm{L}$, prothrombin time activity $<40 \%$

- Albumin $>2.8 \mathrm{~g} / \mathrm{dL}$, total bilirubin $<51.3 \mathrm{umol} / \mathrm{L}$; alanine aminotransferase (ALT) and aspartate transaminase (AST) $<5$ times of upper limit

- No evaluable target lesions

- Uncontrolled or refractory ascites, ongoing variceal bleeding or encephalopathy

- Severe heart, brain or kidney diseases

- Previous or concurrent cancer that is distinct in primary site or histology from HCC

- Pregnant women or lactating women

- Be allergic to adriamycin, lobaplatin, mitomycin and iodised oil

Interventions

Experimental: TACE-RFA

1-2 sessions of TACE treatment, then followed by RFA treatment

Active Comparator: TACE alone

TACE treatment several times until tumour progresses to advanced stage

Primary outcome measures:
1. Overall survival rate [time frame: 3 years]
Secondary outcome measures:
1. Tumour progression rate [time frame: 2 years]
2. Tumour progress to advanced-stage rate [time frame: 2 years]
3. Hepatic dysfunction rate [time frame: 2 years]
4. Adverse event rate [time frame: 3 years]

\section{Starting date}

Contact information
April 2015

Contact: Ming Zhao, doctor+86 020 87343272, zhaoming@sysucc.org.cn

Contact: Tao Pan, doctor+862087343271, pantao0909@hotmail.com

\section{Notes}

\section{NCT02646137}

\begin{tabular}{ll}
\hline Study name & Single session combined locoregional therapies for hepatocellular carcinoma \\
\hline Methods & Allocation: Randomised \\
& Intervention model: Parallel assignment
\end{tabular}

The combination of transcatheter arterial chemoembolisation (TACE) and thermal ablation versus TACE alone for hepatocellular carcinoma (Review)

Copyright (C) 2021 The Cochrane Collaboration. Published by John Wiley \& Sons, Ltd. 
NCT02646137 (Continued)

Masking: None (open-label)

\begin{tabular}{l} 
Inclusion Criteria: \\
Child classification A or B \\
Serum albumin $\geq 3 \mathrm{gm} / \mathrm{L}$ \\
Serum bilirubin $<2.5 \mathrm{mg} / \mathrm{dL}$ \\
Platelet count $\geq 70,000 \mathrm{~mm} 3$ \\
INR $\leq 1.6$ \\
Serum creatinine $<2 \mathrm{mg} / \mathrm{dL}$ \\
Tumour size more than $4 \mathrm{~cm}$ and confined to one lobe of the live \\
Exclusion Criteria: \\
Patients with portal vein thrombosis \\
A technically inaccessible hepatic artery \\
Metastatic HCC \\
More than three lesions \\
Lesions in close proximity to the portal vein, inferior vena cava, or \\
the study. \\
(1) Active comparator: Transarterial chemoembolisation (TACE) \\
(2) Experimental: Radiofrequency ablation with TACE \\
(3) Experimental: Microwave ablation combined with TACE \\
\hline Interventions
\end{tabular}

\begin{tabular}{ll}
\hline Outcomes & Number of patients with successful ablation [time frame: 3 months] \\
\hline Starting date & January 2015 \\
\hline Contact information & $\begin{array}{l}\text { Sherief Abd-Elsalam 00201000040794, mailto:Sherif_tropical\%40yahoo.com?subject=NC- } \\
\text { T02646137, Combined TACE and RF, Single Session Combined Locoregional Therapies for Hepato- } \\
\text { cellular Carcinoma }\end{array}$ \\
\hline Notes & None \\
\hline
\end{tabular}

AASLD: American Association for the Study of Liver Diseases

AFP: alpha foetoprotein

ALB: albumin

ALT: alanine aminotransferase

AST: aspartate transaminase

BCLC B: Barcelona Clinic Liver Cancer Stage B (Intermediate Stage)

BUN: blood area nitrogen

CORTT: abbreviation in study name not written out anywhere in the text record

CT: computer tomography

EASL: European Association for the Study of the Liver

ECOG: Eastern Cooperative Oncology Group

HBsAg: hepatitis B surface antigen

HCC: hepatocellular carcinoma

INR: international normalised ratio

IVC: inferior vena cava

The combination of transcatheter arterial chemoembolisation (TACE) and thermal ablation versus TACE alone for hepatocellular 
MRI: magnetic resonance imaging

MWA: microwave ablation

PT: prothrombin time

PV: portal vein

PVTT: portal vein tumour thrombosis

RFA: radiofrequency ablation

TACE: transarterial chemoembolisation

\section{H I S T O R Y}

Protocol first published: Issue 5, 2019

\section{CONTRIBUTIONSOF AUTHORS}

Formulated the research question: WL

Drafted the protocol: BZL and WL

Drafted the full text of this review: BZL, WL, YCZ, and ET

Provision of statistical expert opinion: $\mathrm{HC}$

All authors approved the publication of the current review version.

\section{DECLARATIONS OF INTEREST}

BZL has no known conflicts of interest. $\mathrm{HC}$ has no known conflicts of interest.

WL has no known conflicts of interest.

ET has no known conflicts of interest.

\section{SOURCES OF SUPPORT}

\section{Internal sources}

- Capital's Funds for Health Improvement and Research, China

ID: CFH 2020-2-2175

\section{External sources}

- The Cochrane Hepato-Biliary Group, Denmark

The Cochrane Hepato-Biliary Group (the CHBG) is one of the 53 international research publishing groups within Cochrane (formerly The Cochrane Collaboration).

\section{DIFFERENCES BETWEEN PROTOCOL ANDREVIEW}

\section{Background}

We added a sentence describing the five main thermal ablation techniques to help the reader understand the experimental intervention of this review.

\section{Methods}

We increased the clarity of the Methods section by rewriting existent information and adding further information in conformity with the latest Cochrane Handbook (Higgins 2021). The main changes are as follows.

- In Outcomes, we added a sentence: "We planned to base our primary conclusions on the outcome results at the longest follow-up. We planned to include trials regardless of whether they reported on our outcomes of interest."

- We moved the planned exploratory analysis on mortality regarding the intervention effect at one, three, and five (primary time point) years, to Sensitivity analysis.

- We merged the exploratory outcome 'Duration of hospital stay' with the secondary outcomes, as exploratory outcomes are no longer encouraged by the Cochrane Handbook.

- We replaced the text on RoB1 with RoB2, as the RoB2 tool was recommended at the time we started our work on the review (Higgins 2019a).

- We extracted data on trial registration and ethics committee approval.

- We updated the text in Unit of analysis issues, adding further details.

The combination of transcatheter arterial chemoembolisation (TACE) and thermal ablation versus TACE alone for hepatocellular 
- We added that we planned to repeat our analyses with the fixed-effect model.

- We moved the text on Trial sequential Analysis to Sensitivity analysis, and we planned to use it for assessment of imprecision.

- We reduced the number of planned subgroup analyses from six to two, following comments from the network editor. The argument was that subgroup analyses are observational in nature and, therefore, they should be justified carefully, and their number limited. We have carefully discussed this issue, and we re-evaluated the significance of the original six subgroup analyses, listed in the published protocol. We reached consensus that the significance of performing subgroup analyses based on the risk of bias and the ablation method was the most important.

- We elaborated text in Summary of findings tables and assessment of the certainty of evidence to ease the readers' understanding. 